\title{
REDES NEURAIS NÃO-SUPERVISIONADAS PARA PROCESSAMENTO DE SEQÜÊNCIAS TEMPORAIS
}

\author{
Guilherme de Alencar Barreto
}

Dissertação apresentada à Escola de Engenharia de São Carlos, da Universidade de São Paulo, como parte dos requisitos para a obtenção do Título de Mestre em Engenharia Elétrica.

Orientador: Prof. Dr. Aluizio Fausto Ribeiro Araújo

São Carlos

1998 
Dedico este trabalho aos meus pais, Roberto e Evanda, pelo contínuo apoio e incentivo. 


\section{AGRADECIMENTOS}

Ao Prof. Dr. Aluizio Fausto Ribeiro Araújo, que mais que um orientador acadêmico, soube ser um grande amigo.

À Thelma Maria Vasconcelos e Silva pelo apoio, paciência, amor e compreensão, sempre me incentivando durante esta caminhada, contribuindo muito para a conclusão deste trabalho.

A todas as pessoas que me ajudaram nesta caminhada, muitas delas caminharam comigo e hoje posso e tenho o orgulho de chamá-los de amigos. Em especial, aos companheiros do Departamento de Engenharia Elétrica: Marcelo Vieira, Hélio D’Arbo, Marcelo Rosa, Arthur Plínio, Renato Tinós, Ricardo Sovat, João Bosco, Patrícia Leite, Mário Oleskowski. E às amigas do ICMSC: Juliana, Maristela, Alessandra, Marisa, Cris Endo, Sissy.

Ao Departamento de Engenharia Elétrica pela utilização e fácil acesso aos seus laboratórios, bem como aos professores e funcionários que estiveram sempre dispostos a colaborar.

Ao Programa Institucional de Capacitação de Docentes em nome da Fundação Coordenação de Aperfeiçoamento de Pessoal de Nível Superior e Universidade Federal do Ceará (PICDT/CAPES/UFC), pelo suporte financeiro fornecido durante o período da realização deste trabalho, sem o qual o mesmo não seria possível. 


\section{SUMÁRIO}

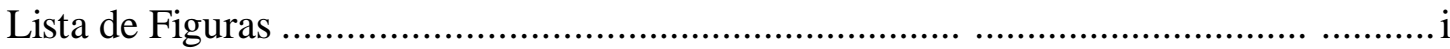

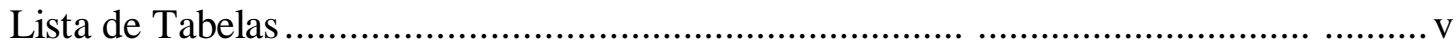

Lista de Abreviaturas e Siglas ..........................................................................

Lista de Símbolos.................................................................................. vi

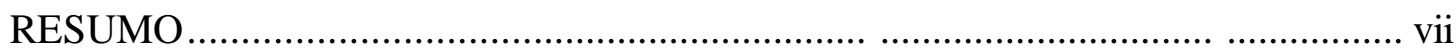

ABSTRACT .................................................................................... viii

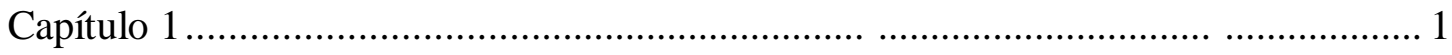

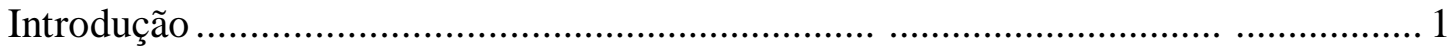

1.1 Motivação Geral ................................................................................ 2

1.2 Processamento de Seqüências Temporais ...................................................... 3

1.3 Desenvolvimento da Pesquisa e a Organização da Dissertação .........................4

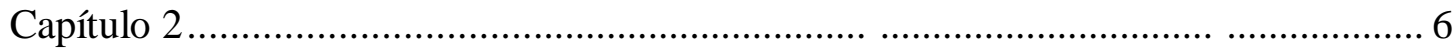

2.1 Processamento de Seqüências Temporais .................................................... 6

2.1.1 Representação de Seqüências Temporais ................................................. 7

2.1.2 Contexto, Grau e Tipos de Seqüências Temporais................................... 8

2.2 Classes de Problemas em Seqüências Temporais ............................................ 8

2.3 Robótica - Conceitos Básicos.................................................................. 11

2.3.1 Sistemas de Controle de Robôs ........................................................... 12

2.4 Por que Redes Neurais Artificiais Não-Supervisionadas ?.............................13

2.5 Classificação das Trajetórias e Enunciado do Problema .................................... 13

2.6 Convenções de Nomenclatura ................................................................. 14

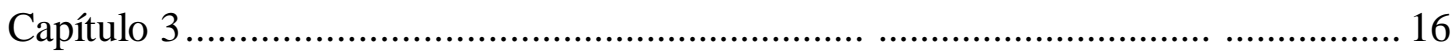

Modelos Não-Supervisionados para Processamento de Padrões Estáticos: Definições e

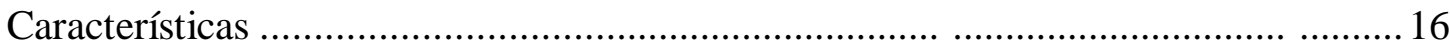

3.1 Modelos Não-Supervisionados: Definição e Utilização................................... 16

3.1.1 Sinais de Entrada e Função de Ativação ................................................. 17

3.1.2 Aplicação de Modelos Não-Supervisionados.......................................... 17

3.2 Redes Não-Supervisionadas com Aprendizagem Competitiva.........................18

3.3 Redes Competitivas para Determinação de Valores Extremos ........................19

3.4 Modelos Competitivos para Classificação de Padrões Estáticos.....................21

3.4.1 Modelos Vencedor-leva-tudo..........................................................21

3.4.2 Modelo de Aprendizagem Competitiva Diferencial...................................23

3.4.3 Neurônios que Não Aprendem........................................................24

3.5 Mapas Auto-Organizáveis de Características............................................. 24

3.6 Modelos de Redes Neurais com Aprendizagem Hebbiana...............................26

3.6.1 Neurônio Linear com Aprendizagem Hebbiana ...................................... 27

3.6.2 A Regra de Hebb e Conexões Laterais Treináveis .................................29

3.7 Resumo do Capítulo .......................................................................... 31 


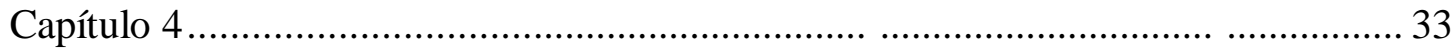

4.1 Implementação de Memória de Curta Duração.............................................. 34

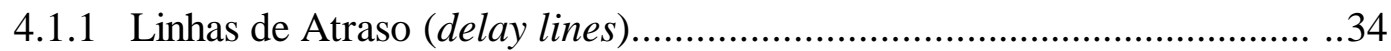

4.1.2 Traço de Decaimento (decay traces) ................................................... 35

4.1.3 Núcleos Exponenciais Normalizados (normalized exponential kernels) ....35

4.1.4 Modelos interativos (interactive models) ............................................ 36

4.2 Redes Não-Supervisionadas para Processamento de Seqüências Temporais ...38

4.2.1 Modelos com Aprendizagem Competitiva ............................................. 38

4.2.2 Versões Temporais de Mapas Auto-organizáveis ...................................39

4.2.3 Incorporando Informação Temporal aos Dados de Entrada......................39

4.2.4 Incorporando MCD à Dinâmica do Modelo Neural..................................41

4.2.5 Versão Temporal de Modelos com Aprendizagem Anti-Hebbiana ............45

4.3 Modelos para Reconhecimento e Reprodução de Seqüências Temporais

Propostos por WANG \& ARBIB .................................................................47

4.4 Modelos para Reconhecimento e Reprodução de Sequiências Temporais

Propostos por WANG \& YUWONO ...................................................... 51

4.5 Resumo do Capítulo .......................................................................... 51

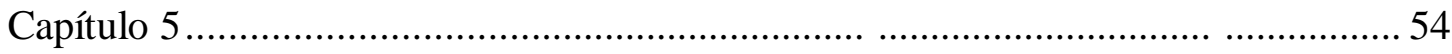

5.1 Robótica e o Processamento de Seqüências Temporais ................................54

5.2 Processamento de Seqüências do Tipo Percepção-Ação....................................55

5.2.1 Segmentação de Seqüências e Conexão de Subseqüências .......................56

5.2.2 Uso de Seqüências Armazenadas para Selecionar Ações ..........................57

5.3 Aprendizagem de Trajetórias de Robôs ................................................... 59

5.4 Aprendizagem da Cinemática Inversa via Modelos Não-Supervisionados ......63

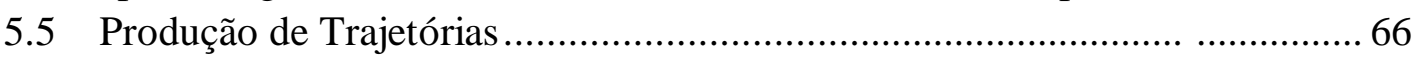

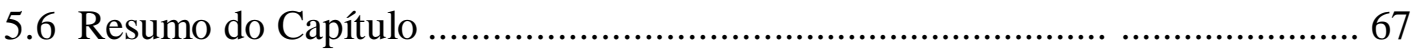

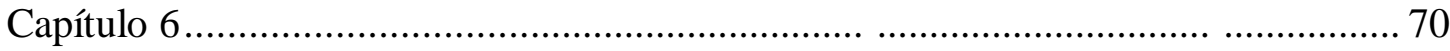

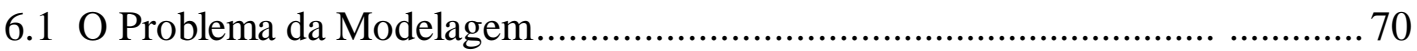

6.1.1 Propriedades Desejáveis em um Bom Modelo ....................................... 71

6.2 Proposição de Modelos para Processamento Temporal .................................73

6.2.1 Detalhando o Problema a Ser Modelado ................................................. 73

6.3 Aprendendo Seqüências Temporais - Modelo Categorização e

Associação Temporal (CAT) .................................................................. 75

6.3.1 Competindo por Padrões Temporais: Categorização ...............................77

6.3.2 Modelando a Ordem Temporal por Conexões Sinápticas Intracamada:

Associação Temporal......................................................................... 79

6.3.3 Resumo do Algoritmo do Modelo CAT ............................................... 81

6.4 Adicionando Contexto ao Modelo .......................................................... 82

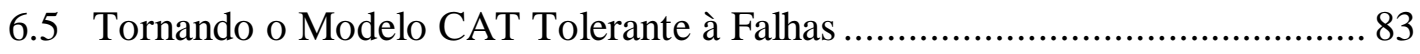

6.5.1 Incorporando o Conceito de Vizinhança Topológica .............................83

6.5.2 Incorporando o Conceito de Vizinhança por Proximidade .......................84

6.5.3 Comentários sobre as Modificações Propostas ....................................... 85

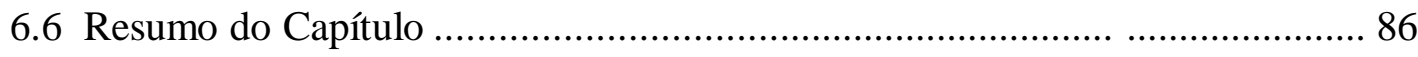




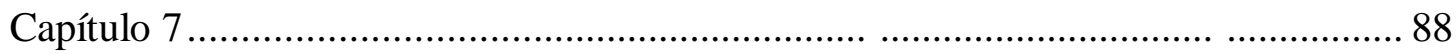

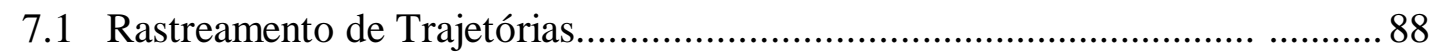

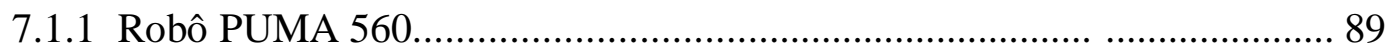

7.1.2 O Sistema Simulado........................................................................ 90

7.2 Trajetórias Consideradas para Estudo ....................................................... 91

7.3 Visualização das Trajetórias .................................................................. 92

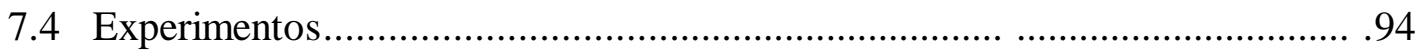

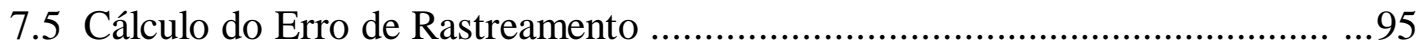

7.6 Funcionamento - Modelo CAT sem unidades de contexto ..............................96

7.7 Aprendendo Trajetórias Complexas ........................................................ 103

7.8 Tolerância à Falhas nos Neurônios .......................................................... 105

7.9 Capacidade de Generalização ................................................................. 107

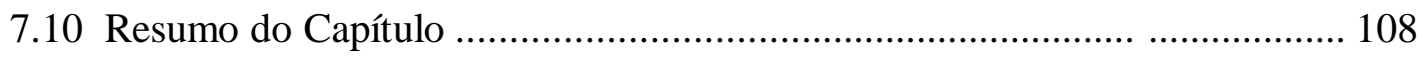

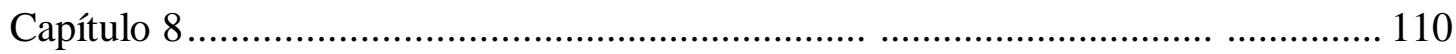

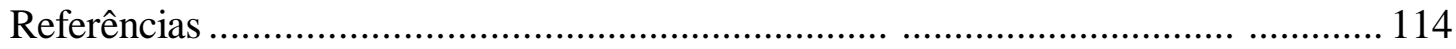

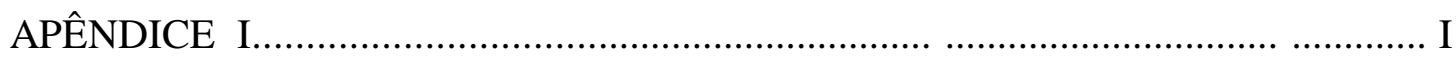

APÊNDICE II ................................................................................ VII

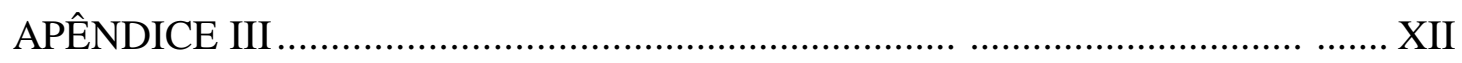

APÊNDICE IV ..................................................................................... XIII

APÊNDICE V .................................................................................. 


\section{LISTA DE FIGURAS}

Figura 1: Características de uma máquina autônoma e sua iteração com o ambiente externo.

Figura 2: Três seqüências de mesma ordem de eventos A-B-C, mas com durações relativas das componentes diferentes........................................................ 10

Figura 3: Arquitetura da rede neural Maxnet. A entrada, $\mathrm{x}_{i}$, é desacoplada após a saída ter sido calculada na primeira iteração $(t=1)$.

Figura 4: Arquiteturas de redes neurais competitivas. As inibições laterais (a) só são necessárias quando não se usa distância euclideana (b) para determinar o neurônio vencedor.

Figura 5: Uma possível topologia para o mapa auto-organizável de características proposto por Kohonen. As unidades de entrada estão totalmente conectadas com os neurônios da camada de saída.

Figura 6: Rede de uma camada de neurônios lineares $\left(y_{j}=\Sigma_{i} w_{j i} x_{i}\right)$, cujos pesos podem aprender através da regra de Hebb. . .27

Figura 7: Duas implementações de memórias de curto prazo: (a) Através de um registrador de deslocamento e (b) Através de array com diferentes atrasadores. .34

Figura 8: Traços na MCD. (a) decaimento exponencial; (b) núcleos exponenciais normalizados; (c) núcleos gamma e (d) modelo STORE.

Figura 9: Versões temporais para o MAOK. (a) Ponderando os valores das entradas com pesos exponenciais; (b) concatenando os vetores de entrada em instantes diferentes e (c) utilizando dois níveis de mapas com ponderação exponencial do vetor de respostas.

Figura 10: Acoplamento unidimensional de neurônios para ativação espaçotemporal.

Figura 11: Topologia da rede anti-hebbiana de Földiak. (a) versão original e (b) modelo com memória sináptica proposto por GIROLAMI \& FYFE (1996). .......46

Figura 12: Modelo de neurônio dual. 47

Figura 13: Conexões sinápticas múltiplas para codificação de subsequiências recorrentes. 48

Figura 14: Arquitetura geral para reconhecimento de sequências. 49

Figura 15: Arquitetura de rede para reprodução de sequiencias temporais proposta por WANG \& ARBIB (1990). 
Figura 16: Arquitetura para aprendizagem de contexto em seqüências complexas segundo WANG \& ARBIB (1993)........................................................50

Figura 17: Modelo hierárquico do mundo para processamento de sequiências do tipo percepção-ação.

Figura 18: Arquitetura de duas camadas para aprendizagem e reprodução de trajetórias de um braço mecânico com 2 DOF. Só algumas conexões são mostradas. 60

Figura 19: Arquitetura da rede neural para codificação da trajetória desejada, segundo BUGMANN et al. (1998). 62

Figura 20: Arquitetura do modelo neural para processamento de trajetórias de robô. Apenas algumas conexões são mostradas para efeito de simplificação. 75

Figura 21: Arquitetura modificada do modelo CAT para inclusão de informação de contexto. Esta é necessária para resolver qualquer ambigüidade que venha a surgir quando trajetórias se cruzam em um ou mais pontos. 82

Figura 22: Robô PUMA 560 escolhido para teste dos modelos não-supervisionados para produção de seqüências temporais.

Figura 23: Simulação gráfica do robô PUMA 560 usada para visualização das trajetórias. 90

Figura 24: Trajetórias que tem em comum: (a) Nenhum estado; (b) Apenas o estado inicial; (c) Pelos menos o estado final; (d) Pontos intermediários. O círculo cheio indica o estado inicial e o " $\mathrm{x}$ " o estado final da trajetória.................................91

Figura 25: Trajetórias do tipo $\mathrm{m}-\mathrm{m} / \mathrm{sc}$. (a)-(c) correspondem à posição espacial das trajetórias. Figuras (d)-(f) são a visualização das trajetórias em (a), (b) e (c).....92

Figura 26: Trajetórias do tipo 1-m. (a)-(c) correspondem à posição espacial das trajetórias. Figuras (d)-(f) são a visualização das trajetórias em (a), (b) e (c).....93

Figura 27: Trajetórias do tipo m-1. (a)-(c) correspondem à posição espacial das trajetórias. Figuras (d)-(f) são a visualização das trajetórias em (a), (b) e (c).....93

Figura 28: Trajetórias do tipo m-m/cc. (a)-(c) correspondem à posição espacial das trajetórias. Figuras (d)-(f) são a visualização das trajetórias em (a), (b) e (c).....94

Figura 29: Treinamento do modelo CAT sem contexto para trajetória I1-F1. (a) configuração inicial das conexões intracamada; (b)-(m) estabelecimento das autoconexões e das conexões laterais. O número de conexões laterais é igual ao número de transições de estado. 97 
Figura 30: Reprodução da trajetória I1-F1. (a)-(l) Determinação do neurônio mais semelhante à entrada (cinza) e do neurônio que codifica o próximo estado (preto). 98

Figura 31: Variação do erro de rastreamento como função da taxa de aprendizagem $\delta$. 101

Figura 32: Trajetórias espaciais fornecidas pela rede e as desejadas para sequiências $\mathrm{m}-\mathrm{m} / \mathrm{sc}$ usando o modelo CAT sem contexto e sem redundância. 102

Figura 33: Ângulos em radianos das juntas (reais e reproduzidos) para seqüências do tipo m-m/sc. Trajetórias: (a)-(b) I1-F1, (c)-(d) I2-F2 e (e)-(f) I3-F3 ................. 102

Figura 34: Torques (reais e reproduzidos) nas juntas para trajetórias do tipo m-m/sc. Trajetórias: (a)-(b) I1-F1, (c)-(d) I2-F2 e (e)-(f) I3-F3 ................................. 103

Figura 35: Trajetórias espaciais fornecidas pela rede e as desejadas para seqüências m-1 usando o modelo CAT com contexto e vizinhança topológica. (a)-(c) Resultados para vizinhos à esquerda e (d)-(f) para vizinhos à direita. 105

Figura 36: Trajetórias espaciais reais e geradas pela rede para sequiências do tipo m-m/cc usando o modelo 3 (com contexto e com redundância). (a)-(c) Entradas treinadas e (d)-(f) entradas não treinadas (com ruído).

Figura 37: Esquema simplificado de um neurônio.............................................. III

Figura 38: Modelo chamado Perceptron........................................................ IV

Figura 39: Representação de uma conexão sináptica entre dois neurônios................... V

Figura 40: Tipos de representações para neurônios segundo GROSSBERG (1974). (a) neurônio instar e (b) neurônio outstar................................................ XI

Figura 41: Convergência dos vetores de peso sinápticos para os centróides da distribuição considerada......................................................................... VIII

Figura 42: Trajetórias de um dos vetores de pesos do modelo, convergindo para o

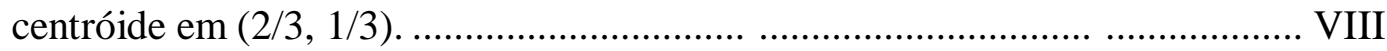

Figura 43: Pesos finais após treinamento. (a) pesos excitatórios; (b) pesos inibitórios. Os valores dos pesos são proporcionais ao lado dos quadrados. XIV

Figura 44: Resposta da rede para os diferentes tipos de padrões de treinamento e de teste. (a) padrões de treinamento; (b) Padrões múltiplos e (c) padrões ambíguos (representação de incerteza). Conexões inibitórias não são mostradas por motivos de clareza. $\mathrm{XV}$

Figura 45: Tipos de juntas: (a) linear ou prismática, (b) rotacional, (c) de torção e (d) revolvente. XVII

Figura 46: Parâmetros para os elos e juntas. XVIII 


\section{LISTA DE TABELAS}

Tabela 1: Exemplos de reprodução incorreta de trajetórias 1-m............................. 104

Tabela 2: Exemplos de reprodução correta de trajetórias 1-m................................ 104

Tabela 3: Posições espaciais armazenadas pelo vencedor e seus vizinhos................. 106

Tabela 4: Erros de rastreamento para simulações usando modelo 2 .......................106

Tabela 5: Constantes cinemáticas, $\alpha$ em graus, $a$ e $d$ estão em m......................... XIX

Tabela 6: Valores da massa $(\mathrm{kg})$ e centro de gravidade $(\mathrm{m})$ dos elos...................... XIX

Tabela 7: Momentos de inércia sobre centro de gravidade $\left(\mathrm{kg}-\mathrm{m}^{2}\right)$.......................XIX

Tabela 8: Inércia induzida (ARMATURE) e prazer suficiente.............................XIX 


\section{LISTA DE ABREVIATURAS E SIGLAS}

\begin{tabular}{|c|c|}
\hline CAT & - Categorização e Associação Temporal \\
\hline MCD & - Memória de Curta Duração \\
\hline MAOK & - Mapa Auto-Organizável de Kohonen \\
\hline MAOR & - Mapa Auto-Organizável de Kohonen Recorrente \\
\hline MTK & - Mapa de Kohonen Temporal \\
\hline NGL & - Número de Graus de Liberdade \\
\hline NRBF & - Normalized Radial Basis Function \\
\hline PCA & - Principal Components Analysis \\
\hline PUMA & - Programmable Universal Machine Assembly \\
\hline $\mathrm{RBF}$ & - Radial Basis Function \\
\hline RNA/RNAs & - Rede Neural Artificial/Redes Neurais Artificiais \\
\hline SPA & - Seqüências do tipo Percepção-Ação \\
\hline STR & - Sequiências do tipo Trajetórias de Robôs \\
\hline $\mathrm{m}-1$ & - Trajetórias com vários pontos iniciais e um único ponto meta \\
\hline $1-\mathrm{m}$ & - Trajetórias com um único ponto inicial e vários pontos meta \\
\hline $\mathrm{m}-\mathrm{m} / \mathrm{sc}$ & $\begin{array}{l}\text { - Trajetórias com vários pontos iniciais e vários pontos meta onde não } \\
\text { existem pontos em comum entre as diferentes trajetórias }\end{array}$ \\
\hline $\mathrm{m}-\mathrm{m} / \mathrm{sc}$ & $\begin{array}{l}\text { - Trajetórias com vários pontos iniciais e vários pontos meta onde } \\
\text { existem pontos em comum entre as diferentes trajetórias }\end{array}$ \\
\hline
\end{tabular}




\section{LISTA DE SÍMBOLOS}

$S \quad$ - Símbolo representativo de uma seqüência temporal qualquer.

$\boldsymbol{A}$ - Alfabeto de onde são retirados os símbolos para representar $S$

$\mathbf{s}\left(t_{i}\right), \mathbf{p}_{i} \quad$ - Vetor componente da seqüência $S$, significando uma representação condensada do sinal na vizinhança de $t_{i}, i=1, \ldots, \mathrm{N}$.

$n, m$ - número de unidades de entrada e de saída da rede neural, respectivamente.

$\mathbf{x}(t), x_{i}(t) \quad$ - vetor de entrada e sua componente $i$ no instante $t$, respectivamente.

- número de unidades de saída da rede neural.

$\mathbf{w}_{j}(t), w_{j i}(t)$ - conexão sináptica (intercamadas) que liga um neurônio na camada de entrada $i$ a um neurônio na camada de saída $j$.

$\mathbf{m}_{j}(t), m_{j k}(t)$ - conexão sináptica (intracamada) que liga um neurônio na camada de saída $k$ a um outro neurônio na mesma camada de saída $j$.

$a_{j}(t), y_{j}(t) \quad$ - valor da ativação e da saída do neurônio $j$ no instante $t$.

$f_{j}(t) \quad$ - fator de exclusão associado ao neurônio $j$.

$v, v(t), \operatorname{win}(t)$ - índice indicativo do neurônio vencedor de uma competição.

$h_{j v}(t) \quad$ - função Vizinhança para o algoritmo do MAOK.

VIZ $_{v(t)} \quad$ - intervalo contendo os índices dos neurônios (vencedor e sua vizinhança) que são ajustados no MAOK.

$V_{j}(t) \quad$ - leaky integrator potential para o neurônio $j$.

$\operatorname{Temp}_{j}(t) \quad$ - ativação temporal do neurônio $j$.

$\mathbf{q}(t), \theta(t), \theta_{i}(t)$ - vetor de ângulos (em radianos) das juntas e componente $i$ deste vetor, $i=1, \ldots, 6$.

$\tau(t), \tau_{i}(t) \quad$ - vetor de torques das juntas e a componente $i$ deste vetor, $i=1, \ldots, 6$.

$(x, y, z) \quad$ - coordenada espacial do associada ao efetuador do robô.

$S(),. g(),. h($.$) - Função de ativação (ou transferência).$

$\alpha, \beta, \delta, \varepsilon, \quad$ - Símbolos usados para designar taxas de aprendizagem ou fatores de

$\gamma, \eta, \lambda, \mu \quad$ ganho em regras de ativação 


\title{
RESUMO
}

\author{
BARRETO, G. de A. Redes Neurais Não-Supervisionadas para Processamento de \\ Seqüências Temporais. São Carlos, 1998. 118p. Dissertação (Mestrado) \\ - Escola de Engenharia de São Carlos, Universidade de São Paulo.
}

Em muitos domínios de aplicação, a variável tempo é uma dimensão essencial. Este é o caso da robótica, na qual trajetórias de robôs podem ser interpretadas como sequiências temporais cuja ordem de ocorrência de suas componentes precisa ser considerada. Nesta dissertação, desenvolve-se um modelo de rede neural nãosupervisionada para aprendizagem e reprodução de trajetórias do Robô PUMA 560. Estas trajetórias podem ter estados em comum, o que torna o processo de reprodução susceptível a ambigüidades. O modelo proposto consiste em uma rede competitiva composta por dois conjuntos de pesos sinápticos: pesos intercamadas e pesos intracamada. Pesos intercamadas conectam as unidades na camada de entrada com os neurônios da camada de saída e codificam a informação espacial contida no estímulo de entrada atual. Os pesos intracamada conectam os neurônios da camada de saída entre si, sendo divididos em dois grupos: autoconexões e conexões laterais. A função destes é codificar a ordem temporal dos estados da trajetória, estabelecendo associações entre estados consecutivos através de uma regra hebbiana. Três mecanismos adicionais são propostos de forma a tornar a aprendizagem e reprodução das trajetórias mais confiável: unidades de contexto, exclusão de neurônios e redundância na representação dos estados. A rede funciona indicando na sua saída o estado atual e o próximo estado da trajetória. As simulações com o modelo proposto ilustram a habilidade do modelo em aprender e reproduzir múltiplas trajetórias com precisão e sem ambigüidades. A rede também é capaz de reproduzir trajetórias mesmo diante de perdas de neurônios e de generalizar diante da presença de ruído nos estímulos de entrada da rede.

Palavras-chave: redes não-supervisionadas, contexto, aprendizagem competitiva, aprendizagem hebbiana temporal, mecanismo de exclusão, redundância, seqüências temporais, reprodução de trajetórias, tolerância a falhas. 


\section{ABSTRACT}

\section{BARRETO, G. de A. Unsupervised Neural Networks for Temporal Sequence Processing. São Carlos, 1998. 118p. Dissertação (Mestrado) - Escola de Engenharia de São Carlos, Universidade de São Paulo.}

In many application domains, the variable time is an essential dimension. This is the case of Robotics, where robot trajectories can be interpreted as temporal sequences in which the order of occurrence of each component needs to be considered. In this dissertation, an unsupervised neural network model is developed for learning and reproducing trajectories of a Robot PUMA 560. These trajectories can have states in common, making the process of reproduction susceptible to ambiguities. The proposed model consists of a competitive network with two groups of synaptic connections: interlayer and intralayer ones. The interlayer weights connect units in the input layer with neurons in the output layer and they encode the spatial information contained in the current input stimulus. The intralayer weights connect the neurons of the output layer to each other, being divided in two groups: self-connections and lateral connections. The function of these links is to encode the temporal order of the trajectory states, establishing associations among consecutive states through a Hebbian rule. Three additional mechanisms are proposed in order to make trajectory learning and reproduction more reliable: context units, exclusion of neurons and redundancy in the representation of the states. The model outputs the current state and the next state of the trajectory. The simulations with the proposed model illustrate the ability of the network in learning and reproducing multiple trajectories accurately and without ambiguities. In addition, the proposed neural network model is able to reproduce trajectories even when neuron failures occur and can generalize well in the presence of noise in the input stimulus.

Keywords: Unsupervised neural networks, context, competitive learning, temporal Hebbian learning, exclusion mechanism, redundancy, temporal sequences, trajectories reproduction, fault tolerance. 


\section{Capítulo 1}

\section{Introdução}

Um dos aspectos fundamentais da inteligência natural é a habilidade em processar informação temporal. A aprendizagem e a produção de padrões temporais está intimamente associada com nossa habilidade em perceber e gerar movimentos do corpo e de suas partes, fala e linguagem, música, etc [WANG \& YUWONO, 1996]. Mais ainda, processar padrões temporais é uma habilidade de sobrevivência necessária para muitos animais, que em certos casos necessitam reconhecer situações perigosas, escapar de inimigos, etc. Dessa forma, por ser uma habilidade desejável, qualquer sistema inteligente, natural ou artificial, deve ser capaz de detectar a ordem temporal com que eventos ocorrem e/ou reproduzi-la de forma adequada e precisa.

Um dos principais sistemas artificiais que se tem procurado embutir e simular alguma forma de comportamento inteligente são os robôs. Robôs são dispositivos mecânicos versáteis, equipados com atuadores e sensores sob o controle de um sistema de computador [HALPERIN et al., 1998]. Muita pesquisa tem sido desenvolvida com o objetivo de tornar estas máquinas menos susceptíveis à intervenção humana durante a realização de uma tarefa específica. Dotar um robô de maior autonomia, tornando-o capaz de tomar decisões e realizar ações semelhantes àquelas realizadas por organismos inteligentes (embora não necessariamente da mesma forma) demanda interação do robô com o meio ambiente no qual se encontra inserido (Figura 1).

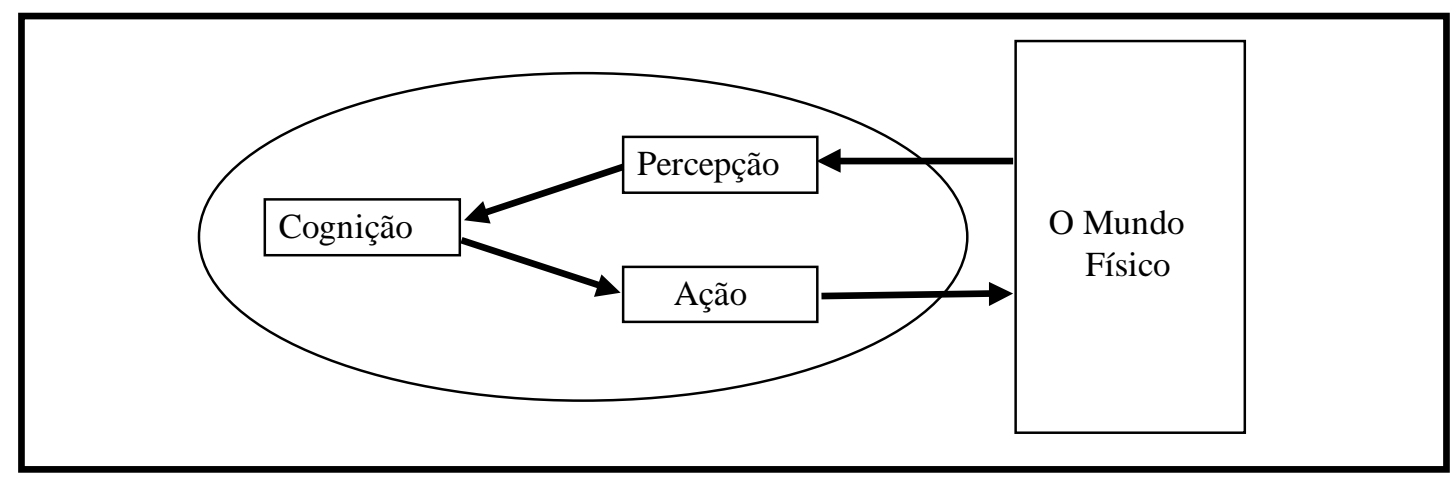

Figura 1: Características de uma máquina autônoma e sua iteração com o ambiente externo. 
Inicialmente, o robô deve ser capaz de coletar o maior conjunto possível de informações sobre o meio ambiente em que está inserido (percepção). De posse desses dados que coletou do mundo, analisar as informações de maneira adequada (cognição) para finalmente ser capaz de tomar atitudes e agir sobre o mundo baseando-se naquilo que entendeu ser o mais correto (ação).

A tarefa de percepção consiste em "perceber" o mundo através de diferentes canais. O ser humano usa para isso os cinco sentidos: visão, audição, tato, olfato e paladar. Robôs, também são capazes de processar informações visuais, tácteis e auditivas, usando para isso vários sensores diferentes. A tarefa de cognição está ligada à capacidade de o ser humano entender, raciocinar, aprender e decidir usando as informações que foram coletadas do mundo real. Por fim, a escolha da ação está relacionada com a capacidade de atuar no e/ou de modificar o mundo. Em qualquer uma dessas tarefas, a informação temporal se faz presente.

\subsection{Motivação Geral}

Robôs manipuladores encontram numerosas aplicações nos cenários industriais, em geral, executando tarefas simples e repetitivas. Programar braços robóticos que sejam capazes de executar uma ampla variedade de tarefas é um antigo objetivo da robótica. A falta de flexibilidade dos robôs industriais é considerada uma das principais causas da sua não utilização em massa em processos industriais. Uma forma de dar certo grau de flexibilidade a um robô é dotá-lo de mecanismos "inteligentes". Características como adaptabilidade - capacidade de se adequar a mudanças no meio ambiente, e robustez - capacidade de responder adequadamente apesar dos dados sensoriais serem ruidosos, incompletos ou inexatos, são altamente desejáveis em robôs manipuladores.

Métodos convencionais ou clássicos de controle e planejamento em robôs necessitam conhecer o modelo geométrico do mesmo. Qualquer alteração em um parâmetro desse modelo pode resultar em imprecisões de posicionamento do manipulador. Além disso, tais técnicas não são, em geral, adaptativas e são específicas de uma tarefa.

Para resolver este tipo de problema, a área de Inteligência Artificial clássica parece ser promissora. No entanto, a aplicação de tais técnicas em robótica também 
apresenta limitações significativas. Por exemplo, constatam-se dificuldades em gerar e armazenar todas as possibilidades de modelos suficientemente precisos do robô e do ambiente.

Uma outra possibilidade, explorada neste trabalho, é utilizar Redes Neurais Artificiais (RNAs), pois possuem certas características intrínsecas como robustez, tolerância a falhas, capacidade de aprender com a experiência, etc., que as tornam adequadas para o trato do problema em questão.

Redes neurais artificiais são sistemas biologicamente inspirados, constituindo-se de unidades de processamento (ou neurônios artificiais), densamente interconectadas via sinapses, que trocam informações entre si. A característica chave das RNAs é a sua capacidade de aprender com a experiência. Os principais paradigmas de aprendizagem neural são: aprendizagem supervisionada e aprendizagem não-supervisionada. No primeiro caso, o comportamento de saída é conhecido a priori e a rede é levada a reproduzir as saídas desejadas. No segundo, a rede por si só deve extrair regularidades existentes nos estímulos de entrada. Princípios de aprendizagem neural nãosupervisionada tendem a ser mais plausíveis biologicamente do que as técnicas supervisionadas normalmente usadas em controle.

Estratégias de aprendizagem neural não-supervisionada baseiam-se em dois mecanismos bastante simples: competição e correlação. No primeiro caso, estruturas neurais competem entre si pelo direito de responder a um determinado estímulo sensorial de entrada. No segundo, a estrutura neural se auto-organiza de tal forma a extrair a informação relevante a partir de correlações existentes nos dados sensoriais. Este último tipo de mecanismo de aprendizagem é comumente chamado de aprendizagem hebbiana [HEBB, 1949].

\subsection{Processamento de Seqüências Temporais}

O alvo principal desta pesquisa é o processamento de seqüências temporais, no caso trajetórias de robô, para utilizá-los em sistemas autônomos como aquele mostrado na Figura 1. Entre as tarefas que lidam com seqüências temporais podemos citar: reconhecimento de seqüências, reprodução de seqüência, associação temporal e geração de seqüiências temporais. Essas tarefas serão explicadas no próximo capítulo. 
Este trabalho tem como objetivo desenvolver técnicas para codificar trajetórias de um braço de robô inserido, possivelmente, em ambientes sujeitos a ruídos. Isto é, esta dissertação visa à proposição de um modelo de redes neurais com aprendizagem não-supervisionada que seja capaz de aprender e reproduzir as trajetórias do braço do robô. As principais contribuições deste trabalho podem ser resumidas nos seguintes termos:

- Estudo da dinâmica dos modelos de redes neurais artificiais nãosupervisionadas para processamento de padrões temporais;

- Proposição de um modelo neural não-supervisionado que possa lidar com seqüências temporais complexas, ampliando a gama de aplicação de tais modelos;

- Aplicação do modelo proposto na aprendizagem e produção de trajetórias de robôs manipuladores com diferentes graus de complexidade.

A tarefa a ser aprendida consiste no posicionamento do braço do robô em um local pré-estabelecido (posição final ou meta) empregando estratégias de controle inteligente que tornem o sistema estável, robusto e preciso. Para esse tipo de tarefa, um modelo de rede não-supervisionada deverá ser capaz de se auto-organizar, fornecendo pontos entre as posições inicial e final dadas. Tal modelo deve ser capaz de lidar com trajetórias espaciais que apresentam graus de complexidade diferentes. $\mathrm{O}$ modelo proposto deve ser capaz de aprender essas trajetórias a partir de alguns exemplos e ser capaz de reproduzi-las com fidelidade. Para gerar as trajetórias para treinamento e teste do novo sistema foi escolhido o manipulador PUMA 560.

\subsection{Desenvolvimento da Pesquisa e a Organização da Dissertação}

O relacionamento entre os diversos campos de pesquisa envolvidos nesta dissertação (sequiências temporais, robótica e redes neurais) é explicado em detalhes no Capítulo 2. Contudo, pode se adiantar que o desenvolvimento deste trabalho envolve quatro etapas principais que guardam estreita relação entre si. A primeira delas é o estudo da dinâmica de algoritmos de RNAs com aprendizado não-supervisionado. 
Diversos modelos, competitivos e hebbianos, são avaliados com o intuito de entender porque tais modelos não se prestam ao processamento temporal e extrair propriedades que fossem úteis na proposição de um modelo para processar padrões temporais. Um resumo desta fase é apresentado no Capítulo 3.

A segunda etapa consiste de uma análise semelhante à anterior, focalizando agora em modelos não-supervisionados para processamento de padrões temporais. Não existe aqui um domínio de aplicação específica, sendo que as áreas de aplicação são as mais variadas possíveis. Muitos dos conceitos estudados nesta etapa são agrupados de maneira mais didática no Capítulo 4.

A terceira etapa envolve o estudo de modelos não-supervisionados para processamento temporal com aplicação no campo da Robótica. Os exemplos envolvem tanto aplicações em robôs móveis quanto em braços de robôs manipuladores. Esta fase da pesquisa está descrita no Capítulo 5.

A quarta e última etapa diz respeito a proposição de um modelo de RNA nãosupervisionada para aprendizagem e produção de trajetórias de robôs manipuladores. O princípio básico do modelo a ser proposto é o seguinte: estabelecer associações temporais entre padrões apresentados em instantes de tempo consecutivos. Esta fase está documentada em detalhes no Capítulo 6.

O restante da dissertação está organizado como segue. No Capítulo 7 são realizadas diversas simulações com a rede proposta no Capítulo anterior. Estes experimentos servem para elucidar o funcionamento do modelo, bem como para avaliar a robustez do algoritmo proposto em tarefas de rastreamento de trajetórias com diferentes graus de complexidade. Finalmente, no Capítulo 8, conclui-se este documento comentando as vantagens e sugestões para desenvolvimentos futuros do algoritmo proposto. 


\section{Capítulo 2}

\section{Relacionando Seqüências Temporais, Trajetórias de Robô e Rede Neurais Artificiais}

Este capítulo tem como principal objetivo definir alguns conceitos que serão largamente utilizados no decorrer deste documento. Tais conceitos estão relacionadas a três tópicos principais: (1) definição de sequiências temporais e classes de problemas envolvidas no processamento destas, (2) definição do problema de aprendizagem de trajetórias de robôs manipuladores como um problema de processamento de padrões temporais, e (3) o uso de redes neurais artificiais para tratamento dos dois itens anteriores.

As seções que seguem estão organizadas de forma a estabelecer um elo de ligação entre os três tópicos descritos no parágrafo anterior. Ao final do capítulo, o leitor deverá ter uma idéia clara do problema tratado nesta dissertação e o tipo de solução que será proposta adiante.

\subsection{Processamento de Sequiências Temporais}

Seqüências temporais surgem naturalmente quando se tenta processar qualquer sinal no domínio do tempo, seja com o propósito de reconhecer ou antecipar a presença de características relevantes em uma aplicação particular, seja com o propósito de reproduzir tais características. A fala humana, sinais biomédicos, música ou qualquer função do tempo originada a partir de sensores constitui uma seqüência, cujo significado ou conteúdo não depende apenas da existência de certas características, mas também de sua ordem temporal [RAY \& KARGUPTA, 1996].

Um padrão temporal pode ser contínuo. Neste caso, para posterior processamento por um sistema computacional ele deve ser amostrado e convertido em uma sequiência de padrões discretos no tempo. A partir deste ponto, assume-se que padrões temporais são discretos, e passarão a ser chamados simplesmente de seqüências temporais. 
Um sinal no domínio do tempo é mais convenientemente abstraído como uma seqüência temporal de vetores que representam determinados aspectos ou características, freqüentemente chamada de seqüência espaço-temporal $S$ [RAY \& KARGUPTA, 1996], isto é:

$$
S=\left\{\mathbf{s}\left(t_{i}\right)\right\}, \quad t_{i}=1,2, \ldots, N
$$

em que cada $\mathbf{s}\left(t_{i}\right)$ é um vetor de características, uma representação condensada do sinal na vizinhança do instante $t_{i}$, e $N$ é o número de vetores na seqüência.

Vetores de características que têm sua origem em aplicações de processamento de sinais e da fala normalmente varrem um espaço de alta dimensão. Em aplicações práticas, o número infinito de possíveis vetores de características são, em geral, transformados e reduzidos a um número finito de classes através de uma operação de agrupamento (clustering) para reduzir o número de vetores distintos a um valor gerenciável, provendo desta forma uma entrada transformada para o processador de seqüência temporal. Em outras situações, as seqüências são processadas diretamente sem nenhum pré-processamento.

\subsubsection{Representação de Seqüências Temporais}

Sequências de entrada (pré-processadas ou não) são normalmente vistas e simbolizadas como caracteres tirados de um alfabeto finito, $\boldsymbol{A}$. Assim, uma seqüência temporal $S$ é abstraída para aparecer, por exemplo, como c-j-k-l-t-p-r-m-m-b-o-s.

Dependendo do número de vetores características existentes o alfabeto $\boldsymbol{A}$ pode não ser suficiente para representar tais vetores. Neste caso, outra representação possível consiste em utilizar apenas uma letra do alfabeto com um índice associado [WANG \& ARBIB, 1990], ou seja, uma seqüência $S$ de comprimento $N$ sobre um alfabeto de símbolos é definida como $p_{1}-p_{2}-\ldots-p_{N}$, em que cada $p_{i}(1 \leq i \leq N)$ é um símbolo único pertencente ao alfabeto e representa uma componente (padrão estático) de $S$. Qualquer parte de $S$, por exemplo, $p_{j}-p_{j+1}-\ldots-p_{k}$, em que $1 \leq j \leq k \leq N$, é chamada uma subseqüência de $S$. 


\subsubsection{Contexto, Grau e Tipos de Seqüências Temporais}

Em geral, no sentido de se produzir ou reproduzir, sem ambigüidades, uma componente de uma seqüência, é requerida informação adicional. Esta pode vir na forma de componentes anteriores da sequiência, ou na forma de informação prévia sobre estados iniciais e/ou finais da seqüência. Por exemplo, na sequiência $\boldsymbol{R}-\boldsymbol{E}$-F-E- $\boldsymbol{R}$ $\boldsymbol{E}$-E, a subsequiência anterior $E-R-E$ ao último $E$ é exigida para determinar o $E$, visto que $\boldsymbol{R}-\boldsymbol{E}$ é uma subseqüência que aparece mais de uma vez (recorrente) na sequiência em questão. Desta forma, define-se como contexto local de uma componente $p_{i}$, a subseqüência anterior mais curta que determina a componente $p_{i}$ sem ambigüidades na seqüência $S$, e seu comprimento é chamado de grau da componente $p_{i}$. Informação prévia sobre estados iniciais e/ou finais de uma sequiência é definida como contexto global.

O grau de uma seqüência é o maior grau dentre os graus de suas componentes. Dessa forma, uma sequiência é dita simples quando não contém subsequiências recorrentes (sequiência de grau 1) ou não depende de informação de contexto global. Uma seqüência é dita complexa se seu grau é maior que 1 ou depende de contexto global para resolver ambigüidades.

\subsection{Classes de Problemas em Seqüências Temporais}

Em muitas aplicações científicas e de engenharia é necessário modelar processos dinâmicos que lidam com seqüências temporais. O tipo de informação que se deseja extrair da seqüência vai depender da aplicação. Normalmente, quando se processa algum tipo de padrão temporal, se está interessado em [HERTZ et al., 1991]:

- Reconhecimento de Seqüências: neste caso, deseja-se gerar um padrão de saída particular quando uma seqüência de entrada específica é apresentada. A sequiência de entrada deve ser apenas identificada. Uma aplicação típica é o reconhecimento de voz, em que a saída indicaria a palavra que foi falada.

- Reprodução de Seqüiências Temporais: aqui, o sistema deve ser capaz de gerar a seqüência de entrada quando parte dela (um ou mais estados) lhe é apresentada. Este seria o caso apropriado quando se deseja que a rede aprenda uma seqüência 
melódica, ou seja capaz de prever o curso futuro de uma série temporal a partir de partes desta melodia.

- Associação Temporal de Sequiências: para esta situação, uma sequiência de saída particular deve ser gerada em resposta a uma seqüência específica de entrada. A sequiência de entrada e a de saída podem ser bastante diferentes. Este caso inclui as duas classes anteriores como casos especiais.

- Geração de Sequiências Temporais: neste caso, o sistema gera uma sucessão de estados entre dois pontos quaisquer não consecutivos dados: o ponto inicial e o ponto final. Este conceito está estreitamente ligado ao de interpolação de estados.

Neste ponto é interessante comentar que na literatura os termos reprodução e produção de seqüências temporais são utilizados indistintamente. Este também será o caso para a presente dissertação.

Até o presente momento tem-se falado exaustivamente no termo seqüência temporal. Entretanto, não se comentou ainda que a variável tempo pode ser considerada explicita ou implicitamente em tal seqüência temporal. Desta forma, é interessante perceber que a variável tempo pode vir embutida em uma seqüência temporal de duas maneiras básicas [WANG, 1995]:

(i) Ordem temporal: se as componentes de um padrão temporal são retirados de um alfabeto específico, a ordem temporal se refere à posição relativa destas componentes dentro da seqüência. Por exemplo, a sequiência a-b-c é considerada diferente da c-b-a por causa do ordenamento diferente. Ordem temporal também pode se referir a uma estrutura sintática, tal como sujeitoverbo-objeto, na qual cada componente é escolhido entre um número de símbolos possíveis.

(ii) Duração do tempo: assumindo uma taxa de amostragem uniforme, a duração do tempo é inversamente proporcional à taxa de apresentação (ou de observação) da seqüência. A duração desempenha um papel crítico em algumas tarefas de processamento temporal, tanto no reconhecimento quanto na reprodução de padrões temporais. 
No que se refere à duração do tempo, WANG \& ARBIB (1993) chamam de sistemas invariantes à taxa de apresentação aqueles que não são afetados pela velocidade de observação da sequiência, mas são sensíveis à duração relativa da componente. Sistemas invariantes ao intervalo de duração não são afetados ao se variar as durações das apresentações para as componentes individuais de uma sequiência. Para ilustrar estes aspectos, três seqüências são mostradas na Figura 2. Cada seqüência é composta de três componentes A, B, C, sendo que a duração de cada componente é diferente. Suponha um sistema que é projetado para reconhecer com sucesso a sequiência I. Tal sistema é em seguida testado nas seqüências II e III. Se ambas, seqüência II e seqüência III, são corretamente reconhecidas, o sistema é dito ser invariante ao intervalo de duração, porque ele não consegue distingui-las com base nas diferenças entre os intervalos de duração relativa. Por outro lado, se apenas a seqüência II é reconhecida e a seqüência III não, o sistema é chamado de invariante à taxa de apresentação, porque ele distinguiu seqüências com ordem temporal equivalente, mas com diferentes durações relativas das componentes.

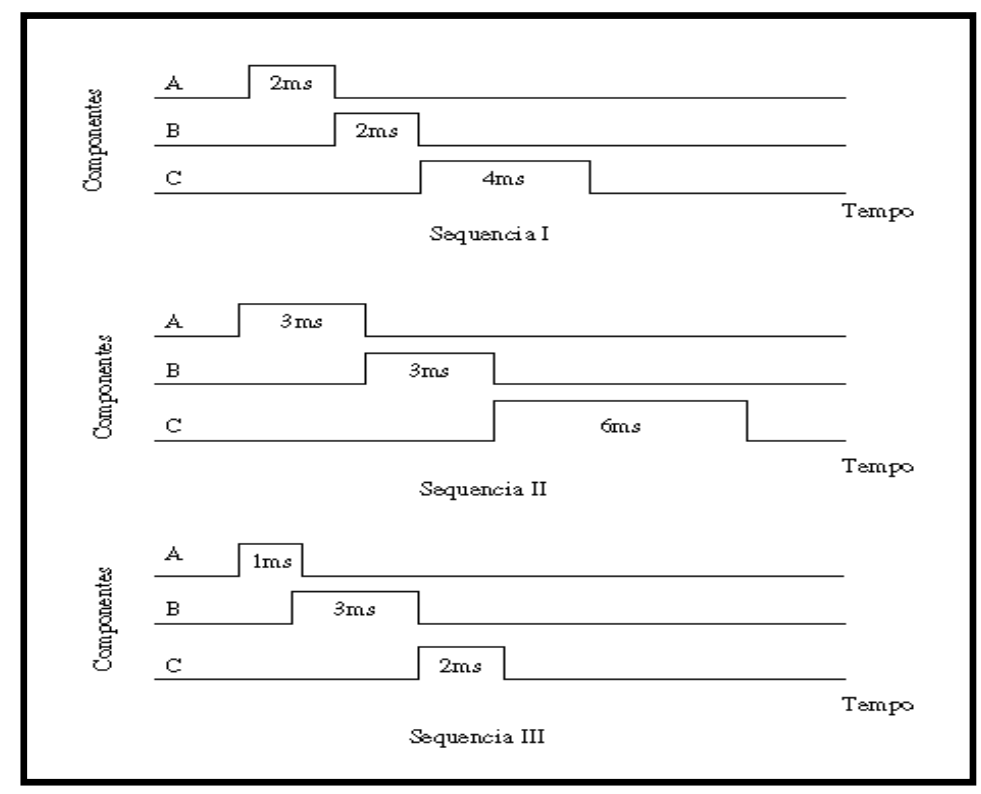

Figura 2: Três seqüências de mesma ordem de eventos A-B-C, mas com durações relativas das componentes diferentes.

Resumindo, sistemas invariantes à taxa de apresentação são sensíveis tanto à ordem dos eventos quanto à duração relativa dos eventos, enquanto que sistemas invariantes ao intervalo de duração são sensíveis apenas à ordem dos eventos. 
No presente trabalho, está-se particularmente interessado na reprodução de seqüências temporais. Os padrões temporais serão gerados a partir de trajetórias de braços de robôs manipuladores e terão graus diferentes de complexidade. Na próxima seção discute-se alguns conceitos em Robótica necessários à formulação do problema.

\subsection{Robótica - Conceitos Básicos}

Robôs manipuladores são dispositivos mecânicos versáteis equipados com atuadores e sensores sob o controle de computadores [HALPERIN et al., 1998]. Eles executam tarefas que envolvem movimentos em um espaço físico. Este espaço está sujeito a leis da natureza e pode estar ocupado por vários objetos. Além disso, robôs são programáveis, o que significa que eles podem realizar uma variedade de tarefas simplesmente mudando o software que os comanda. A movimentação de um braço de robô a partir de uma posição inicial em direção até uma posição final, definindo um histórico temporal das posições espaciais, configurações de ângulos das juntas e torques associados, recebe o nome de trajetória [CRAIG, 1989]. Cada ponto de uma trajetória define o estado do manipulador naquele instante de tempo específico.

Para que seja possível a execução destas trajetórias, que são dependentes de dados sensoriais, três problemas precisam ser resolvidos:

Planejamento de Trajetória: compreende a definição do conjunto de posições espaciais entre os estados inicial e o final que definem a rota do manipulador.

Cinemática Inversa: este problema é colocado como segue: dados a posição e orientação do efetuador do manipulador, calcule todos os conjuntos possíveis de ângulos das juntas que poderiam ser usados para alcançar esta dada posição e orientação. Este é um problema fundamental no uso prático de manipuladores.

O problema da cinemática inversa não é tão simples quanto pode sugerir a definição anterior. A solução das equações cinemáticas não é sempre fácil ou mesmo possível em uma forma fechada. Surgem aqui também as questões de existência de uma solução e de soluções múltiplas. Solucionar este problema é um requisito mínimo para maioria dos sistemas de controle de robôs. 
Dinâmica Inversa: a Dinâmica é o campo de estudo devotado ao estudo das forças exigidas para causar movimento. No sentido de acelerar um manipulador a partir do repouso, deslizar a uma velocidade constante do efetuador e finalmente desacelerar até parar, exige que um complexo conjunto de funções de torque sejam aplicadas pelos atuadores das juntas. A dinâmica inversa determina torques dadas as posições espaciais do manipulador.

Para mover um manipulador de um lugar a outro seguindo um caminho especificado previamente, cada junta deve ser movida de acordo com informações fornecidas pela cinemática e pela dinâmica inversa. A determinação dos ângulos e torques das juntas correspondentes a cada posição espacial é definida como produção de trajetórias.

O problema de execução de trajetórias será abordado nesta dissertação usando uma classe especial de redes neurais artificiais. No Apêndice I, são discutidos conceitos básicos relacionados com redes neurais artificiais. A seguir são brevemente apresentadas as partes constituintes básicas de um sistema de controle de robôs.

\subsubsection{Sistemas de Controle de Robôs}

Um sistema de controle para robôs (manipuladores ou móveis) deve possuir no mínimo três etapas [BUGMANN et al., 1998]. Na primeira, chamada de sensoriamento, a posição do robô deve ser determinada. Isto pode ser feito usando combinação de sensores (câmeras de vídeo, ultra-som, etc.). Em um segundo estágio, denominado de programação ou planejamento, usa-se a informação sobre a configuração (estado) atual do braço obtida a partir da leitura dos sensores para determinar o próximo estado a ser alcançado pelo robô. Em um terceiro e último estágio, chamado de execução, procedimentos clássicos de controle seriam usados para guiar o braço mecânico para o estado fornecido pelo segundo estágio. Ao atingir a posição especificada pelo planejamento, uma nova leitura sensorial é feita e o processo se repete até que o robô atinja a posição desejada.

O alvo deste trabalho de pesquisa é o segundo estágio descrito no parágrafo anterior, ou seja a programação de robôs usando redes neurais não-supervisionadas. A razão da escolha desta técnica é justificada a seguir. 


\subsection{Por que Redes Neurais Artificiais Não-Supervisionadas ?}

Uma das características chaves de robôs é a versatilidade, porém ela só pode ser explorada se o robô puder ser programado facilmente. Em alguns casos, a ausência de ferramentas adequadas de programação fazem com que algumas tarefas sejam até mesmo impossíveis de executar. Em outros casos, o custo da programação pode ser uma parcela significativa do custo total da aplicação. Para se ter uma idéia da importância da programação, ela é responsável por um terço do custo total de sistemas de robôs industriais [HEIKKONEN \& KOIKKALAINEN, 1997].

Assim, o envolvimento de redes neurais na programação de robôs visa a explorar propriedades conhecidas de redes como a capacidade de aprender e de generalizar diante de novas situações e tolerância à falhas, para aumentar a flexibilidade de robôs na execução de uma determinada tarefa. Uma outra razão para o uso de redes neurais artificiais está na limitada habilidade de métodos de programação tradicionais de robôs em lidar com ambigüidades que surgem com freqüência durante a execução de trajetórias, por exemplo.

O uso de RNAs com aprendizagem não-supervisionada pode ser justificado pela necessidade de o sistema ser capaz de extrair por si só a informação necessária ao seu correto funcionamento em um sistema robótico sem (ou com mínima) intervenção de um operador humano. Esta propriedade recebe o nome de auto-organização.

No presente trabalho, as propriedades citadas acima serão usadas para avaliar o desempenho do modelo a ser proposto na execução de tarefas de robótica. A seguir, o problema a ser tratado nesta dissertação é definido.

\subsection{Classificação das Trajetórias e Enunciado do Problema}

Conforme mencionado anteriormente, o foco principal desta pesquisa é a programação de robôs. Esta programação será feita através do uso de um modelo de RNAs não-supervisionadas cuja função será aprender e reproduzir, de modo preciso e sem ambigüidades, trajetórias de robôs.

Trajetórias de robôs são exemplos de seqüências espaço-temporais, pois não só a informação espacial contida em uma componente específica da trajetória é importante, como também a ordem de ocorrência de cada componente. 
Cada trajetória é formada por um conjunto de pontos (componentes da seqüência) que descrevem o estado do robô em um dado instante de tempo. Cada estado consiste na informação de posição espacial do efetuador, de ângulos das juntas e de torques aplicados a cada uma destas juntas do manipulador.

De acordo com as definições apresentadas na Seção 2.1, as trajetórias consideradas para avaliar a performance do modelo a ser introduzido são formadas por um conjunto de $N_{p}$ padrões discretos no tempo. Algumas destas trajetórias têm estados em comum com outras, o que aumenta o grau da complexidade em lidar com elas pois não dependem unicamente do padrão anterior para determinar o estado atual, mas também de informação global de contexto.

Como a taxa de observação dos padrões foi considerada constante, apenas a ordem temporal dos estados precisa ser modelada pela rede. Assim, pode-se classificar tal sistema como sendo invariante ao intervalo de duração.

Como todos os estados das trajetórias já estão determinados, ao aprender cada um deles a rede neural estará realizando rastreamento de trajetória. Esta é a tarefa ser executada pela rede. E para realizá-la adequadamente, é de fundamental importância que todos os estados sejam reproduzidos na íntegra, com pequeno erro e na seqüência correta. Percebe-se aqui a necessidade de duas etapas: uma de classificação individual de cada estado por neurônios da rede, e uma de associação temporal entre os neurônios que codificam estados consecutivos da trajetória. A tarefa de classificação por RNAs não-supervisionadas será discutida em detalhes no Capítulo 3, enquanto formas de realizar associação temporal serão discutidas no Capítulo 4.

\subsection{Convenções de Nomenclatura}

Ao longo deste texto alguns termos serão usados indistintamente. Por exemplo, um neurônio artificial poderá ser chamado simplesmente de neurônio, ou unidade, ou nó, ou ainda célula. Um estímulo de entrada para esse neurônio pode ser referenciado como padrão de entrada, estado ou excitação, ou simplesmente estímulo. Da mesma forma, pesos sinápticos poderão ser chamados também de conexões sinápticas, ou simplesmente conexões.

Alguns termos comuns na língua inglesa como por exemplo, feedforward weights, foram traduzidos para uso nesta dissertação. Para este exemplo específico, 
podem ser encontradas as seguintes formas: pesos de propagação direta, pesos de alimentação direta, ou ainda, pesos intercamadas (por conectarem neurônios em camadas distintas). Outros termos também tiveram sua tradução sugerida ao longo do trabalho. Aqueles cuja tradução se mostrou inadequada para representar o correto significado da palavra, foram mantidos em sua forma original.

Muitos dos termos de origem neurobiológica foram traduzidos para o português tomando por base a referência [OLIVEIRA \& AMARAL, 1997].

No próximo capítulo serão discutidos os dois principais paradigmas de aprendizagem não-supervisionada, a saber: aprendizagem competitiva e a aprendizagem hebbiana. 


\section{Capítulo 3}

\section{Modelos Não-Supervisionados para Processamento de Padrões Estáticos: Definições e Características}

Este capítulo discute os principais conceitos relacionados à aprendizagem de padrões estáticos em modelos de redes neurais artificiais não-supervisionadas. $\mathrm{O}$ entendimento da dinâmica de tais modelos será importante na compreensão dos modelos que serão apresentados nos Capítulos 4 e 5, e na proposição de algoritmos neurais não-supervisionados para processamento de seqüências temporais no Capítulo 6. A análise e discussão destes modelos permitirá entender porque tais opções não são adequadas ao processamento de padrões temporais, e que propriedades devem permanecer e quais não são necessárias para processar padrões temporais.

Na Seção 3.1 é dada uma definição geral de modelos não-supervisionados e suas áreas de aplicação. Na Seção 3.2 discute-se algumas definições relativas à aprendizagem competitiva. Em seguida, nas Seções 3.3 e 3.4 são apresentados modelos competitivos para determinação de valores extremos e classificação de padrões respectivamente. Na Seção 3.5 é apresentado um tipo especial de modelo competitivo chamado mapa auto-organizável de característica. A partir da Seção 3.6 discute-se modelos com aprendizagem hebbiana e anti-hebbiana. O capítulo é concluído na Seção 3.7.

\subsection{Modelos Não-Supervisionados: Definição e Utilização}

Em modelos não-supervisionados, não existe um sinal externo mostrando que valor uma dada unidade de saída deve assumir (professor) ou indicando que os valores daquela saída são adequados ou não (sinal de reforço). De forma que, uma rede nãosupervisionada deve descobrir por si só padrões, características, regularidades, correlações ou categorias embutidas nos dados de entrada e codificá-las na saída.

A maior parte dos casos considerados neste capítulo tem arquitetura e regras de aprendizagem criadas a partir de premissas simples, oriundas principalmente de 
observações e resultados obtidos da pesquisa em neurociência cognitiva. Em outros casos, existe uma quantidade bem definida que está sendo otimizada, tal como o conteúdo de informação ou variância da saída. Alguns dos modelos a serem discutidos também guardam estreita relação com técnicas estatísticas tradicionais para classificação e análise de padrões.

\subsubsection{Sinais de Entrada e Função de Ativação}

Quanto à natureza dos dados de entrada processados por redes nãosupervisionadas, eles podem ser binários, bipolares ou contínuos, dependendo da aplicação. Da mesma forma, as unidades de saída têm representação idêntica. A dinâmica de cada neurônio é orientada por sua função de ativação, descrita por uma equação a diferenças ou por uma equação diferencial, ou em alguns casos, por uma atribuição de valores. A mesma classificação feita para função de ativação vale para regras de aprendizagem. Os tipos de funções de ativação e de regras de aprendizagem descritos anteriormente são amplamente utilizados no campo de RNAs.

\subsubsection{Aplicação de Modelos Não-Supervisionados}

Em sistemas nos quais se aplicam algoritmos não-supervisionados, normalmente, muito pouco se conhece a respeito do conjunto de dados de entrada. O tipo de informação que uma rede não-supervisionada extrai dos dados de entrada depende de sua arquitetura e dinâmica, existindo uma gama de tarefas nas quais se aplicam tais redes, entre as principais se pode citar: (i) agrupamento (clustering): neste caso um conjunto de neurônios de saída, com apenas um ativo por vez, aponta uma categoria dentre várias, a qual um dado padrão de entrada pertence. Cada grupo de padrões semelhantes devem ser classificados como sendo uma única classe na saída; (ii) prototipação (prototyping): aqui, a rede pode formar categorias como no caso anteriores, mas sua saída é um protótipo (exemplo) típico da classe apropriada; (iii) codificação (encoding): nesta situação, a saída compreende uma versão codificada da entrada, talvez até com menos bits, mantendo a maior quantidade de informação relevante possível; (iv) mapas auto-organizáveis (self-organizing maps): nestes, as unidades de saída estão arranjadas segundo uma forma geométrica específica, tal como 
em um array bidimensional. As unidades de saída mapeam os padrões de entrada em diferentes pontos neste arranjo, preservando relações de vizinhança existentes na distribuição de entrada. Deste modo, padrões semelhantes ativam unidades de saídas próximas.

Estes casos não são necessariamente distintos e podem ser combinados de várias maneiras. A combinação das propriedades de agrupamento com prototipação é freqüentemente chamada de quantização vetorial [GRAY, 1984].

A seguir são apresentados os principais grupos de modelos computacionais de redes neurais artificiais não-supervisionadas para processamento de padrões estáticos. Primeiro, trata-se de modelos competitivos, começando por modelos de redes vencedor-leva-tudo (winner-take-all, WTA) para detecção de valores extremos (máximos e mínimos) de um conjunto de dados. Em seguida, discute-se redes competitivas para o problema de agrupamento ou classificação de padrões estáticos. Mapas auto-organizáveis de características são brevemente discutidos como uma extensão natural dos modelos competitivos. Depois, aborda-se modelos com aprendizagem por correlação ou hebbiana. O papel de conexões sinápticas laterais e sua necessidade também serão discutidos tanto em modelos competitivos quanto em modelos hebbianos.

\subsection{Redes Não-Supervisionadas com Aprendizagem Competitiva}

Os modelos de redes neurais que serão descritos agora se baseiam, principalmente, no mecanismo de competição [GROSSBERG, 1976; HERTZ et al., 1991; HAYKIN, 1994]. Tal mecanismo é fundamentado por evidências biológicas e encontra grande aplicação em problemas de Engenharia [KOHONEN, 1997].

A idéia básica da competição é a seguinte: os neurônios da camada de saída “competem" entre si pelo direito de responder, ou seja, de permanecerem ativos para um dado estímulo de entrada. Ao final desta competição, apenas uma unidade permanecerá ativa, como resposta àquela informação da entrada. Os neurônios que compõem tal rede são denominadas células-avós (grandmother cells). A este tipo de codificação da informação de entrada dá-se o nome de localizada.

As principais vantagens da representação da informação por neurônios deste tipo estão na simplicidade de implementação e de interpretação dos padrões de ativação. As 
principais desvantagens estão (i) na baixa tolerância à falhas, pois ao perder uma unidade se perde toda a informação codificada por ela; (ii) na necessidade de se ter uma unidade de saída para toda categoria ou característica envolvida, ou seja $n$ neurônios só conseguem representar $n$ classes ou características.

\subsection{Redes Competitivas para Determinação de Valores Extremos}

Um conjunto particularmente interessante de redes WTA é aquele formado pelas chamadas redes mutuamente inibitórias. Tais modelos usam conexões laterais inibitórias para forçar um comportamento do tipo WTA. A principal aplicação de redes mutuamente inibitórias está na seleção de valores extremos de um dado vetor de entrada. LIPPMANN (1987) propôs um algoritmo discreto no tempo chamado Maxnet, que apesar de sua simplicidade tem recebido especial atenção [YEN et al., 1994; SUM et al., 1996] por fornecer e apresentar características importantes para a análise de redes competitivas.

Maxnet é uma rede neural de camada única, totalmente conectada lateralmente, usada para selecionar o valor máximo ou o mínimo de um conjunto de dados através de um processo de auto-relaxamento. Cada saída de um neurônio é positivamente realimentada para sua entrada com peso 1, e negativamente realimentada (com peso $\varepsilon$ ) para a entrada de todos os outros neurônios. Para uma rede de $n$ neurônios, a arquitetura de Maxnet está mostrada na Figura 3.

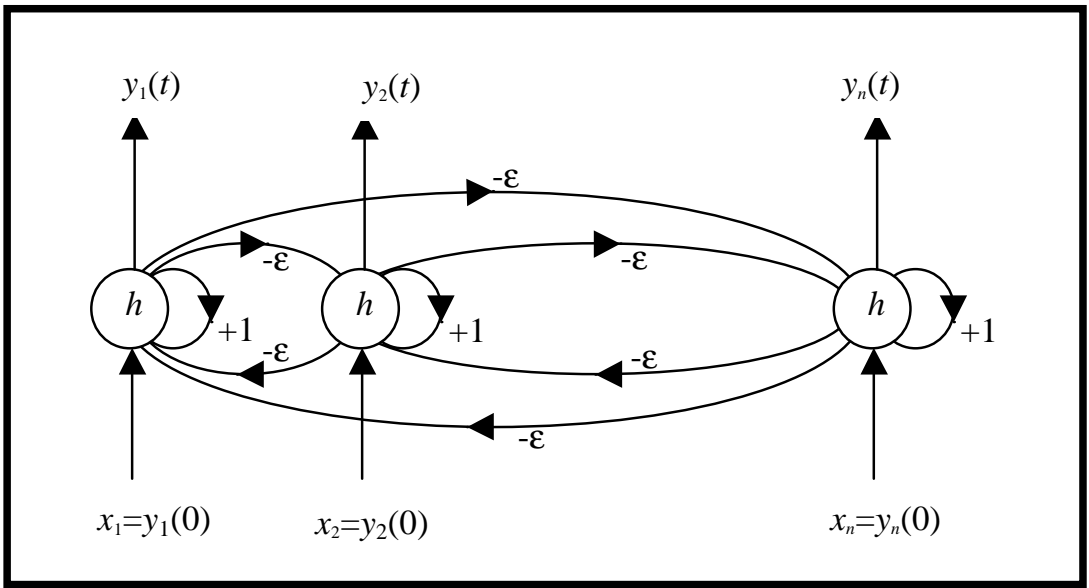

Figura 3: A rede neural Maxnet. As componentes do vetor de entrada, $x_{i}$, são consideradas as saídas iniciais para o processo de autorelaxamento $(t=0)$. 
As variáveis de saída e a função de ativação são chamadas de $y_{j}(t), j=1,2, \ldots, n$ e $h($.), respectivamente. A dinâmica da rede Maxnet é governada pela seguinte equação:

$$
y_{j}(t+1)=h\left[\sum_{k=1}^{n} m_{j k} y_{k}(t)\right]=h\left[y_{j}(t)-\varepsilon \sum_{\substack{k=1 \\ k \neq j}}^{n} y_{k}(t)\right]
$$

na qual $w_{j k}$ é a conexão entre os neurônios $k$ e $j$, tal que $w_{j j}=1$ e $w_{j k}=-\varepsilon$. Após a apresentação de um vetor de entrada $\mathbf{x}=\left[x_{1}, x_{2}, \ldots, x_{n}\right]^{T}$, a rede Maxnet converge, em um tempo finito, para a situação descrita a seguir:

$$
\lim _{t \rightarrow \infty} h\left[y_{j}(t)\right]=\left\{\begin{array}{lll}
\xi, & \text { se } y_{k}(0)>y_{j}(0) & \mathrm{p} / \text { todo } j \neq k \\
0, & \text { se } y_{k}(0)<y_{j}(0) & \mathrm{p} / \text { todo } j \neq k
\end{array}\right.
$$

na qual $h($.$) é a função de ativação, t$ é o instante de iteração, $y_{j}(0)$ e $y_{k}(0)$ são as saídas iniciais das unidades $j$ e $k$ iguais, respectivamente, a $x_{j}$ e $x_{k}$ e $\xi$ é um valor real maior que zero. A matriz de inibição $\mathbf{M}=\left\lfloor m_{j k}\right\rfloor_{n x n}$ é simétrica, sendo descrita a seguir:

$$
\mathbf{M}=\left[\begin{array}{cccc}
1 & -\varepsilon & \cdots & -\varepsilon \\
-\varepsilon & 1 & \cdots & -\varepsilon \\
\cdots & \cdots & \ddots & \cdots \\
-\varepsilon & -\varepsilon & \cdots & 1
\end{array}\right]_{n \times n}
$$

em que $\varepsilon<1 /(n+1)$, garante a convergência do algoritmo. A simetria da matriz $\mathbf{M}$ é necessária para que todos os neurônios tenham chances iguais de responder ao padrão de entrada. Caso contrário, um neurônio poderia, em princípio, suprimir a ativação de todos os outros para todos os padrões [MARSHALL, 1995].

Uma escolha comum para $h($.$) é a função linear saturada, que tem a seguinte$ formulação:

$$
h(x)= \begin{cases}\alpha, & \text { se } x \geq \alpha \\ x, & \text { se } 0<x<\alpha \\ 0, & \text { se } x \leq 0\end{cases}
$$

na qual $\alpha>0$ é uma constante de valor alto, escolhida antecipadamente tal que $h($. tenha uma porção linear dominante. A Equação (5) determina a componente de maior valor do vetor de entrada $\mathbf{x}$. 
Na próxima seção, discute-se uma ampla variedade de modelos de redes neurais competitivas cujo principal objetivo é categorizar padrões de entrada em classes baseando-se em similaridades entre os padrões de entrada.

\subsection{Modelos Competitivos para Classificação de Padrões Estáticos}

Nos modelos WTA que serão apresentados a seguir existe uma única camada de saída $y_{j} \in \mathfrak{R}, j=1 \ldots m$. Um conjunto de entradas $x_{i}, i=1 \ldots n$, está totalmente conectado com as unidades de saída através de conexões sinápticas $w_{j i}$. Arquiteturas típicas deste tipo de rede são mostradas na Figura 4.

\subsubsection{Modelos Vencedor-leva-tudo}

Este modelo caracteriza-se por manter apenas uma unidade de saída ativa por vez: a unidade vencedora. Esta é normalmente aquela com maior soma linear ponderada pelos pesos $\mathbf{w}$ das entradas para um dado vetor de entrada $\mathbf{x}$ :

$$
y_{j}(t)=\sum_{i=1}^{n} w_{j i}(t) x_{i}(t)=\mathbf{w}_{j}^{T}(t) \mathbf{x}(t)=\mathbf{x}^{T}(t) \mathbf{w}_{j}(t)
$$

na qual $\mathbf{x}(t)=\left(x_{1}(t), x_{2}(t), \ldots, x_{n}(t)\right)^{\mathrm{T}}, \mathbf{w}_{j}(t)=\left(w_{j 1}(t), w_{j 2}(t) \ldots, w_{j n}(t)\right)^{\mathrm{T}}$ e $t$ é o instante de observação. Uma outra possibilidade é encontrar o vetor de pesos mais próximo ao vetor de entrada $\mathbf{x}$, ou equivalentemente, mais semelhante usando distância euclideana:

$$
\left\|\mathbf{x}(t)-\mathbf{w}_{v}(t)\right\|=\min _{j}\left\|\mathbf{x}(t)-\mathbf{w}_{j}(t)\right\|
$$

na qual $v$ é o índice do neurônio vencedor. A unidade vencedora tem sua saída fixada em 1, enquanto as unidades que perderam a competição para aquele padrão de entrada tem suas respectivas saídas fixadas em 0 [RUMELHART \& ZIPSER, 1985].

Caso se faça uso da Equação (6), pode se usar uma rede mutuamente inibitória do tipo descrito na Seção 3.3 para encontrar o valor máximo de $y_{j}(t)$. Entretanto, para fins de implementação, as conexões laterais inibitórias não precisam ser modeladas diretamente, podendo simplesmente escolher a unidade de saída com maior valor $y_{j}$. 

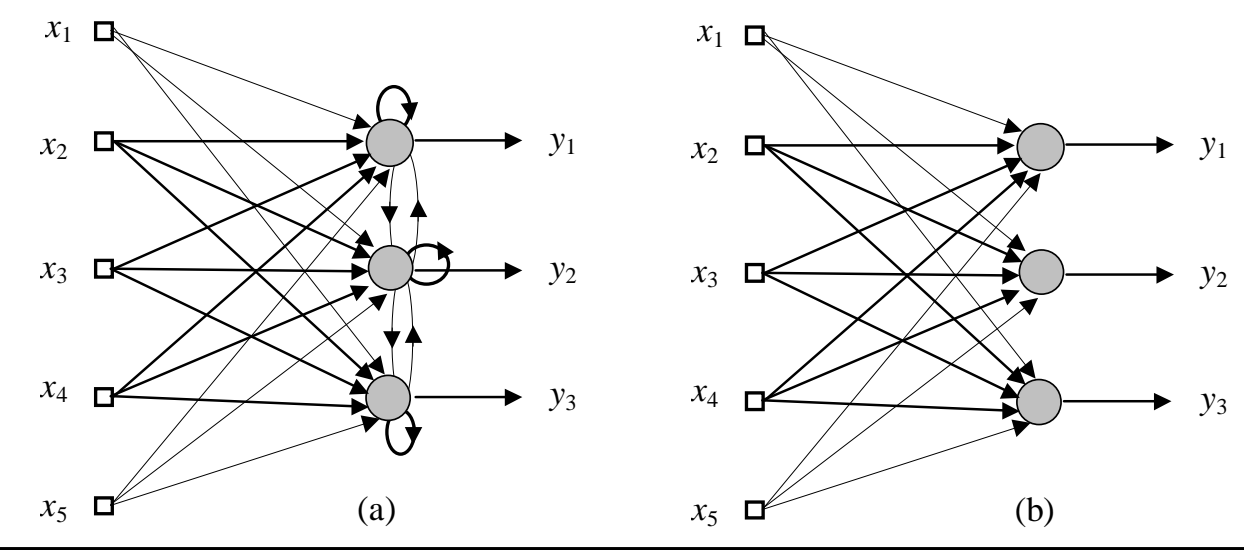

Figura 4: Arquiteturas de redes neurais competitivas. As inibições laterais (a) só são necessárias quando não se usa distância euclideana (b) para determinar o neurônio vencedor.

Uma rede competitiva WTA implementa um classificador de padrões estáticos. Tais redes utilizam regras de aprendizagem não-supervisionadas para encontrar classes nos padrões de entrada. Inicialmente atribui-se valores pequenos e aleatórios aos pesos de propagação direta $w_{j i}$. Recomenda-se que qualquer simetria seja quebrada para diminuir a chance de duas unidades de saída distintas responderem ao mesmo padrão de entrada. Em seguida, um conjunto de padrões escolhidos para treinamento é apresentado seqüencial ou aleatoriamente à rede. Toda vez que um padrão for escolhido e apresentado à rede ele é recolocado no conjunto de treinamento. Para cada entrada apresentada acha-se a unidade vencedora de saída $v$ e atualiza-se apenas os pesos sinápticos $w_{v i}$ associados com a unidade vencedora de modo levar o vetor $\mathbf{w}_{v}$ para mais próximo do estímulo de entrada atual x. Uma possível forma de realizar esta operação é através da seguinte equação:

$$
\Delta w_{v i}(t)=\eta\left[x_{i}(t)-w_{v i}(t)\right]
$$

ou na forma matricial,

$$
\Delta \mathbf{w}_{v}(t)=\eta\left[\mathbf{x}(t)-\mathbf{w}_{v}(t)\right]
$$

Esta última equação é que se popularizou como a regra de aprendizagem competitiva. As Equações (8) e (9) movem o vetor de pesos sinápticos na direção da entrada, tornando-o mais semelhante a ela. Este procedimento aumenta a chance deste neurônio de vencer em competições futuras pelo mesmo padrão de entrada. O 
resultado final é um atrator estável, correspondendo ao centróide das distribuições de entrada (ver Apêndice III).

\subsubsection{Modelo de Aprendizagem Competitiva Diferencial}

O modelo de RNA descrito na seção anterior, ou utiliza conexões laterais inibitórias, ou utiliza distância euclideana para encontrar o neurônio vencedor. Um modelo competitivo que usa ambos os mecanismos, chamado de aprendizagem competitiva diferencial, foi proposto por KONG \& KOSKO (1991) e KOSKO (1992) como um novo paradigma de aprendizagem não-supervisionada. A rede tem a mesma arquitetura dos modelos competitivos convencionais (Figura 4) e apenas seus pesos sinápticos do neurônio vencedor são atualizados a cada apresentação de um padrão de entrada. O neurônio vencedor é encontrado de acordo com a Equação (7) e os pesos de alimentação direta $\mathbf{w}_{v}(t)$ são atualizados de acordo com a seguinte equação:

$$
\mathbf{w}_{v}(t+1)=\mathbf{w}_{v}(t)+\eta(t) \Delta S_{v}\left(y_{v}(t)\right)\left[\mathbf{x}(t)-\mathbf{w}_{v}(t)\right]
$$

na qual $0<\eta(t) \ll 1$ é a taxa de aprendizagem, e $\Delta S_{v}\left(y_{v}(t)\right)$ é a variação no tempo do sinal competitivo $S_{v}\left(y_{v}\right)$ do neurônio vencedor $v$. Na prática, é usado apenas o sinal da diferença entre as ativações, $\operatorname{sgn}\left[\Delta y_{v}\right]=\operatorname{sgn}\left[y_{v}(t)-y_{v}(t-1)\right]$. As ativações dos neurônios na camada de saída são calculadas de acordo com o modelo aditivo:

$$
y_{j}(t+1)=y_{j}(t)+\sum_{i=1}^{n} w_{j i}(t) S_{i}\left(x_{i}(t)\right)+\sum_{k=1}^{m} m_{j k}(t) S_{k}\left(y_{k}(t)\right)
$$

Os pesos $m_{j k}$ definem autoconexões excitatórias e conexões laterais inibitórias fixas. Estas conexões são pré-fixadas no início do processo de aprendizagem. Uma escolha comum é fazer $m_{j j}=1$ e $m_{j k}=-1$ para todo $j \neq k$.

Como no modelo competitivo original, os vetores sinápticos do modelo DCL convergem para centróides das classes de decisão e tendem a flutuar aleatoriamente em torno dos centróides. BARRETO \& ARAÚJO (1998a) estudaram o papel das conexões laterais inibitórias no modelo DCL e suas implicações no desempenho do algoritmo (ver Apêndice II). 


\subsubsection{Neurônios que Não Aprendem}

Um problema que acontece com certa freqüência com modelos competitivos de redes neurais é a ocorrência de unidades mortas (dead units), ou seja, neurônios que não foram utilizados durante o treinamento. Estas unidades nunca ganham uma competição pelo fato de seus vetores de peso terem sido inicializados numa região do espaço longe de qualquer vetor de entrada. A ocorrência de unidades mortas, neste tipo de modelo, pode ser desejável se padrões de entradas diferentes ocorrerem no futuro. Se este não é o caso, tais unidades podem ser evitadas através da utilização de um mecanismo de consciência [GROSSBERG, 1976; DeSIENO, 1988] ou de sensibilidade à freqüência de vitórias [AHALT et al., 1990]. A idéia destes mecanismos é forçar que as $m$ unidades de saída na camada competitiva ganhem, em média, em $1 / m$ do total das iterações de treinamento. Assim, neurônios que ganhem com muita frequiência passam a ter reduzidas suas chances de vitória, dando oportunidade a outros.

AHALT et al. (1990), por exemplo, sugerem a introdução de um fator $u_{j}(t)$, que é o número total de vezes que o neurônio $j$ foi o vencedor durante o treinamento, na Equação (7) tal que:

$$
u_{v}(t)\left\|\mathbf{x}(t)-\mathbf{w}_{v}(t)\right\|=\min _{i}\left\{u_{j}(t)\left\|\mathbf{x}(t)-\mathbf{w}_{j}(t)\right\|\right\}
$$

na qual $v$ é o índice do neurônio vencedor. Nota-se que o fato de um dado neurônio ganhar com frequiência as competições é contabilizado em $u_{j}(t)$, diminuindo a chance desta unidade ser novamente o vencedor e dando a outras unidades com valor menor de $u_{j}(t)$ a oportunidade de ser o vencedor.

$\mathrm{Na}$ próxima seção discute-se um modelo de rede neural competitiva cujas unidades de saída estão arranjadas em uma forma geométrica específica e cujos os neurônios próximos (vizinhos) ao neurônio também tem seus vetores de pesos ajustados.

\subsection{Mapas Auto-Organizáveis de Características}

Em modelos competitivos, as unidades de saída não estão organizadas em uma forma espacial específica. Uma extensão de modelos competitivos, chamados 
genericamente de mapas auto-organizáveis de características (sigla em inglês, SOFM), distingue-se por organizar as unidades de saída em uma disposição geométrica particular.

A idéia fundamental de mapas auto-organizáveis de características foi originalmente introduzida por MARLSBURG (1973) e GROSSBERG (1976) para explicar a formação de mapas topológicos neurais. Baseado nestes trabalhos, KOHONEN (1982) propôs um modelo que passou a ser conhecido por mapa autoorganizável de Kohonen (MAOK), e que tem sido usado com sucesso para resolver um grande número de aplicações em reconhecimento de padrões, Ciências e Engenharia.

O mapa auto-organizável de características de Kohonen é um modelo de rede neural competitiva que é capaz de projetar dados de dimensão alta em um array de dimensão inferior (Figura 5). A projeção é feita de forma adaptativa e preserva características topológicas dos dados de entrada. Um processo de aprendizagem competitiva é aplicado aos neurônios, tal que cada unidade responde seletivamente a um certo número de padrões de entrada.

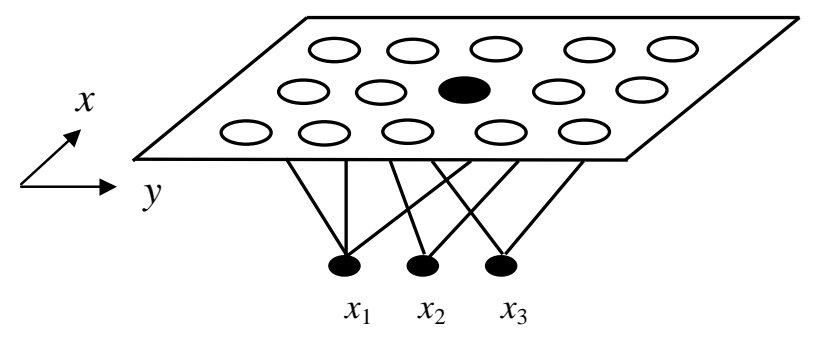

Figura 5: Uma possível topologia para o mapa auto-organizável de características proposto por Kohonen. As unidades de entrada estão totalmente conectadas com os neurônios da camada de saída.

Primeiro, para cada amostra de treinamento apresentada à rede, a unidade mais próxima (vencedora) do vetor de entrada é encontrada. Segundo, esta unidade juntamente com suas unidades vizinhas têm seus pesos modificados. Pelo fato de as unidades de saída estarem arranjadas em um mapa ordenado, estas adquirem uma determinada ordenação em que relações de distância são preservadas durante o processo de aprendizagem.

Após o neurônio vencedor ter sido encontrado, as unidades no mapa são então atualizadas. A regra de ajuste dos pesos tem a seguinte forma: 


$$
\mathbf{w}_{j}(t+1)=\mathbf{w}_{j}(t)+\beta(t) h_{j v}(t)\left[\mathbf{x}(t)-\mathbf{w}_{j}(t)\right]
$$

na qual $\mathbf{w}_{j}(t)$ é o vetor de pesos da unidade $j$ no instante $t, \mathbf{x}(t)$ é o vetor de entrada apresentado no instante $t ; \beta(t)$ é a taxa de aprendizagem representada por uma função

que decresce à medida que $t$ cresce; $h_{j v}(t)$ é a função vizinhança cujo valor depende da unidade vencedora $v(t)$, das outras unidades $j$ e do instante $t$. Normalmente, $h_{j v}(t)$ tem a forma de uma função com valor máximo em $j=v(t)$ e decrescente à medida que se distancia do nó vencedor. A função gaussiana é normalmente usada para este fim:

$$
h_{j v}(t)=\exp \left(\frac{-\left\|\mathbf{w}_{v}(t)-\mathbf{w}_{j}(t)\right\|^{2}}{2 \rho^{2}(t)}\right)
$$

A largura da função vizinhança $\rho(t)$ decresce à medida que o tempo passa. $O$ treinamento é realizado um número fixo de vezes, $t=1,2, \ldots, t_{\max }$, ou até que os pesos tenham pequena variação.

Mapas auto-organizáveis de característica são, possivelmente, o modelo de rede não-supervisionada com maior número de aplicações. As propriedades dos mapas auto-organizáveis os tornam uma ferramenta útil na compreensão e modelagem de mapas computacionais no cérebro. Além disso, tais propriedades tem se mostrado úteis também em um grande número de aplicações, nos mais diversos campos, a saber [HAYKIN, 1994]: controle de braços de robô, quantização vetorial, equalização adaptativa, análise e reconhecimento de voz, visualização de faltas em máquinas, etc.

Os modelos de RNA discutidos anteriormente mantém um único neurônio (ou um reduzido grupo) ativo por estímulo de entrada. A seguir serão mostrados alguns algoritmos que não possuem esta restrição. Todos os neurônios são treinados e podem permanecer ativos toda vez que um estímulo de entrada é apresentado à rede.

\subsection{Modelos de Redes Neurais com Aprendizagem Hebbiana}

Nesta seção são discutidas algumas técnicas baseadas em conexões sinápticas que são ajustadas usando a regra de Hebb [HEBB, 1949]. As saídas têm valores contínuos e não têm um comportamento tipo WTA, característico das redes 
competitivas. Neste caso, várias unidades podem permanecer ativas indicando a presença de características distintas no estímulo de entrada (representação distribuída). Assim, modelos hebbianos são também chamados de modelos de causas múltiplas [DAYAN \& ZEMEL, 1995].

\subsubsection{Neurônio Linear com Aprendizagem Hebbiana}

O caso mais simples envolve redes de uma camada com unidades lineares (Figura 6). Este tipo de neurônio multiplica suas $n$ entradas $x_{i}$ pelo peso de conexão sináptica $w_{j i}$ e soma o resultado de modo a gerar uma saída $y_{j}$ :

$$
y_{j}(t)=\sum_{i=1}^{n} w_{j i}(t) x_{i}(t)=\mathbf{w}_{j}{ }^{T}(t) \mathbf{x}(t)=\mathbf{x}^{T}(t) \mathbf{w}_{j}(t)
$$

na qual $\mathbf{w}_{j}(t)=\left(w_{j 1}(t), \ldots, w_{j n}(t)\right)^{\mathrm{T}}$ é o vetor de pesos e $\mathbf{x}(t)=\left(x_{1}(t), \ldots, x_{n}(t)\right)^{\mathrm{T}}$ é o vetor de entrada. A variável $t$ é o instante de iteração.

Como na maioria dos modelos de redes neurais artificiais, o neurônio "aprende" mudando o valor de seus pesos sinápticos. A aprendizagem por regra de Hebb, também conhecida por aprendizagem por correlação, foi formulada tomando uma proposição feita por Donald Hebb (1949):

“Quando um axônio da célula A está próximo o suficiente para excitar uma célula B e, repetida ou persistentemente, influenciar no seu disparo, algum processo de crescimento ou mudança metabólica acontece em uma ou ambas as células, tal que a eficiência de A em ser uma das células que dispara B é aumentada”.

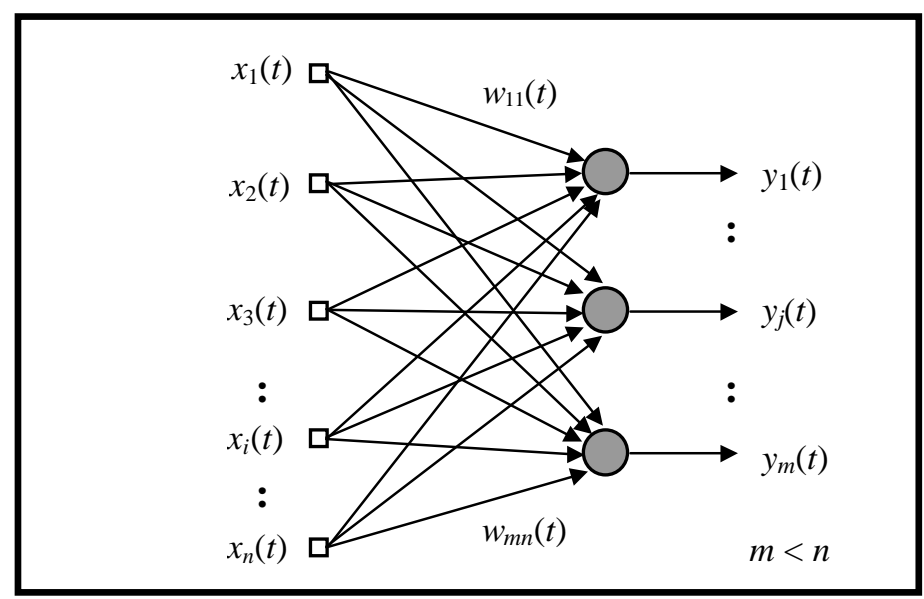

Figura 6: Rede de uma camada de neurônios lineares $y_{j}=\Sigma_{i} w_{j i}$ $\left.x_{i}\right)$, cujos pesos podem aprender através da regra de Hebb. 
A idéia é atrativa devido a sua simplicidade, que se baseia puramente na correlação entre padrões de ativação, e também devido a sua localidade (toda a informação requerida para mudar a intensidade do acoplamento entre duas células está disponível neste ponto). Sua formulação matemática tem a seguinte forma:

$$
\Delta w_{j i}(t)=\eta y_{j}(t) x_{i}(t)
$$

na qual $\eta$ controla o passo de aprendizagem, $y_{j}(t)$ é a resposta da rede ao padrão de entrada $\mathbf{x}$ no instante de observação $t$ e $x_{i}(t)$ é $i$-ésima componente de $\mathbf{x}$.

A Equação (16) fortalece a saída para cada entrada apresentada, assim padrões de entrada mais frequientes têm maior influência à medida que o treinamento acontece. Logo, estes padrões produzirão saídas maiores [HERTZ et al., 1991].

Ao convergir, os pesos devem parar de mudar. Assim, em um ponto de convergência, se este ponto existir, $E\left(\Delta \mathbf{w}_{j}\right)=0$, em que $E$ é o operador esperança estatística. Entretanto, uma dificuldade que a regra de Hebb impõe é que pesos sinápticos treinados por tal regra tendem a crescer sem limites. O que se tem é um laço de realimentação positiva: um peso de valor elevado produzirá um valor alto de $y_{j}$ (Equação 15) que por sua vez aumentará ainda mais este peso (Equação 16), e assim por diante.

Pode-se prevenir a divergência dos pesos treinados pela regra de Hebb, restringindo o crescimento do vetor de pesos $\mathbf{w}_{j}$. Existem várias maneiras de se fazer isto, tal como uma simples renormalização $w_{j}^{*}=\alpha w_{j}$ de todos os pesos depois de cada atualização, escolhendo $\alpha$ tal que $\left\|\mathbf{w}_{j}^{*}\right\|=1$.

GROSSBERG (1974) propôs duas variações (ver Apêndice III) para maiores detalhes) em cima da regra de Hebb clássica que usam um elemento de penalização que limita o crescimento excessivo dos pesos. A primeira dessas modificações, chamada de regra instar, tem a seguinte forma:

$$
\Delta w_{j i}(t)=\alpha y_{j}(t)\left[w_{j i}(t)-x_{i}(t)\right]
$$

na qual $\alpha$ é a taxa de aprendizagem. A segunda modificação, chamada de regra outstar, tem a seguinte formulação: 


$$
\Delta w_{j i}(t)=\alpha x_{i}(t)\left[w_{j i}(t)-y_{j}(t)\right]
$$

OJA (1982) também propôs uma leve modificação na regra de Hebb original. O autor mostrou ser possível fazer o vetor de pesos $\mathbf{w}_{j}$ convergir para um comprimento constante e igual a 1 , ou seja, $\left\|\mathbf{w}_{j}\right\|=1$, sem que seja necessário uma normalização explícita. A regra de Oja tem a seguinte forma:

$$
\Delta w_{j i}(t)=\eta y_{j}(t)\left[x_{i}(t)-y_{j}(t) w_{j i}(t)\right]
$$

A principal aplicação das regra hebbianas descritas acima está na implementação de uma técnica estatística conhecida como análise das componentes principais (sigla em inglês, PCA). Para maiores detalhes desta técnica e sua implementação via redes neurais ver DIAMANTARAS (1996) e HARPUR (1997).

Os modelos hebbianos apresentados até aqui utilizam a regra de Hebb para treinar os pesos de alimentação direta. Na próxima seção, serão brevemente discutidos modelos que utilizam uma versão inibitória da regra de Hebb para treinar conexões laterais.

\subsubsection{A Regra de Hebb e Conexões Laterais Treináveis}

As conexões laterais tratadas até este ponto têm seus valores fixados da definição rede, permanecendo sem alteração durante todo o processo de treinamento. Mais recentemente, alguns modelos de RNA com aprendizagem não-supervisionada têm incorporado em sua dinâmica de aprendizagem o uso de conexões laterais treináveis. O caso mais comum, envolve uma versão inibitória da regra de Hebb clássica que neste caso, recebe o nome de regra anti-hebbiana [FÖLDIAK, 1990; HERTZ et al., 1991; MARSHALL, 1995]. Esta regra tem a seguinte formulação:

$$
\Delta w_{\overline{j r}}(t)=-\gamma y_{j}(t) y_{r}(t)
$$

na qual $\gamma$ é a taxa de aprendizagem e $y_{j}(t)$ e $y_{r}(t)$ são as ativações dos neurônios de saída $j$ e $r$, respectivamente. A regra anti-hebbiana (20) é semelhante à regra hebbiana clássica invertendo apenas a direção da mudança. A regra anti-hebbiana afirma que 
uma sinapse inibitória deve ser enfraquecida se as ativações dos neurônios pré- e pós-sinápticos forem correlacionadas.

Um modelo de rede neural, chamado de EXIN, que usa regras hebbianas para treinar os pesos de alimentação direta e anti-hebbianas para treinar as conexões laterais foi proposto por MARSHALL [1990a, 1990b, 1995].

As ativações dos neurônios de saída são descritas por um sistema de equações diferencias acopladas e não-lineares. A dinâmica da ativação do neurônio de saída $j$ é governada pela seguinte equação:

$$
\frac{d y_{j}(t)}{d t}=-A y_{j}(t)+\beta\left(B-y_{j}(t)\right) E_{j}(t)-\gamma\left(C+y_{j}(t)\right) I_{j}(t)
$$

na qual $y_{j}$ é a ativação do neurônio de saída $j ; A$ é uma constante de decaimento, $B$ e $C$ são, respectivamente, a máxima e a mínima ativação permitida. $\beta$ e $\gamma$ são fatores de ganho. O termo $E_{j}$ representa a influência do padrão de entrada ponderado pelos pesos excitatórios, sendo definido como

$$
E_{j}(t)=\frac{\sum_{i=1}^{n} w_{j i}^{+}(t)\left[x_{i}(t)\right]}{1+\sum_{i=1}^{n} w_{j i}^{+}(t)}
$$

O termo $I_{j}$ representa a influência das ativações de saída $a_{j}$ ponderadas pelas inibições laterais, sendo definido como

$$
I_{j}(t)=\sum_{k=1}^{m} w_{\overline{j k}}(t)\left[y_{k}(t)\right]
$$

Assume-se que os valores de ativação mudam normalmente numa escala de tempo menor do que as mudanças nas entradas, no qual apenas os valores de equilíbrio de (21) são requeridos. Entretanto, visto que o valor de $y_{j}(t)$ pode depender dos valores das ativações das outras unidades na camada, as equações diferenciais são acopladas e os valores de equilíbrio só podem ser encontrados por integração numérica. Este é um processo computacionalmente intensivo e o tempo requerido para tal se torna impraticável à medida que o tamanho do problema (e conseqüentemente da rede) é aumentado. 
As conexões excitatórias de entrada, $w_{j i}^{+}$, conectam a entrada $i$ ao neurônio de saída $j$ são atualizadas de acordo com uma regra hebbiana do tipo instar:

$$
\frac{d w_{j i}^{+}(t)}{d t}=\varepsilon f\left(y_{j}(t)\right)\left[g\left(x_{i}(t)\right)-w_{j i}^{+}(t)\right]
$$

na qual $\varepsilon>0$ é a taxa de aprendizagem (de valor baixo); e $f, g$ são funções crescentes e retificadas, por exemplo $g\left(x_{i}\right)=\max \left(0, x_{i}\right)$. As conexões laterais inibitórias são ajustadas de acordo com a seguinte regra de aprendizagem do tipo outstar:

$$
\frac{d w_{\overline{j k}}(t)}{d t}=\eta h\left(y_{k}\right)\left[q\left(y_{j}\right)-w_{\overline{j k}}(t)\right]
$$

na qual $0<\eta<<\varepsilon$ é a taxa de aprendizagem; e $h, q$ são funções crescentes retificadas, por exemplo $h\left(y_{j}\right)=\max \left(0, y_{j}\right)$. A regra (25), por governar conexões laterais inibitórias, é comumente chamada de regra anti-hebbiana.

A rede EXIN foi proposta com a intenção de lidar com padrões que possuam certo grau de superposição e tem sido usada em diversos experimentos relacionados com processamento de informação e modelagem no córtex visual. BARRETO \& ARAÚJO (1998b) estudaram o papel da aprendizagem hebbiana e anti-hebbiana neste modelo, propondo também meios de diminuir o esforço computacional gasto na solução numérica da Equação (21).

\subsection{Resumo do Capítulo}

Neste capítulo foram apresentados e discutidos alguns modelos de RNAs com aprendizagem não-supervisionada que constituíram a primeira etapa de estudo para desenvolvimento desta pesquisa. Os dois principais paradigmas de treinamento para esse tipo de rede neural são: aprendizagem competitiva e aprendizagem hebbiana. Esta última também chamada de aprendizagem por correlação.

Os modelos mostrados neste capítulo, não se prestam diretamente ao processamento de padrões temporais. Por exemplo, se uma seqüência temporal que possui componentes aparecendo mais de uma vez for apresentada a uma rede 
competitiva do tipo descrita na Seção 3.4, estas componentes seriam codificadas pelo mesmo neurônio da rede. A informação espacial seria preservada, porém a informação de ordem temporal seria perdida. Portanto, no modelo temporal a ser proposto esta característica deve ser evitada.

As redes discutidas possuem certas propriedades que serão úteis na proposição de um modelo neural não-supervisionado para processamento temporal, dentre as quais pode-se destacar:

- Necessidade de classificação das componentes individuais da sequiência via aprendizagem competitiva;

- Uso de arquiteturas simples de uma camada e dois níveis de conexões: intercamadas (entrada-saída) e intracamadas (saída-saída).

- Uso de aprendizagem do tipo hebbiana no treinamento das conexões intracamada (conexões laterais).

- Uso de relações de vizinhança com o objetivo de manter mais de uma representação de cada componente da seqüência, aumentando a robustez (tolerância à falhas e ao ruído) do modelo;

As propriedades e características listadas acima serão combinadas em um único modelo de forma a tratar informação temporal. É claro que algumas destas propriedades terão que ser reinterpretadas de acordo com o novo objetivo. Por exemplo, a aprendizagem hebbiana em conexões laterais serão usadas para aprender a ordem temporal da seqüências, e não mais a descorrelacionar neurônios de saída.

É importante ressaltar que muitas vezes trajetórias de robôs possuem um elevado grau de superposição (tarefas semelhantes). Esta é uma situação que o modelo a ser proposto no Capítulo 6 deve ser capaz de lidar. Para se ter uma idéia da dificuldade desta tarefa, apenas recentemente é que foram propostos modelos não-supervisionados (EXIN, Seção 3.6.2) que trataram com superposição de padrões de forma satisfatória.

No próximo capítulo serão discutidos modelos de redes neurais artificiais nãosupervisionadas que incluem mecanismos capazes de codificar informação temporal. 


\section{Capítulo 4}

\section{Redes Neurais Não-Supervisionadas para Processamento Temporal: Definições e Modelos}

Os modelos não-supervisionados discutidos anteriormente não são adequados para processar informação temporal. Em parte, pelo fato de a dinâmica destes modelos não ter sido projetada para incluir direta ou indiretamente a variável tempo em seu processamento e em parte, pelo alvo preferencial destes algoritmos ser classificação espacial - e não temporal - de padrões.

Para que se possa estabelecer associações entre padrões apresentados à rede em instantes de tempo distintos é necessário que padrões anteriores permaneçam presentes, de alguma forma, no instante em que o padrão atual é apresentado. Desta forma, pode-se criar mecanismos que passem a considerar a ordem temporal com que os padrões ocorrem. Costuma-se chamar este tipo de mecanismo de modelos de Memória de Curta Duração (MCD). Portanto, definir MCD e suas diversas implementações é essencial para entender o processamento de seqüências temporais.

Na próxima seção serão mostradas as formas mais comuns de se implementar modelos de MCD e como diferentes algoritmos de RNAs não-supervisionadas os incorporam à sua dinâmica. A forma como mecanismos de MCD são adicionados a redes não-supervisionadas servirá também como critério de apresentação dos modelos ao longo do capítulo. Basicamente, tem-se duas abordagens: (1) incorporar MCD aos padrões de entrada, reorganizando-os de forma a levar em conta o histórico temporal dos eventos, ou (2) incorporar MCD diretamente na dinâmica de ativações (nível de neurônio) e/ou aprendizagem (nível de sinapse).

O restante do capítulo apresenta diversos modelos não-supervisionados para processamento temporal. Primeiro serão mostrados modelos competitivos (Seção 4.2.1). Em seguida, versões temporais do mapa auto-organizável de Kohonen serão discutidos (Seção 4.2.2). Depois, um modelo anti-hebbiano temporal é apresentado na Seção 4.2.5. Estes modelos tratam da tarefa de reconhecimento de sequiências temporais. Redes para (re)produção de seqüências temporais serão descritas nas 
Seções 4.3 e 4.4. A seguir, MCD é definida e diversas formas de implementá-la são discutidas.

\subsection{Implementação de Memória de Curta Duração}

Fundamentalmente diferente do processamento de padrões estáticos, o processamento de padrões temporais requer que uma rede neural tenha capacidade de manter uma componente da seqüência (ou alguma informação referente a ela) por um certo período de tempo. Esta propriedade é chamada de memória de curta duração e tem sua formulação computacional baseada em estudos relativos à memória em seres vivos. A forma como é implementada uma MCD tem sido usada como critério de classificação de redes neurais para processamento temporal [MOZER, 1993]. As quatro principais formas de considerar MCD são definidas a seguir [WANG, 1995].

\subsubsection{Linhas de Atraso (delay lines)}

A forma mais simples de MCD usa buffers de comprimento fixo para manter os $N+1$ símbolos de entrada, $\mathbf{x}(t)$, mais recentes. A Figura 7 mostra duas possíveis implementações usando registradores de deslocamento ou um array com diferentes linhas de atraso. As MCD por linhas de atraso transformam um padrão temporal em um espacial onde a variável tempo forma uma outra dimensão. Este tipo de MCD é muito usado em RNAs para reconhecimento de seqüências [WAIBEL et al., 1989].

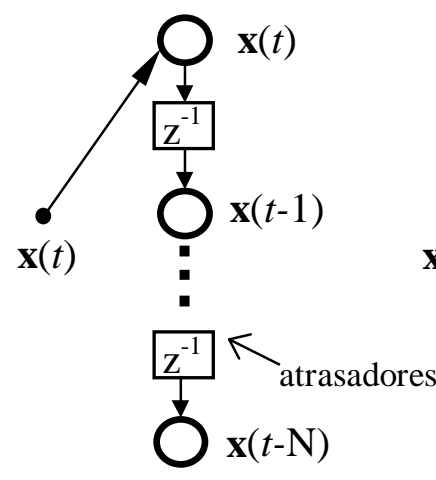

(a)

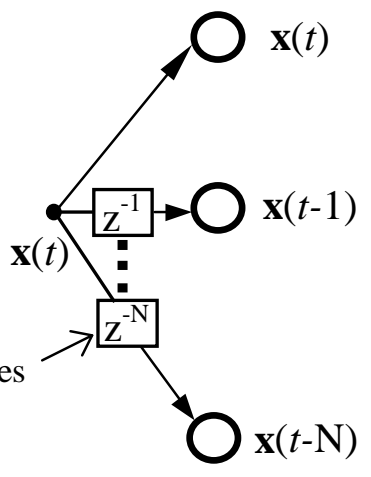

(b)

Figura 7: Duas implementações de memórias de curto prazo: (a) Através de um registrador de deslocamento e (b) Através de array com diferentes atrasadores. 


\subsubsection{Traço de Decaimento (decay traces)}

Um item armazenado em uma MCD deste tipo decai suavemente com o passar do tempo (Figura 8a). Teoricamente, informação temporal pode ser recuperada com precisão a partir do valor atual da componente $x_{i}(t)$. Entretanto, por causa do rápido decaimento e da presença de ruído, apenas um número limitado dos itens mais recentes pode ser recuperado da MCD de forma confiável.

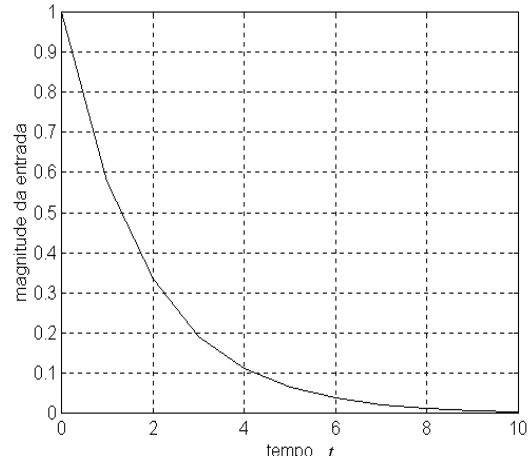

(a)

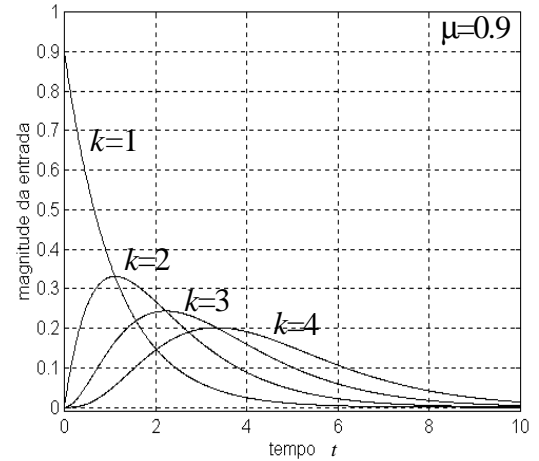

(c)

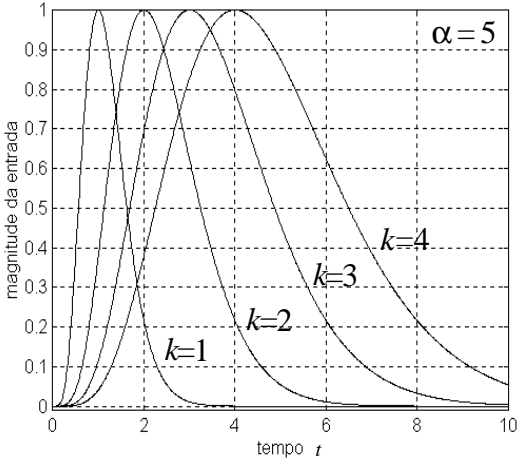

(b)

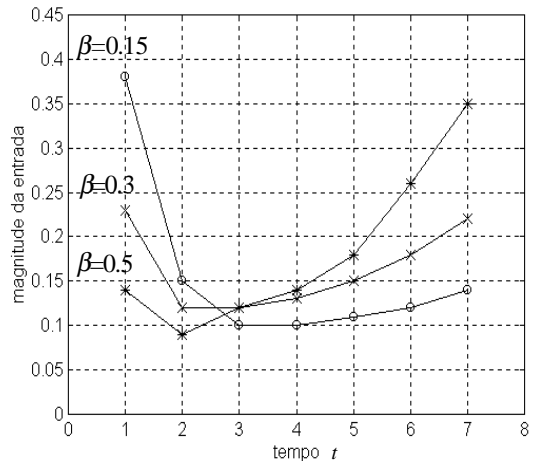

(d)

Figura 8: Traços na MCD. (a) decaimento exponencial; (b) núcleos exponenciais normalizados; (c) núcleos gamma e (d) modelo STORE.

Este modelo de MCD usa apenas uma unidade para representar um símbolo $\mathbf{x}(t)$, em vez das $N+1$ unidades usadas pela MCD por linhas de atraso. Entretanto, na sua forma mais simples este modelo não é adequado para representar sequiências complexas, visto que não consegue "dizer" se o símbolo ocorreu mais de uma vez.

\subsubsection{Núcleos Exponenciais Normalizados (normalized exponential kernels)}

Propostos por TANK \& HOPFIELD (1987), consistem em um conjunto de núcleos exponenciais que amostram a história temporal e são descritos como: 


$$
f_{k}(t)=\left(\frac{t}{k}\right)^{\alpha} e^{\alpha\left(1-\frac{t}{k}\right)}, \quad \operatorname{para} k=1, \ldots, K
$$

na qual $\alpha$ regula a largura de cada núcleo, $K$ é chamado de ordem da memória, $t$ é o instante de tempo atual e $k$ é índice relativo às unidades da MCD.

A Figura 8 b mostra um grupo de quatro núcleos deste tipo. Existem $K$ unidades para representar cada símbolo neste tipo de MCD. Diferentemente dos modelos de MCD por linhas de atraso, onde cada unidade amostra um símbolo em um instante de tempo específico $t$, cada unidade neste modelo amostra um símbolo por um certo período de tempo com pico em um instante de tempo específico $(t=k)$.

De maneira semelhante, DE VRIES \& PRINCIPE (1992) propuseram um modelo de MCD que denominaram de gamma, e é descrito como:

$$
g_{k}(t)=\frac{\mu^{k}}{(k-1) !} t^{k-1} e^{-\mu t}, \quad \text { para } k=1, \ldots, K
$$

em que $\mu$ é um parâmetro entre 0 e 1 . O valor de $K$ é chamado de ordem da memória e existem $K$ unidades para armazenar o símbolo $\mathbf{x}(t)$ na MCD. A Figura 11c mostra um conjunto de quatro destes núcleos. Visto que $g_{k}$ tem valor máximo em $t=(k-1) / \mu, \mu$ determina a amplitude do pico de cada núcleo na MCD. Desta forma, diferente do modelo anterior (Equação 26), uma história temporal de $N$ instantes de tempo pode ser amostrada por menos de $N$ núcleos gamma. Uma outra vantagem é que funções núcleo podem ser computadas recursivamente, enquanto que em núcleos exponenciais normalizados, a convolução entre as funções do tipo núcleo e o histórico de atividade de $\mathbf{x}(t)$ deve ser calculada.

\subsubsection{Modelos interativos (interactive models)}

Para os modelos anteriores de MCD, o traço de cada símbolo é totalmente independente de outros símbolos na MCD. Uma propriedade básica da MCD humana é que ela tem capacidade de retenção de informação limitada, tal que a manutenção de

um símbolo e a duração deste na MCD depende, de maneira crítica, das outras 
entradas que chegam à MCD [WANG, 1995]. A seguir discute-se dois modelos que abordam interações entre os itens na MCD.

WANG \& ARBIB (1993), baseados na teoria de interferência do conhecimento, propuseram um modelo de MCD na qual um item de entrada permanece na MCD enquanto o número de itens não excede o valor $T$ (capacidade da $\mathrm{MCD}$ ). Mais especificamente:

$$
x_{i}(t)=\left\{\begin{array}{cc}
T & \text { se } I_{i}(t)=1 \\
x_{i}(t-1)-1 & \text { se } x_{i}(t-1)>0, y(t)=1 \\
x_{i}(t-1) & \text { para os outros casos }
\end{array}\right.
$$

na qual $y(t)$ detecta se existe uma nova entrada chegando à MCD. Uma vez que $x_{i}(t)$ recebe uma entrada externa $I_{i}$, seu valor de ativação é feito igual a $T$. Este valor decresce quando as últimas entradas chegam. Este mecanismo foi implementado usando uma rede mutuamente inibitória. Este modelo de MCD baseado em interferência tem traços temporais flexíveis, dependendo de quão freqüente as últimas entradas entram na MCD. De acordo com a Equação (28), os itens mais recentes têm ativações maiores, mostrando assim um fator de recenticidade (recency factor)

O estudo da capacidade humana em reter sequiências mostra que em adição à recenticidade, há ainda o fator de primazia (primacy factor) por meio do qual os itens iniciais de uma seqüência são menos propensos ao esquecimento. BRADSKI et al. (1994) propuseram um modelo interativo de MCD denominado STORE, mostrando que ambas, recenticidade e primazia são consideradas pelo seguinte modelo usando um par de unidades, $x_{i}$ e $y_{i}$, para armazenar um símbolo na MCD:

$$
\begin{aligned}
& x_{i}(t+1)=x_{i}(t)+\left[\beta I_{i}(t)+y_{i}(t)-x_{i}(t) x(t)\right] I(t) \\
& y_{i}(t+1)=y_{i}(t)+\left[x_{i}(t)-y_{i}(t)\right][1-I(t)]
\end{aligned}
$$

na qual $x(t)=\Sigma_{j} x_{j}(t)$ e $I(t)=\Sigma_{j} I_{j}(t)$ e $\beta$ é o único parâmetro no modelo. Neste modelo, o termo de inibição global $I(t)$ na Equação (29a), reduz o valor de $x_{i}(t)$ em favor de novos itens. Além disso, o laço excitatório entre $x_{i}$ e $y_{i}$ favorece itens antigos na MCD. Combinadas, estas equações são capazes de produzir as curvas em forma de arco para 
uma seqüência de itens. A Figura 8d mostra três curvas diferentes geradas usando as Equações (29a) e (29b) com diferentes valores de $\beta$.

Pode-se resumir o que foi apresentado nas seções anteriores afirmando que o processamento temporal exige da rede neural uma maneira de implementar MCD cujo objetivo primordial é deixar disponível no instante de tempo atual "vestígios" das ativações das unidades em instantes passados.

Mecanismos de MCD são utilizados nos modelos de RNAs não-supervisionados para processamento temporal apresentados nas seções que seguem. $\mathrm{O}$ foco principal estará na apresentação dos modelos e não nas suas respectivas aplicações.

\subsection{Redes Não-Supervisionadas para Processamento de Seqüências Temporais}

Nesta seção serão apresentados os principais modelos de redes nãosupervisionadas para processamento de padrões temporais. A exposição adotada aqui será por critério de semelhança (topologia, tipo de regra de aprendizagem, extensão de modelos estáticos, etc.), visando uma organização mais didática do capítulo. Também serão discutidos as motivações para tais modelos, assim como, em menor escala, suas aplicações.

\subsubsection{Modelos com Aprendizagem Competitiva}

Um dos primeiros modelos para produção de seqüências foi a avalanche de outstar (outstar avalanche) proposta por GROSSBERG (1969). Tal modelo é composto de $n$ neurônios outstars dispostos em seqüência. Cada outstar $\mathbf{M}_{i}$ armazena um padrão estático e é ativado por um sinal no seu vértice $v_{i}$. Estes vértices estão conectados como $v_{1} \rightarrow v_{2} \rightarrow \ldots \rightarrow v_{n}$, e um sinal de $v_{i}$ chega com algum atraso em $v_{i+1}$. Assim um sinal inicial em $v_{1}$ pode produzir seqüencialmente os padrões espaciais armazenados em $\mathbf{M}_{1}, \mathbf{M}_{2, \ldots}, \mathbf{M}_{n}$, respectivamente.

GRANGER et al. (1994) propuseram um modelo, biologicamente inspirado, para reconhecimento de seqüências temporais. Tal modelo usa uma regra de aprendizagem competitiva não-hebbiana que, ao fim da apresentação da seqüência, desenvolve detetores de seqüência. Cada detetor codifica uma sequiência com a 
componente inicial tendo o peso mais forte, enquanto que as componentes subsequentes têm pesos sucessivamente mais fracos. Os autores argumentam que esta rede tem uma alta capacidade de armazenamento, porém não apresentam testes conclusivos.

\subsubsection{Versões Temporais de Mapas Auto-organizáveis}

Os modelos a seguir são extensões do mapa auto-organizável de Kohonen (Seção 3.5), que é um modelo neural para classificação de padrões estáticos. Tais extensões visam processar informação seqüencial e, em geral, utilizam uma das duas abordagens básicas citadas no início do capítulo para considerar MCD neste tipo de modelo.

\subsubsection{Incorporando Informação Temporal aos Dados de Entrada}

KANGAS (1990) propôs três modelos para representar aspectos seqüenciais dos dados usando mapas auto-organizáveis em aplicações de reconhecimento de fonemas (Figura 9).

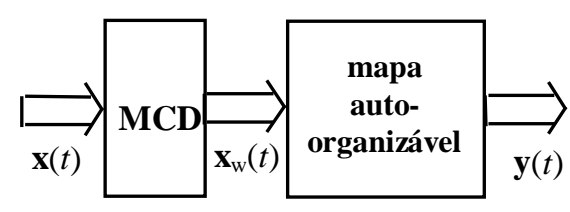

(a)

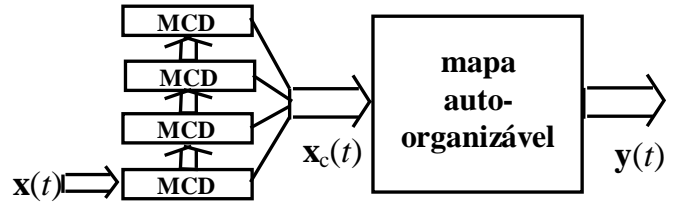

(b)

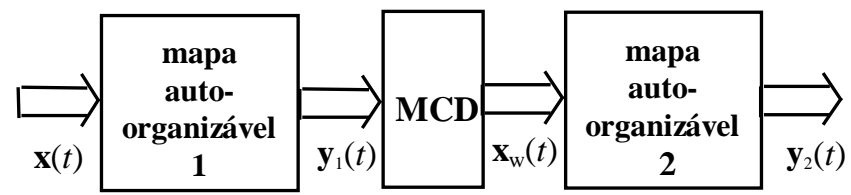

(c)

Figura 9: Versões temporais para o MAOK. (a) Ponderando os valores das entradas com pesos exponenciais; (b) concatenando os vetores de entrada em instantes diferentes e (c) utilizando dois níveis de mapas com ponderação exponencial do vetor de respostas.

No primeiro modelo (Figura 9a) simplesmente se pondera os padrões de entrada no tempo usando a seguinte equação recursiva:

$$
\mathbf{x}_{w}(t)=w \mathbf{x}(t)+(1-w) \mathbf{x}_{w}(t-1)
$$


na qual o vetor $\mathbf{x}_{w}(t)$ é usado como entrada do mapa auto-organizável, $\mathbf{x}(t)$ é o padrão de entrada e $w$ é um fator de ponderação. A saída do mapa é representada pelo vetor de ativações $\mathbf{y}(t)$. Pode-se observar que, se $w$ for muito pequeno, o conteúdo de informação das entradas mais recentes será perdido. Por outro lado, se $w$ for muito grande, os padrões mais antigos serão logo esquecidos. É interessante perceber que o procedimento de ponderação também diminui o efeito provocado pela presença de ruído aditivo nas entradas.

O segundo modelo (Figura 9b) utiliza vários registradores de deslocamento para implementar uma MCD. Os padrões deslocados no tempo são concatenados e apresentados à rede, sendo que o comprimento da janela de tempo é definido de antemão. A concatenação de vários vetores aumenta consideravelmente o tempo de treinamento. Contudo, torna possível obter resultados muitos bons em reconhecimento porque a informação das entradas anteriores está sempre presente, não existindo esquecimento de informação valiosa como no primeiro modelo. Diferentemente do primeiro modelo, o ruído aditivo na entrada não é atenuado.

Para o terceiro modelo (Figura 9c), o primeiro algoritmo é combinado com um outro mapa. Este modelo se baseia na idéia de tomar uma seqüência de padrões resposta do mapa 1 como o item a ser classificado pelo mapa 2. Esta seqüência de padrões de ativação contém toda a informação necessária sobre os padrões de entrada $\mathbf{x}(t)$ e também sobre a ordem de ocorrência destes. Diferentes posições no mapa 1 são representadas por posições diferentes no vetor de saída $\mathbf{y}_{1}$. Estas respostas são então ponderadas pela Equação (30) para $\mathbf{x}=\mathbf{y}_{1}$, permitindo que vestígios (rastros) das áreas ativas no mapa 1 possam permanecer por um certo período de tempo (dependendo do valor de $w)$.

Os modelos apresentados nos parágrafos anteriores apresentaram melhorias consideráveis no reconhecimento de fonemas quando comparados ao MAOK. Enquanto este obteve $10,4 \%$ de erro na classificação dos fonemas, o segundo e terceiro modelo obtiveram 7,0\% e 5,0\%, respectivamente.

Os modelos descritos a seguir introduzem mecanismos que permitem o processamento temporal diretamente na dinâmica da rede neural. 


\subsubsection{Incorporando MCD à Dinâmica do Modelo Neural}

CHAPPELL \& TAYLOR (1993) propuseram uma arquitetura, que chamaram de Mapa Temporal de Kohonen (MTK), para classificação de seqüências. Neste modelo, modificações biologicamente plausíveis foram introduzidas com o objetivo de tornar a rede apta a processar informação temporal. O MTK mantém o histórico de ativação de cada neurônio atualizando um valor chamado de leaky integrator potential: $V_{j}(t)=$ $\xi V_{j}(t-1)-(1 / 2)\left\|\mathbf{x}(t)-\mathbf{w}_{j}(t)\right\|^{2}, 0<\xi<1$. O envolvimento de ativações passadas é melhor visto através da solução desta equação: $V_{j}(t)=-(1 / 2) \sum_{k=0}^{n-1} \xi^{k}\left\|\mathbf{x}(t-k)-\mathbf{w}_{j}(t-k)\right\|^{2}+$ $\xi^{n} V_{j}(t-n)$. O neurônio vencedor $v$ é escolhido de acordo com $V_{v}(t)=\max _{j}\left\{V_{j}(t)\right\}$. Assim, a atividade de cada nó, representada pelo potencial $V_{j}(t)$, depende do vetor de entrada atual e dos vetores de entrada prévios. Isto cria vizinhanças com sensibilidade ao passado (contexto). Então, cada sequiência é processada mapeando-se um vetor por instante de tempo, onde o último nó vencedor serve para representar a seqüência inteira. Desta forma, há necessidade de se ter um nó separado para cada seqüência possível. Entretanto, o MTK sofre também de perda de contexto. A determinação do nó vencedor depende quase que inteiramente dos vetores de entrada mais recentes. Por exemplo, a seqüência b-a-a-a-a muito provavelmente seria mapeada para o mesmo nó que a seqüência a-a-a-a-a, tornando este modelo aplicável apenas a seqüências de grau pequeno.

JAMES \& MIIKKULAINEN (1995) apresentaram um modelo, extensão do mapa de Kohonen, para classificação de seqüências. Tal modelo foi chamado de SARDNET e inclui um mecanismo simples de retenção e decaimento da ativação dos neurônios com o objetivo de criar padrões de resposta únicos e distribuídos para diferentes seqüências de entrada. Toda vez que um neurônio é escolhido vencedor, sua saída é feita igual a 1, decaindo toda vez que uma nova entrada for apresentada. Este mecanismo simplesmente implementa uma forma de MCD, em que o histórico das ativações dos vencedores em competições anteriores é mantido, diminuindo de intensidade à medida que novas entradas chegam. Ao final da apresentação da seqüência, o valor das ativações retidas indica a ordem de chegada do vetor de entrada e sua posição na seqüência, do menos ativo (primeira componente da seqüência a chegar) ao mais ativo (última componente a chegar). A arquitetura SARDNET é capaz 
de produzir representações extremamente densas, porém descritivas das entradas seqüenciais em poucas iterações de treinamento. A rede demonstrou ser bem sucedida ao realizar o mapeamento de seqüências arbitrárias de números binários e reais, assim como representações fonéticas de palavras da língua inglesa. Entretanto, seu uso está limitado à simples detecção isolada de seqüências.

KOPECZ (1995) propôs uma regra de aprendizagem do tipo hebbiana diferencial cujo objetivo é extrair informação de uma seqüência de eventos de entrada, estabelecendo conexões laterais entre unidades de um mapa auto-organizável. O autor definiu dois tipos de conexões laterais entre os neurônios. O primeiro tipo, conexões laterais simétricas $w_{i j}^{S}$, respondem pela ativação localizada (espacial) dos neurônios do mapa em função de um estímulo externo. Foram consideradas duas situações para estas conexões simétricas: ativação de apenas um neurônio no mapa (WTA) ou ativação de uma população de unidades (cluster). O segundo tipo, conexões laterais assimétricas $w_{i j}^{a}$, codificam a ordem temporal dos estímulos de entrada. Estas conexões assimétricas são ajustadas de acordo com mudanças na atividade das unidades, cuja dinâmica durante o treinamento é governada pela seguinte equação:

$$
\frac{d w_{i j}^{a}(t)}{d t}=S\left(u_{i}\right) \frac{d S\left(u_{j}\right)}{d t} \quad ; \quad \frac{d w_{j i}^{a}(t)}{d t}=-\frac{d w_{i j}^{a}(t)}{d t}
$$

em que a dinâmica de ativações é definida pela seguinte equação:

$$
\tau \frac{d u_{i}(t)}{d t}=-u_{i}(t)-h+\sum_{j} w_{j i}^{s}(t) S\left(u_{j}(t)\right)+I_{i}(t)
$$

na qual $S\left(u_{i}\right)=1$, se $u_{i}>0$ e $S\left(u_{i}\right)=0$, caso contrário. $S\left(u_{i}\right)$ é chamado de ativação da unidade $i, h$ é um parâmetro constante e $I_{i}$ representa a entrada externa da unidade $i$. A recuperação da sequiência é feita incluindo-se os pesos sinápticos assimétricos na dinâmica da Equação (32), ou seja:

$$
\tau \frac{d u_{i}(t)}{d t}=-u_{i}(t)-h+\sum_{j}\left(w_{j i}^{s}(t)+\varepsilon w_{j i}^{a}(t)\right) S\left(u_{j}(t)\right)
$$


Durante a reprodução da seqüência, o parâmetro livre $\varepsilon$ serve para ajustar a velocidade com que a sequiência é recuperada. Uma seqüência pode ser aprendida com uma única iteração de treinamento sem qualquer parâmetro livre na dinâmica de aprendizagem (Equação 32). Quando se considera uma população de unidades simultaneamente ativas, a aprendizagem e o início da recuperação da seqüência são robustos à presença de ruído nos sinais de entradas. Este modelo foi testado com seqüências geradas artificialmente, sendo capaz de aprendê-las e recuperá-las sem erro. A principal limitação deste algoritmo está na sua incapacidade de armazenar seqüências que possuam elementos em comum, ou para uma seqüência que tenha elementos repetidos (sequiência complexa).

De modo análogo, EULIANO \& PRINCIPE (1996) adicionaram acoplamentos espaciais e temporais ao MAOK com a intenção de gerar vizinhanças localizadas espacial e temporalmente. Este acoplamento é baseado na propagação de ondas de ativação (difusão de ativação) que começam em cada neurônio vencedor e vão sendo naturalmente atenuadas com o tempo. Como no MAOK, o algoritmo de treinamento consiste de dois estágios: primeiro, acha-se o vencedor. Depois, atualiza-se os pesos do vencedor e de sua vizinhança. Este segundo estágio é exatamente igual àquele da rede de Kohonen, mas o primeiro é modificado de modo a incluir informação temporal antes da determinação do vencedor. O vencedor é selecionado de acordo com a seguintes equações:

$$
\begin{gathered}
\operatorname{win}(t)=\arg \min \left[\left\|\mathbf{x}(t)-\mathbf{w}_{j}(t)\right\|-\beta \operatorname{temp}_{j}(t)\right] \\
\operatorname{temp}_{j}(t)=\lambda \cdot\left[\operatorname{temp}_{j}(t-1)+\delta_{j, \operatorname{win}(t-1)}\right]+(1-\lambda) \cdot\left[\operatorname{temp}_{j-1}(t-1)+\delta_{j-1, \operatorname{win}(t-1)}\right]
\end{gathered}
$$

em que $j=1, \ldots, N, \beta$ é chamado parâmetro temporal-espacial, $\lambda$ define o decaimento e a largura da frente de onda, $\delta$ é a função delta de Kronecker e $t e m p_{j}(t)$ é chamado de ativação temporal do nó $j$. Percebe-se que aumentando $\beta$, o sistema força os padrões de entrada a serem seqüenciais no mapa de saída. Diminuindo $\beta$, o sistema opera de forma mais semelhante ao MAOK, usando apenas informação espacial (distância euclideana) para encontrar o vencedor. Nas simulações apresentadas pelos autores, o 
valor de $\beta$ decresce com o passar do tempo de modo semelhante à taxa de aprendizagem e à vizinhança.

Quando vencedores sucessivos são ordenados na direção temporal, frentes de ondas de atividade temporal são criadas e usadas para aumentar a possibilidade de um nó vencer a próxima competição na mesma direção. O acoplamento espaço-temporal é facilmente implementado usando apenas cálculos e conexões locais. Uma vez treinado, este mapa pode ser usado para detecção ou recuperação de padrões. Além disso, é capaz de lidar com excelente performance com time-warping e com padrões que tenham sobreposição de vetores. A Figura 10 mostra um acoplamento espaçotemporal para uma rede de Kohonen unidimensional.

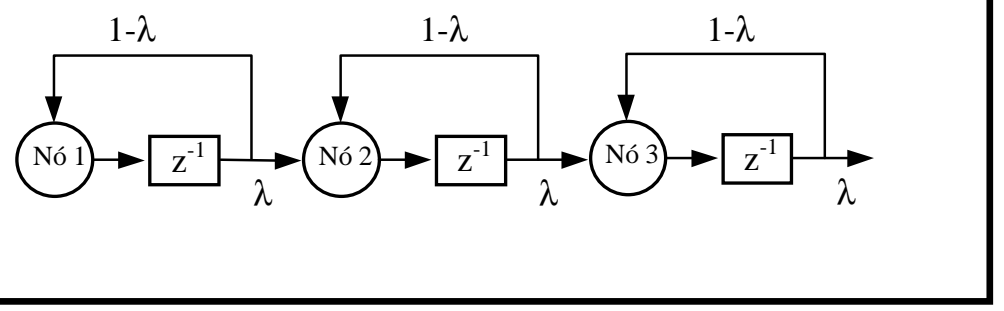

Figura 10: Acoplamento unidimensional de neurônios para ativação espaço-temporal.

VARSTA et al. (1997) propuseram um modelo de mapa auto-organizável recorrente (MAOR) para processamento temporal. O algoritmo proposto é semelhante ao MAOK, sendo que no MAOR o contexto da sequiência temporal está incorporado ao procedimento de busca pelo neurônio vencedor, assim como ao processo de atualização dos vetores de peso do mapa, pela introdução de equações a diferenças recursivas associadas a cada unidade do mapa. O neurônio vencedor, neste caso, é encontrado através da seguinte fórmula:

$$
\mathbf{y}_{v}=\min _{j}\left\{\left\|\mathbf{y}_{j}(t)\right\|\right\}
$$

na qual o índice $v$ indica o neurônio vencedor e o vetor $\mathbf{y}_{j}$, chamado vetor diferença, é calculado como:

$$
\mathbf{y}_{j}(t)=(1-\alpha) \mathbf{y}_{j}(t-1)+\alpha\left[\mathbf{x}(t)-\mathbf{w}_{j}(t)\right]
$$


na qual $\mathbf{w}_{i}(t)$ é o vetor de pesos associado à unidade $j$, e em que $0<\alpha \leq 1$ é o fator de ponderação que determina o efeito de vetores diferença anteriores e do novo vetor de entrada no cálculo de $\mathbf{y}_{i}(t)$. Os pesos também são ajustados em função de $\mathbf{y}_{i}(t)$ :

$$
\mathbf{w}_{j}(t+1)=\mathbf{w}_{j}(t+1)+\gamma(t) h_{j v}(t) \mathbf{y}_{j}(t)
$$

na qual $0<\gamma(t)<1$ é a taxa de aprendizagem e $h_{j v}(t)$ é a função vizinhança definida como na Equação (14). Percebe-se que se $\alpha=1$, o algoritmo do MAOR se reduz ao algoritmo original do mapa de Kohonen. Os resultados experimentais apresentados pelos autores são ainda preliminares, mas sugerem que o MAOR é capaz de aprender e distinguir diferentes tipos de seqüências temporais.

\subsubsection{Versão Temporal de Modelos com Aprendizagem Anti-Hebbiana}

GIROLAMI \& FIFE (1996) propuseram um modelo temporal para aprendizagem anti-hebbiana linear tomando como base o modelo proposto por FÖLDIAK (1989). O propósito de modelos anti-hebbianos é descorrelacionar as unidades de saída da rede, neste caso aplicada a separação de mistura de sinais de voz convolvidos. No modelo original, a equação que governa a dinâmica de um neurônio é dada por:

$$
\tau \frac{d y_{j}(t)}{d t}=-y_{j}(t)+x_{j}(t)+\sum_{k=1}^{m} m_{j k}(t) y_{k}(t)
$$

ou por,

$$
y_{j}(t)=x_{j}(t)+\sum_{k=1}^{m} m_{j k}(t) y_{k}(t)
$$

em que $x_{j}(t)$ é a entrada, $y_{j}(t)$ a saída e $\tau$ é uma constante de tempo, $m$ é o número de neurônios e $m_{j k}$ é a conexão lateral ligando os neurônios $j$ e $k$. Os pesos neste modelo são ajustados de acordo com a regra anti-hebbiana clássica:

$$
\Delta m_{i j}(t)=-\eta y_{i}(t) y_{j}(t) \quad \forall i \neq j=1 \ldots m
$$


Os autores tomaram o modelo original e o estenderam a partir da definição de conexões sinápticas laterais baseada em memória (memory based synaptic lateral weights). A Figura 11 mostra o modelo temporal onde as linhas de atraso estão representadas pelos atrasadores $\mathrm{z}^{-1}$.

A saída da rede é agora calculada levando-se em conta pesos e saída em instantes anteriores:

$$
y_{j}(t)=x_{j}(t)+\sum_{k=1}^{m} \sum_{r=0}^{d} m_{j k}(t-r) y_{k}(t-r)
$$

em que $d$ é o número de atrasos. A regra de aprendizagem para os pesos com memória passa a ser definida como:

$$
\Delta m_{j k}(r)=-\eta y_{j}(t) y_{k}(t-r) \quad \forall i \neq j \wedge r=1 \ldots d
$$

Neste caso, a aprendizagem anti-hebbiana temporal provoca a convergência dos pesos da rede para os coeficientes do filtro FIR da função de transferência não misturada, recuperando os sinais originais. A partir dos resultados da simulação do modelo temporal em dois sinais de voz que sofreram uma mistura e convolução, os autores concluíram que o modelo anti-Hebbiano linear temporal é suficiente para realizar a desconvolução cega de dois sinais de voz.

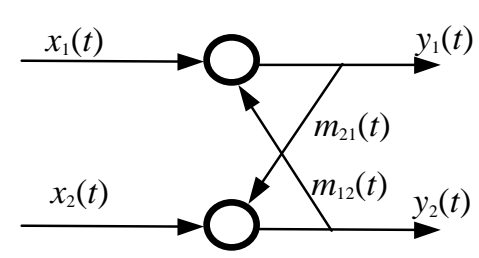

(a)

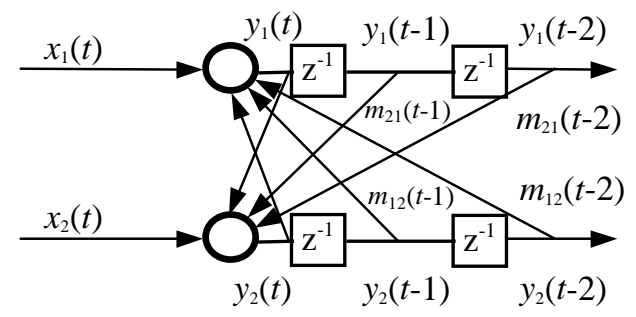

(b)

Figura 11: Topologia da rede anti-hebbiana de Földiak. (a) versão original e (b) modelo com memória sináptica proposto por GIROLAMI \& FYFE (1996).

Os modelos a serem discutidos a seguir encerram conceitos e características importantes para o processamento de padrões temporais, cujo entendimento não é tão direto como nos modelos apresentados até agora. Desta forma, optou-se por mostrálos em seções próprias de modo a facilitar a compreensão dos mesmos. 


\subsection{Modelos para Reconhecimento e Reprodução de Seqüências Temporais Propostos por WANG \& ARBIB}

Baseados na idéia de usar um modelo de MCD com decaimento para resolver ambigüidades que surgem durante o processamento de seqüências complexas, WANG \& ARBIB (1990) propuseram um modelo para aprender a reconhecer e gerar seqüências temporais complexas. Neste modelo, a MCD é implementada por blocos que consistem em dois neurônios com conexões excitatórias recorrentes entre si, ou seja, um modelo de neurônio dual (Figura 12) que armazena um sinal por um certo período. A saída deste neurônio é um trem de impulsos que decai gradualmente, diferente das saídas tipo threshold usados em muitos modelos de redes neurais. Aplicando uma regra hebbiana a cada sinapse juntamente com uma regra de normalização entre todos os pesos sinápticos de um neurônio, mostra-se que uma grandeza chamada de potencial de entrada cresce monotonicamente com a apresentação da seqüência até a sua saturação.

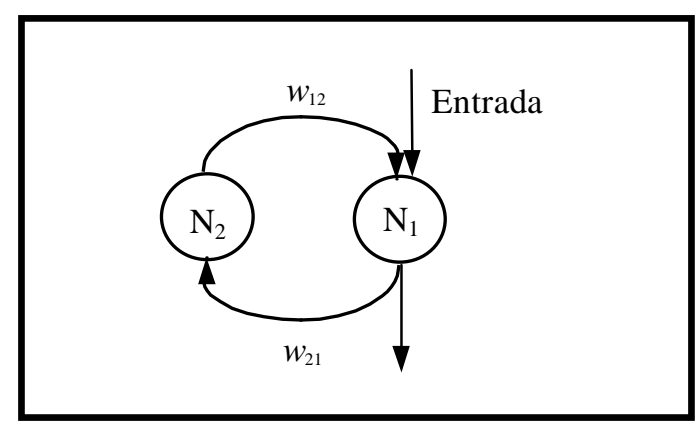

Figura 12: Modelo de neurônio dual.

O potencial de entrada é a soma ponderada dos vetores de entrada. Depois deste treinamento, um threshold com valor igual ao do nível de saturação do potencial de entrada é atribuído a cada neurônio, fazendo com que o neurônio dispare somente quando seus sinais de entrada estão arranjados em uma sequiência específica. Esta propriedade leva ao conceito de neurônio detetor de sequiência (sequence-detecting neuron). É importante observar que, depois do treinamento, este tipo de neurônio é disparado por uma seqüência prévia de padrões e não por apenas um padrão prévio. Entretanto, existe um problema com este modelo de neurônio detetor de seqüência caso ele seja aplicado na detecção de seqüências complexas. Quando uma seqüência $S$ : A-B-A-C-A-B-E-B-D, é apresentada ao modelo anterior, então a apresentação de uma subseqüência recorrente sobrescreverá o sinal da apresentação anterior mantida na 
MCD. Ou seja, o neurônio detetor de sequiência só pode detectar a última presença de um padrão recorrente. Para resolver este problema, introduz-se sinapses múltiplas entre dois neurônios (Figura 13), cada uma das quais correspondendo a uma ocorrência da subsequiência recorrente. Desta forma, a rede pode reconhecer e gerar seqüências complexas.

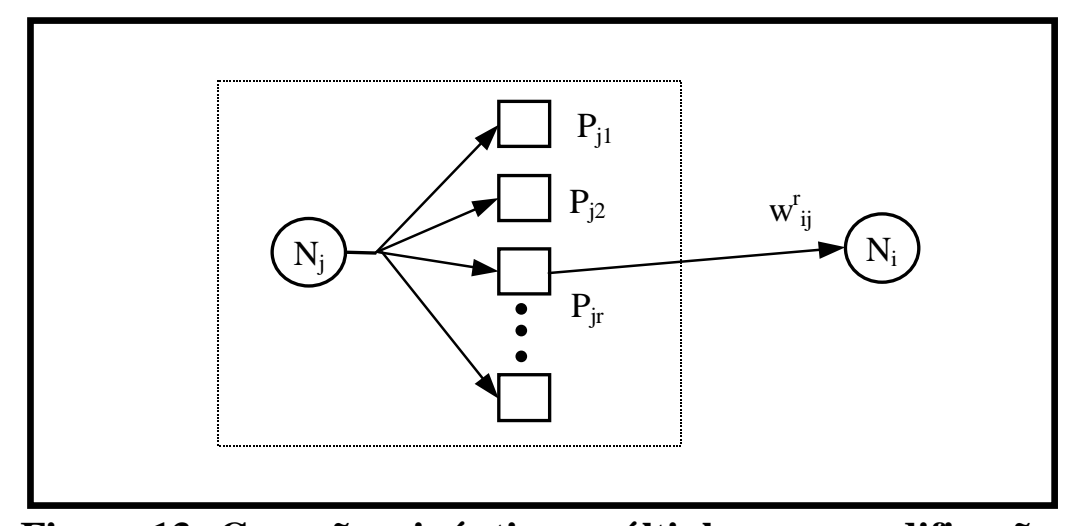

Figura 13: Conexões sinápticas múltiplas para codificação de subseqüências recorrentes.

Este modelo neural também pode ser usado para reconhecer seqüências temporais que contenham distorções. Isto pode ser realizado de acordo com os dois passos que seguem:

1) Diminuir o threshold de cada neurônio detetor de seqüência. Assim, este neurônio pode ser disparado por um conjunto de sequiências próximas àquela que foi aprendida.

2) No caso anterior, uma seqüência atualmente sendo apresentada pode ativar mais de um neurônio detetor. Para evitar esta situação, os sinais de todos os neurônios que dispararam são levados à uma rede competitiva do tipo WTA, assegurando que apenas o neurônio mais ativo permaneça ativado.

Com essa extensão, o modelo pode ser usado para reconhecimento de seqüências de uma maneira geral.

A Figura 14 mostra a arquitetura do sistema proposto. Nesta figura, cada neurônio da camada de entrada representa um padrão espacial. As conexões desta camada para a camada de reconhecimento são do tipo todos-para-um (por simplicidade apenas um neurônio foi mostrado). As conexões da camada de reconhecimento para a camada de competição tem uma correspondência de um-para- 
um. A camada de competição pode ser implementada usando a rede Maxnet discutida na Seção 2.3.

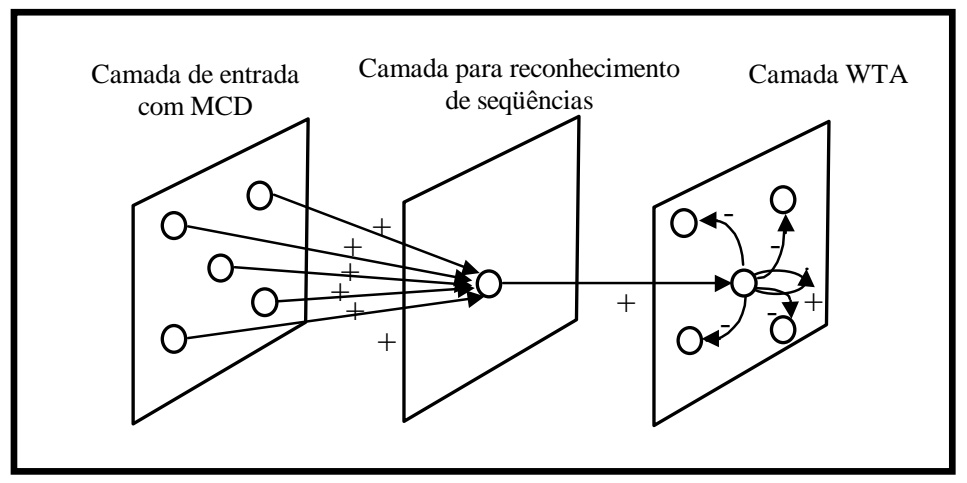

Figura 14: Arquitetura geral para reconhecimento de sequências.

Para gerar sequiências temporais, cada componente de uma seqüência é associado com um detetor de contexto (Figura 15) que aprende a ativar unicamente esta componente. A parte inicial de uma seqüência forma o contexto para a ativação da próxima componente, e esta recém-ativada componente se junta à MCD para formar o contexto que ativará a próxima componente e assim por diante. Este processo continua até que a seqüência inteira seja gerada.

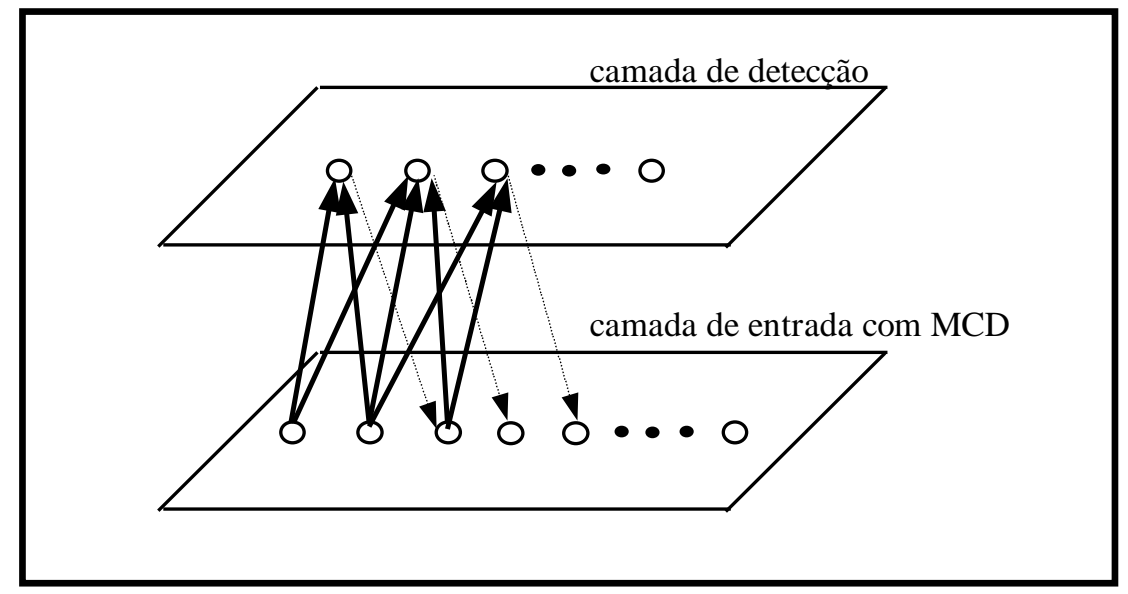

Figura 15: Arquitetura de rede para reprodução de seqüências temporais proposta por WANG \& ARBIB (1990).

WANG \& ARBIB (1993) abordaram tópicos como time warping e segmentação (chunking) de subseqüências usando um modelo semelhante ao proposto em WANG \& ARBIB (1990). Naquele modelo em particular, seqüências podem ser reconhecidas de forma hierárquica e sem serem afetadas pela velocidade de apresentação (sistemas invariantes à taxa). $\mathrm{O}$ reconhecimento hierárquico possibilita ao sistema identificar seqüências cuja dependência temporal é muito mais longa do que a capacidade da 
MCD. Na geração de seqüências complexas, o sistema consegue manter constante as durações relativas entre as componentes, enquanto varia a taxa de duração global da sequiência. Este modelo também propõe um mecanismo de auto-organização para determinar o tamanho do contexto de cada componente da sequiência.

A arquitetura do modelo é mostrada na Figura 16, onde a camada de entrada é um modelo de MCD e uma unidade na camada de detecção de contexto codifica o contexto para cada componente na seqüência. As conexões de realimentação da camada de detecção para a camada de entrada associam detetores de contexto com suas componentes correspondentes. Cada detetor de contexto aprende a reconhecer uma subseqüência especifica do mesmo modo que o reconhecimento de seqüências, tendo associado um parâmetro que denota o grau do contexto a ser codificado (inicialmente igual a 1). Se a seqüência é simples, ela pode ser facilmente aprendida. Caso contrário, a seguinte situação é obrigada a ocorrer: uma subseqüência na MCD antecipará mais do que uma componente, ou seja, ativará mais de uma unidade na segunda camada (ambigüidade potencial).

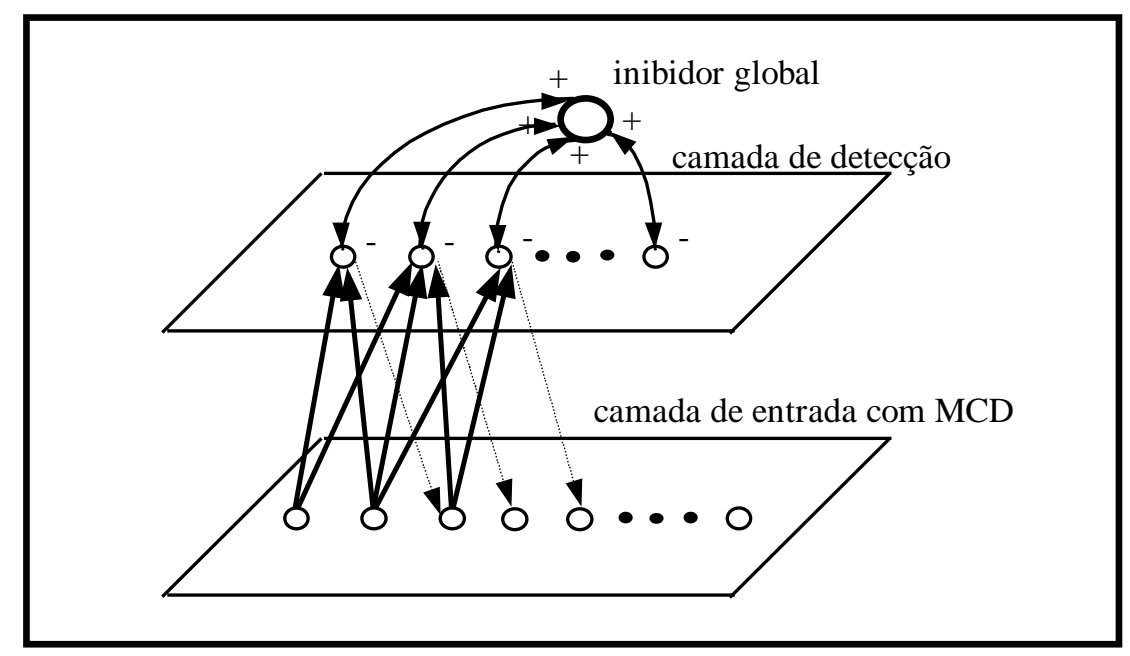

Figura 16: Arquitetura para aprendizagem de contexto em seqüências complexas segundo WANG \& ARBIB (1993).

O inibidor global detectará esta situação e seu disparo incrementará os parâmetros de grau das unidades atualmente ativas na camada de detecção, tal que estas unidades detectarão contextos mais longos da próxima vez. Este processo continua durante o treino até que nenhuma ambigüidade exista. Os autores mostraram que este algoritmo de auto-organização de contexto consegue identificar o contexto de cada componente em uma sequiência arbitrária. Por exemplo, para todas as 
componentes (com exceção da primeira) da seqüência $\boldsymbol{J}-\boldsymbol{B}-\boldsymbol{A}-\boldsymbol{C}-\boldsymbol{D}-\boldsymbol{A}-\boldsymbol{B}-\boldsymbol{A}-\boldsymbol{E}-\boldsymbol{F}-\boldsymbol{A}-\boldsymbol{B}-$ $\boldsymbol{A}-\boldsymbol{G}-\boldsymbol{H}-\boldsymbol{A}-\boldsymbol{B}-\boldsymbol{A}-\boldsymbol{H}-\boldsymbol{I}$, o algoritmo encontra os seguintes graus $\{1,2,3,1,1,2,3,4,1$, $1,2,3,4,1,2,2,3,4,2\}$.

\subsection{Modelos para Reconhecimento e Reprodução de Seqüências Temporais Propostos por WANG \& YUWONO}

Tomando como base os modelos anteriores de [WANG \& ARBIB, 1990, 1993], WANG \& YUWONO (1995) propuseram e investigaram analiticamente um modelo neural para geração temporal de padrões complexos. Este modelo usa um mecanismo de antecipação para resolver ambigüidades que surgem durante a produção de seqüências complexas.

WANG \& YUWONO (1996) abordaram o problema de aprendizagem incremental de múltiplas seqüências temporais. Neste caso, novas seqüências são aprendidas assim que sequiências antigas tenham sido adquiridas.

Uma forma direta de se implementar este tipo de aprendizagem é concatenandose estas seqüências em uma única seqüência longa durante o treinamento. Dado que cada seqüência tenha um único identificador, um modelo pode aprender todas as seqüências se ele puder aprender a seqüência concatenada. Entretanto, o conceito de aprendizagem seqüencial de múltiplas sequiências é um tópico inteiramente diferente. Trata-se de uma forma mais desejável de treinamento porque permite que o modelo adquira novo conhecimento com base numa memória já existente (uma forma de aprendizagem incremental). A aprendizagem incremental não apenas se ajusta bem ao

processo de aprendizagem humana [WANG \& YUWONO, 1996], como também é importante para muitas aplicações que não possuem todo o conjunto de treinamento disponível no começo e onde a aprendizagem é um processo contínuo.

\subsection{Resumo do Capítulo}

Uma das seções mais importantes deste capítulo trata da definição de memória de curta duração, elemento imprescindível para o processamento seqüencial de padrões. Sua função é manter diferentes elementos da seqüência de entrada disponíveis por um determinado período de tempo, de modo que associações entre estes elementos 
possam ser aprendidas pela rede. Diversas implementações destes conceitos foram então apresentadas.

Depois destas definições, os principais modelos de aprendizagem nãosupervisionadas para processamento temporal foram discutidos. Tais modelos foram classificados por critério de semelhança, onde discutiu-se suas arquiteturas, dinâmicas e áreas de aplicação. Em geral, modelos não-supervisionados para processamento temporal são extensões de modelos já existentes para processamento de padrões estáticos. As modificações propostas nestas extensões se dão principalmente em dois níveis. O primeiro nível visa à incorporação de informação temporal ao processamento alterando a forma de apresentação dos dados de entrada à rede, deixando a dinâmica de ativação e de aprendizagem como nos modelos originais. O segundo, incorpora informação temporal diretamente na dinâmica de ativação e de aprendizagem do modelo usando, em geral, algum tipo de modelo de MCD.

A apresentação dos diversos modelos visou mostrar o estado da arte no uso de redes não-supervisionadas para processamento temporal. Não se preocupou em mostrar uma aplicação específica, mas sim a forma como estes modelos lidam com padrões temporais. Percebeu-se que a grande maioria destes modelos trata do problema de reconhecimento de seqüências, enquanto uma pequena parcela trata do problema de reprodução. Tem-se aqui uma das principais motivações deste trabalho de pesquisa: a existência limitada de modelos de RNAs não-supervisionadas que tratem de reprodução de seqüências temporais. Mais ainda, quando tratam do problema da reprodução

Dos conceitos discutidos ao longo do capítulo, os seguintes são de fundamental importância na proposição de modelos para reprodução de seqüências: (i) MCD por linhas de atraso, (ii) papel do contexto na reprodução sem ambigüidades, e (iii) codificação de informação temporal em pesos sinápticos laterais.

O mecanismo de MCD a ser usado será do tipo com linhas de atraso. Entretanto, diferentemente da maioria dos modelos [WAIBEL et al., 1989; KANGAS, 1990] que também utilizam este tipo de implementação, os padrões de ativação de saída é que serão mantidos na MCD e não os padrões de entrada. Desta forma, o modelo incorporará a MCD à sua dinâmica de ativação e de aprendizagem.

$\mathrm{Na}$ aprendizagem, a MCD permitirá que sejam criadas associações temporais entre neurônios vencedores em competições sucessivas. Estas associações serão 
codificadas pelas conexões laterais de tal modo a aprender a ordem temporal de ocorrência dos padrões na seqüência.

Alguns dos outros conceitos vistos neste capítulo não serão usados diretamente no desenvolvimento do modelo no Capítulo 6, mas serão importantes na compreensão do funcionamento das arquiteturas de redes não-supervisionadas em Robótica. Conforme será visto no próximo capítulo, a robótica é uma área de aplicação natural para processamento de seqüências temporais. 


\section{Capítulo 5}

\section{Redes Neurais Não-Supervisionadas em Robótica: Revisão Bibliográfica}

No capítulo anterior alguns modelos de redes não-supervisionadas para processamento de sequiências temporais foram apresentados. $\mathrm{O}$ foco estava, principalmente, na modelagem e na incorporação de informação temporal pelas redes. Conforme era de se esperar, tais modelos foram motivados principalmente pela aplicação, embora alguns poucos deles tinham a intenção de modelar algum processo neurocognitivo ou neurobiológico. Neste capítulo, continua-se a abordar redes nãosupervisionadas mas agora se concentrando em uma área de atuação específica: a Robótica. Serão apresentados modelos de redes para planejamento e/ou controle, aprendizagem, e recuperação de trajetórias tanto de robôs manipuladores quanto de robôs móveis. Apesar de estes últimos não serem de interesse direto para o desenvolvimento desta dissertação, alguns conceitos utilizados nestes sistemas serão úteis na proposição de modelos não-supervisionados para reprodução de trajetórias.

O restante do capítulo está dividido da seguinte forma: na Seção 5.1 a robótica é apresentada como uma área natural de aplicações que envolvem o processamento de seqüências. Nesta seção, define-se também os tipos mais comuns de sequiências temporais encontradas em robótica. Na Seção 5.2 são apresentados modelos nãosupervisionados que lidam com seqüências cujas saídas relacionam ações a grandezas sensoriadas pelo robô. Já na Seção 5.3 são introduzidos modelos cujas saídas são estados futuros da trajetória. $\mathrm{Na}$ Seção 5.4 são mostrados modelos nãosupervisionados que aprendem a resolver o problema da cinemática inversa. O capítulo é concluído na Seção 5.5.

\subsection{Robótica e o Processamento de Seqüências Temporais}

Como em muitas outras áreas do conhecimento científico, a robótica tem sido um campo fértil para o desenvolvimento de técnicas de aprendizagem de máquinas 
baseadas em modelos de redes neurais artificiais. Por este motivo, modelos neurais têm sido propostos com o intuito de controlar braços mecânicos e para planejar, aprender e reproduzir trajetórias. Uma característica comum a todos estes modelos é a necessidade de processar uma seqüência de eventos em um certo período de tempo. Tais eventos definem uma trajetória espacial a ser seguida ou um conjunto de ações a serem tomadas para a realização de uma tarefa. Portanto, tem-se aqui duas abordagens importantes para o problema de processamento de seqüências em Robótica:

- Aprendizagem de seqüências do tipo percepção-ação (SPA)

- Aprendizagem de sequiências de trajetórias de robôs (STR)

No primeiro caso, informações sensoriais são associadas com determinadas ações [BUGMANN et al., 1998], por exemplo, "quando este padrão é visto deste ângulo, vire à direita”. As hipóteses fundamentais levantadas por esta abordagem são [DENHAM \& McCABE, 1996]: (i) o mundo é percebido não como "fotografias" individuais isoladas mas sim, como uma seqüência de estímulos sensoriais que estão associados no tempo; e (ii) toda seqüência sensorial é determinada por uma seqüência associada de ações do robô, em que cada ação determina os estímulos sensoriais que serão recebidos em seguida.

Com relação à aprendizagem de trajetórias de robô, a rede recebe como entrada o estado atual do braço mecânico (tal como leituras sensoriais de posição, ângulos das juntas, torques) e responde com o próximo estado da trajetória de modo a realizar uma tarefa definida antecipadamente. Este comportamento antecipativo é útil em situações que envolvam ambigüidades de resposta da rede [RAO \& FUENTES, 1996; BUGMANN et al., 1998]. Esta abordagem encontra principal aplicação em rastreamento de trajetórias pré-fixadas.

\subsection{Processamento de Seqüiências do Tipo Percepção-Ação}

DENHAM \& McCABE (1995, 1996) descreveram uma abordagem para o controle de robôs móveis que usa pares formados por sequiências de estímulos sensoriais e seqüências de ações para construir um modelo interno do ambiente no qual o robô está navegando. As hipóteses apresentadas pelos autores supõem que o 
comportamento de um robô autônomo, assim como o de um animal, na aprendizagem e execução de tarefas sensório-motoras é determinada pela habilidade do robô (ou do animal) para aprender e recordar seqüências de experiências sensoriais e de ações motoras associadas.

\subsubsection{Segmentação de Seqüências e Conexão de Subseqüências}

A navegação contínua do robô em seu ambiente resulta na criação de longas SPAs, as quais podem conter muitas subseqüências idênticas. Assim, o desenvolvimento de um modelo interno do ambiente do robô exige que longas SPAs sejam segmentadas de acordo com algum mecanismo intrinsecamente determinado, de modo que estas subseqüências individuais representem componentes do mundo que possuam significados. Além disso, associações devem ser criadas entre estes segmentos de modo a permitir combinações dinâmicas e flexíveis que sejam adequadas ao objetivo atual do robô. Nestes sentido, um segmento é uma porção particular da memória que representa uma parte do ambiente, a partir da qual o robô pode fazer predições ou suposições a respeito dos resultados de suas ações. As ligações que foram criadas entre diferentes segmentos permitem ao robô determinar que parte da memória é apropriada para seleção de ações futuras.

No modelo proposto, os mecanismos de segmentação (chunking) e ligação (linking) são disparados pela realização de um objetivo específico ou pela detecção de novidade (novelty detection). Um objetivo é alcançado quando a expectativa sensorial interna gerada pelo modelo "casa-se" com a realidade sensorial externa lida. Este fato estimula o sistema de recompensa que por sua vez ativa a aprendizagem.

A detecção de novidades ativa a aprendizagem de outro modo. Neste caso, a memória, na forma de um conjunto de SPAs, fornece um conjunto de predições ou expectativas sobre o estímulo sensorial que resultará de uma determinada ação, baseando-se em um subconjunto de SPAs que mais se assemelha ao mais recente histórico de experiências sensório-motoras do robô. Se estas predições não são confirmadas pela realidade, então assume-se que o robô deve estar tendo um nova experiência sensório-motora. Tal novidade ativa a aprendizagem, e uma SPA nova ou estendida é formada na memória. 
O modelo do mundo é organizado hierarquicamente em dois níveis mostrados na Figura 17. O primeiro nível consiste de SPA que são aprendidas como resultado da detecção de novidades, e representam desta forma conhecimento sobre partes do mundo que são caracterizadas por uma única SPA. Estes componentes de memória são criados conectando pares percepção-ação seqüencialmente no tempo.

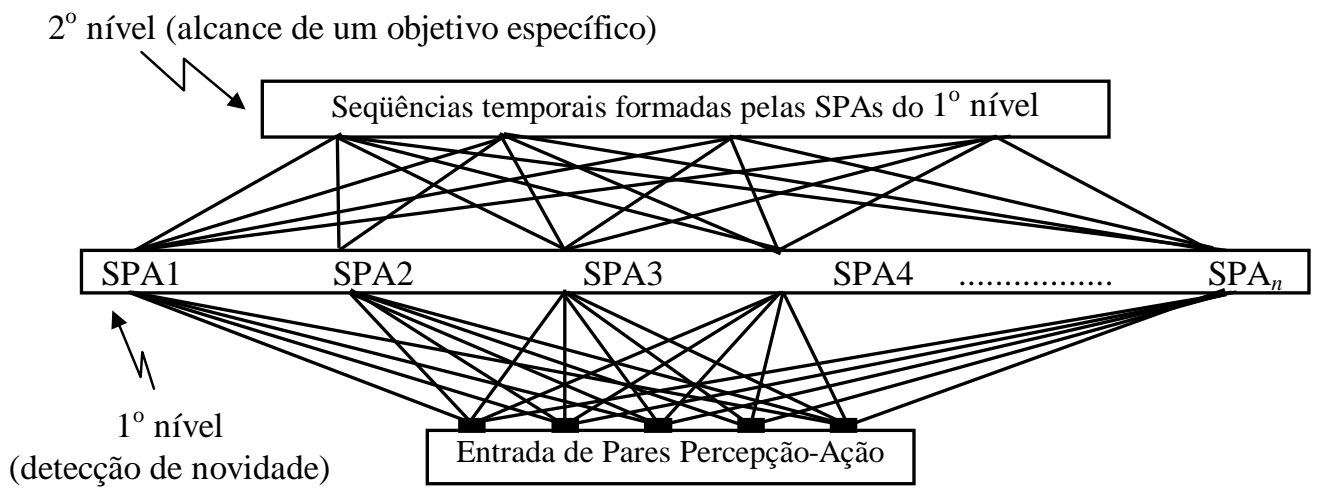

Figura 17: Modelo hierárquico do mundo para processamento de seqüências do tipo percepção-ação.

O segundo nível consiste de seqüências de SPAs que são aprendidas como resultado do alcance de um objetivo específico. Elas são criadas conectando-se seqüencialmente no tempo SPAs específicas, representando assim conhecimento sobre como partes do mundo relacionam-se no espaço entre si com relação ao alcance de um objetivo específico. As seqüências armazenadas neste segundo nível estão assim relacionadas com o alcance de um objetivo: uma seqüência particular de SPAs somente será mantida na memória se e quando um objetivo específico é atingido.

\subsubsection{Uso de Seqüiências Armazenadas para Selecionar Ações}

Em qualquer estado de conhecimento do robô sobre seu mundo, seu modelo interno pode ser usado para selecionar ações adequadas. Na ausência de um objetivo específico, quando o robô é guiado por curiosidade (navegação exploratória), o primeiro nível do modelo é usado da seguinte forma. A história atual de pares percepção-ação é comparada com todas as SPAs neste nível para encontrar aquela a que mais se assemelha. A SPA que ganha a competição é usada para selecionar a próxima ação simplesmente recuperando a próxima componente nesta seqüência. Isto 
também determina o próximo estímulo sensorial esperado. Se esta expectativa é confirmada, uma nova competição é realizada e o processo de seleção é repetido. Se não ocorre uma concordância, esta provoca o armazenamento da SPA atual como sendo representante de novo conhecimento sobre o mundo. Em alguns casos, este novo conhecimento pode simplesmente estender uma SPA já armazenada. Se for necessário, uma nova ação é selecionada de acordo com alguma motivação intrínseca dando início a uma nova competição.

Na presença de um objetivo específico, ações são selecionadas como descrito no parágrafo anterior. A diferença está no fato de que, neste caso, seqüências de SPAs passam a ser gravadas no segundo nível da memória, até que um objetivo particular tenha sido alcançado. Neste instante, a seqüência usada para alcançar este objetivo é gravada na memória. A seleção da próxima SPA (que será usada para selecionar a próxima ação) ao final do uso da SPA atual é feita mantendo-se a competição entre aquelas seqüências de SPAs que estão associadas com o objetivo atual, isto é, aquelas para os quais a retenção na memória foi determinada pelo alcance do objetivo em questão. O vencedor desta competição é determinado por seu grau de semelhança com a história passada do robô. Sendo tal história descrita por uma seqüência de SPAs, e não por uma seqüência de pares percepção-ação.

O processo de aprendizagem em cada nível resultará no armazenamento de longas seqüências na memória: seqüências de pares percepção-ação ou seqüências de SPA. Resultará ainda, na criação de novas seqüências, dependendo da familiaridade do robô com aquela parte do mundo, ou de sua localização em lugares não visitados anteriormente. Para minimizar a ocorrência de comportamento oscilatório das sequiências armazenadas, situação em que o robô move para frente e para trás ao longo do mesmo caminho, deve ser dado ao robô incentivos para a busca de novidades. Por exemplo, continuar a mover-se na mesma direção de antes, na ausência de qualquer informação melhor.

Para implementar, os mecanismos de segmentação e conexão de SPAs, os autores utilizaram uma versão modificada da rede proposta por WANG \& ARBIB (1993), discutida na Seção 4.3.

HEIKKONEN et al. (1995) e HEIKKONEN \& KOIKKALAINEN (1997) propuseram vários modelos baseados no MAOK para controle de um robô móvel. Equipados com um controlador neural baseado no MAOK, tal robô pôde combinar sua 
informação sensorial (sem qualquer ajuda externa) para obter uma representação que seja aplicável diretamente para navegação e desvio de obstáculos. A plausibilidade do sistema de controle proposto é testado com um simulador de robô móvel, onde os experimentos relatados demonstram que o sistema de controle aprende rapidamente a selecionar ações adequadas para estímulos sensoriais de entrada, a adaptar-se facilmente a novos ambientes, a colidir cada vez menos freqüentemente enquanto navega.

\subsection{Aprendizagem de Trajetórias de Robôs}

ALTHÖFER \& BUGMANN (1995) propuseram dois novos tipos de redes neurais para planejamento e aprendizagem de sequiências de movimentos de um braço de robô. O primeiro desses modelos é uma implementação neural da técnica grid resistivo [MUSÍLEK, 1995] para planejamento de trajetórias. Para se usar este grid, o espaço de estados do robô deve ser dividido em um conjunto de pequenos cubos $N$ dimensionais $(N=2$ ou 3). Cada cubo corresponde a um nó no grid resistivo. Cada nó está conectado a seus $2 \mathrm{~N}$ vizinhos. O planejamento pode ser executado atribuindo ao potencial do nó correspondente ao estado meta um valor alto. Aos nós correspondendo a obstáculos, ou estados proibidos, são atribuídos um potencial nulo. Correntes elétricas fluem do alvo, através do grid, em direção aos obstáculos. Em qualquer ponto no grid, a direção do fluxo de corrente indica o caminho mais curto para a meta. A implementação neural de um grid resistivo é direta. Neste caso, um neurônio é atribuído a cada nó do grid. A principal vantagem deste método é que ele garante encontrar uma solução para o problema do planejamento, se ela existir. Entretanto, também possui as limitações de métodos que são baseados em grids, principalmente a baixa resolução devido à discretização.

Quando aplicado a braços manipuladores, a baixa resolução proporcionada pelo método do grid resistivo provoca movimentos bruscos (jerkiness) e imprecisão no posicionamento da garra do manipulador. Como solução para este problema, os autores propuseram um novo modelo de rede de duas camadas (Figura 18) para aprendizagem das trajetórias produzidas pelo grid resistivo. 


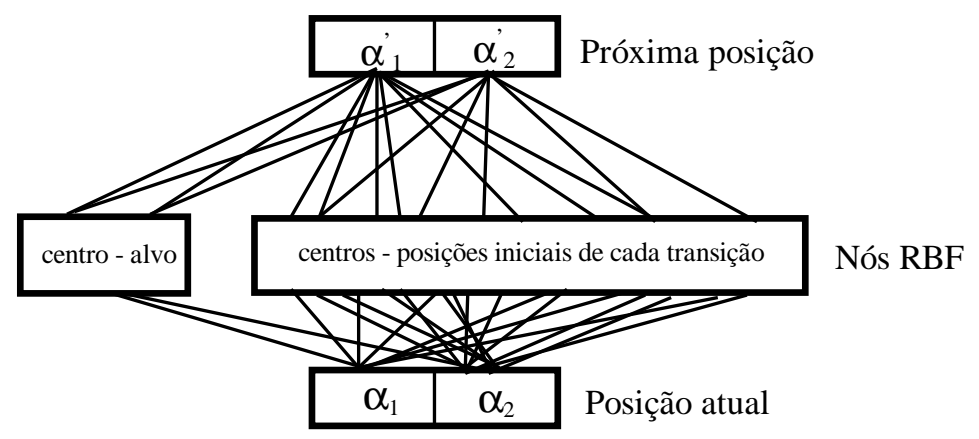

Figura 18: Arquitetura de duas camadas para aprendizagem e reprodução de trajetórias de um braço mecânico com 2 DOF. Só algumas conexões são mostradas.

A primeira camada é composta de $\mathrm{N}_{h}$ neurônios do tipo RBF. Estes neurônios recebem os 2 ângulos das juntas do manipulador, $\alpha_{1}$ e $\alpha_{2}$, como entradas. Eles respondem com maior intensidade quando estes ângulos são iguais aos centros $\left(\alpha_{10}^{j}\right.$ e $\left.\alpha_{20}^{j}\right)$ de seus campos receptivos, de acordo com a seguinte equação:

$$
y_{j}=\exp \left[-\frac{1}{2 \sigma_{j}^{2}} \sum_{i}\left(\alpha_{i}^{j}-\alpha_{i 0}^{j}\right)^{2}\right]
$$

na qual $\sigma_{j}$ define a largura do campo receptivo. Os neurônios da primeira camada projetam pesos $w_{r j}$ para a camada de saída, que por sua vez, determinam a próxima posição no espaço de configuração. A camada de saída consiste em dois neurônios com saída $\alpha_{1}^{\prime}$ e $\alpha_{2}^{\prime}$ cujas atividades de saída são calculadas de acordo com a seguinte equação:

$$
\alpha_{r}^{\prime}=\frac{\sum_{j} w_{r j} y_{j}}{\sum_{j} y_{j}}
$$

Esta operação corresponde à atividade média ponderada pelos pesos de entrada. A Equação (44) permite codificar os valores dos próximos ângulos nos pesos que vão da primeira camada até a camada de saída.

A rede é treinada durante a leitura de uma seqüência de movimentos determinados pelo grid resistivo. A cada transição de um nó $n_{t}$ do grid para outro, $n_{t+1}$, 
um novo neurônio RBF é recrutado, seu campo receptivo é centrado na posição de partida correspondendo ao neurônio $n_{t}$, e seus pesos para a camada de saída são feitos iguais aos valores dos ângulos das juntas correspondentes ao nó $n_{t+1}$.

Durante a reprodução da trajetória, somente a saída desta rede é usada para controlar o movimento do braço (o grid resistivo não é mais utilizado). Como neurônios do tipo RBF têm um certo grau de superposição, um pequeno número de nós na primeira camada pode ser ativado e pode apontar para diferentes configurações. Entretanto, a Equação (44) faz com que a maior ativação $y_{j}$ tenha maior peso na decisão devido à normalização.

Para resolver o problema do posicionamento impreciso, dois neurônios extras são usados. Estes têm seus campos receptivos centrados em duas configurações finais do braço, e têm seus pesos de saída apontando exatamente para estas configurações finais. Cada um destes nós está ligado por cinco conexões aos neurônios de saída. O número 5 é arbitrário, só devendo ser alto suficiente para dar um peso dominante aos ângulos indicados por estes dois neurônios RBF extras. Desse modo, quando o braço aproxima-se de uma das configurações finais selecionadas, ele se torna fortemente atraído para a posição final exata. Este modelo neural proposto é capaz de gerar trajetórias suaves do braço e um posicionamento final preciso da garra do manipulador.

Mais recentemente, BUGMANN et al. (1998) usaram um modelo semelhante ao descrito em ALTHÖFER \& BUGMANN (1995) para codificar a seqüência de posições que formam a trajetória de uma cadeira de rodas autônoma. Tal rede opera produzindo a próxima posição que a cadeira deve ocupar. De acordo com a trajetória que tinha que seguir, a cadeira passava várias vezes pelos mesmos pontos, implicando assim no surgimento de um problema conhecido como perceptual aliasing [RAO \& FUENTES, 1996]. Este problema refere-se à situação em que duas ou mais entradas sensoriais idênticas requerem diferentes respostas de um sistema autônomo. Para solucionar tal problema, informação adicional sobre a fase é adicionada à informação de posição (Figura 19).

Como são usados neurônios do tipo RBF então vários destes nós tem centros na mesma posição, pois uma dada trajetória pelo fato da trajetória passar várias vezes por um mesmo ponto. A informação de fase evita que vários destes neurônios fiquem ativos ao mesmo tempo. 


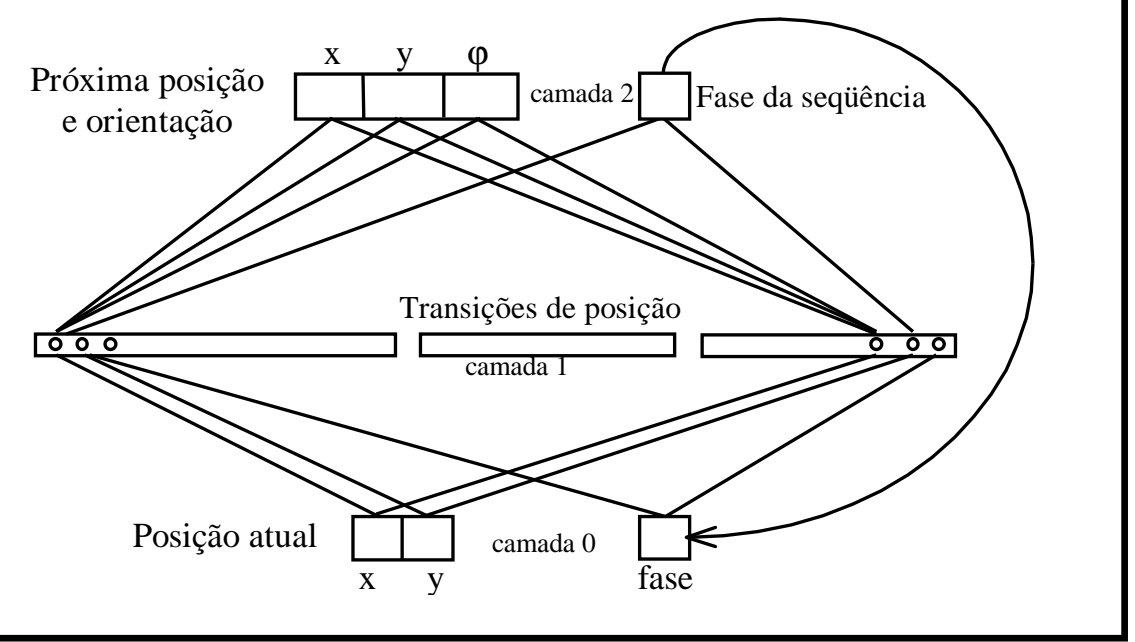

Figura 19: Arquitetura da rede neural para codificação da trajetória desejada, segundo BUGMANN et al. (1998).

Esta informação é incorporada à arquitetura através do acréscimo de um nó chamado de "fase da seqüência". Os pesos de cada um dos neurônios da camada 1 ao neurônio "fase da seqüência" são iguais a sua posição (ou fase) na seqüência. Por exemplo, se o primeiro nó na seqüência estiver ativo, o nó "fase da seqüência" terá sua saída igual a 1, se o décimo nó está ativo, a saída será 10, etc. A saída do nó "fase da seqüência" é usada como entrada pelos neurônios da camada 1 (transições de posição). Seus pesos de entrada são igualados à fase correspondente subtraída de 0,5 , ou seja, o décimo nó tem um campo receptivo para fases centrado em 9,5. Desta forma, nós são ativados quando o sistema está na fase anterior a sua própria (ou na sua própria) e quando a cadeira de rodas está na posição definida pelos dois pesos da "posição atual" na camada 0. Portanto, quando uma posição corresponde a muitos nós, apenas aquele cujo campo receptivo corresponde à fase atual ficará ativo e pode indicar a próxima posição da trajetória.

O uso de neurônios tipo RBF cria um campo de atração por sobre todo o espaço e possibilita que a cadeira recupere sua trajetória original após desviar-se de obstáculos. Os modelos na próxima seção foram desenvolvidos com objetivo de resolver o problema da cinemática inversa. 


\subsection{Aprendizagem da Cinemática Inversa via Modelos Não- Supervisionados}

KUPERSTEIN $(1988,1989)$ propôs um modelo para coordenação visuo-motora usando mapas topográficos. Este modelo, que já foi implementado e testado em um braço de robô real, aprende durante uma fase de treinamento a controlar um braço com 5 graus de liberdade (4 nas juntas e um na garra), tal que ele possa alcançar objetos que lhe tenham sido apresentados. Esta tarefa é implementada através do uso de um conjunto de mapas topográficos que representam a posição do objeto alvo e os valores das componentes dos vetores de peso determinam a saída para os atuadores do braço. No modelo de Kuperstein, cada mapa topográfico tem apenas uma dimensão e tem uma ordenação topográfica fixa, imposta inicialmente. Apenas os pesos de saída são atualizados durante o processo de aprendizagem. Como consequiência, para projeto do sistema, a faixa de valores que a entrada assume deve ser conhecida de antemão e mudanças adaptativas na resolução da população neural requerida para controle não são possíveis. Além disso, como os mapas são unidimensionais e suas saídas para cada atuador são somadas linearmente, eles só podem aproximar, de forma precisa, uma classe restrita de leis de controle.

MARTINETZ et al. (1990) e RITTER et al. (1992) propuseram uma abordagem que visa resolver as principais limitações do modelo de Kuperstein. O modelo proposto é uma extensão do modelo de Kohonen para formação de mapas autoorganizáveis de características. Neste modelo, a ordenação e a resolução do mapa topográfico evolui durante a aprendizagem (ajustando uma camada de pesos de entrada) determinando a distribuição dos neurônios no espaço de trabalho do robô. Desta forma o problema de se ter uma resolução fixa é resolvido. Para atualização dos pesos de saída, usa-se um esquema de correção do erro de posicionamento baseado na regra de aprendizagem de Widrow-Hoff. Um mapa topográfico tridimensional é usado para representar o espaço de trabalho, eliminando assim as restrições que surgem quando se usa um acoplamento aditivo de vários mapas de uma dimensão. $\mathrm{O}$ uso de um mapa topográfico permite que muitas unidades cooperem entre si durante a fase de aprendizagem, contribuindo fortemente para a eficiência e robustez do algoritmo. 
O sistema descrito consiste de um robô manipulador com três graus de liberdade que tem que apanhar objetos em um espaço 3-D. O meio é observado por duas câmeras fixas, que geram as coordenadas $\left(\boldsymbol{u}_{1}, \boldsymbol{u}_{2}\right)$ e $\left(\boldsymbol{u}_{3}, \boldsymbol{u}_{4}\right)$ da imagem do ponto alvo.

Os neurônios da rede estão dispostos em um arranjo tridimensional e têm uma relação 1:1 com subregiões do espaço de trabalho 3D do robô, ou seja, o arranjo 3D dos neurônios é uma representação discreta do espaço de trabalho. Cada neurônio $j$ no arranjo, além do vetor de pesos, tem um vetor de coordenadas das juntas $\theta_{j}=\left(\theta_{j 1}\right.$, $\left.\theta_{j 2}, \theta_{j 3}\right)$ e uma matriz Jacobiana $\mathbf{A}_{j}$ associada a ele.

O movimento neste sistema é dividido em duas etapas: um movimento inicial ou de aproximação e um movimento fino ou de ajuste. Na primeira etapa, a posição espacial observada $\mathbf{u}_{\text {alvo }}=\left[\mathbf{u}_{1}, \mathbf{u}_{2}, \mathbf{u}_{3}, \mathbf{u}_{4}\right]$ do objeto é fornecida à rede e esta seleciona $\mathrm{o}$ neurônio $s$ como vencedor porque seu vetor de pesos $\mathbf{w}_{s}$ está mais próximo de $\mathbf{u}_{\text {alvo }}$. Durante o movimento inicial, $\theta_{s}$ é fornecido ao robô que então realiza seu movimento usando a matriz Jacobiana $\mathbf{A}_{s}$ :

$$
\boldsymbol{\theta}_{i}=\boldsymbol{\theta}_{s}+\mathbf{A}_{s}\left(\mathbf{u}_{\text {alvo }}-\mathbf{w}_{s}\right)
$$

Este movimento leva o efetuador para uma posição na vizinhança do ponto alvo. As coordenadas do efetuador vistas pelas câmeras são chamadas, então, de $\boldsymbol{v}_{i}$. Para corrigir o erro devido à discretização do espaço de trabalho, é realizado um movimento adicional corretivo que depende da distância entre a posição observada pelas câmeras durante o movimento inicial $\boldsymbol{v}_{i}$ e o alvo no espaço $\mathbf{u}_{\text {alvo }}$ :

$$
\boldsymbol{\theta}_{f}=\boldsymbol{\theta}_{i}+\mathbf{A}_{s}\left(\mathbf{u}_{a l v o}-\mathbf{v}_{i}\right)
$$

As coordenadas (observadas pelas câmeras) resultantes deste movimento fino são chamadas de $\boldsymbol{v}_{f}$. Os pesos dos neurônios $j$ no arranjo 3D são ajustados de acordo com:

$$
\mathbf{w}_{j}(t+1)=\mathbf{w}_{j}(t)+\gamma(t) h_{i j}(t)\left[\mathbf{u}_{a l v o}-\mathbf{w}_{j}(t)\right]
$$

em que $\gamma(t)$ é a taxa de aprendizagem e $h_{i j}(t)$ é a função vizinhança. 
Neste algoritmo, tanto a matriz Jacobiana $\mathbf{A}_{j}$ quanto os ângulos das juntas são também adaptados de acordo com as seguintes equações:

$$
\begin{aligned}
& \boldsymbol{\theta}_{j}(t+1)=\boldsymbol{\theta}_{j}(t)+\boldsymbol{\gamma}^{\prime}(t) h_{j s}^{\prime}\left[\boldsymbol{\theta}^{*}-\boldsymbol{\theta}_{j}(t)\right] \\
& \mathbf{A}_{j}(t+1)=\mathbf{A}_{j}(t)+\boldsymbol{\gamma}^{\prime}(t) h_{j s}^{\prime}\left[\mathbf{A}^{*}-\mathbf{A}_{j}(t)\right]
\end{aligned}
$$

em que $h_{i j}(t)$ e $h_{i j}^{\prime}(t)$ são funções gaussianas que dependem da distância entre os neurônios $i$ e $j$ e com valor máximo em $i=j . \theta^{*}$ e $\mathbf{A}^{*}$ são estimativas melhoradas de $\theta_{s}$ e $\mathbf{A}_{s}$, respectivamente. Sendo calculadas de acordo com as equações que seguem:

$$
\begin{gathered}
\boldsymbol{\theta}^{*}=\boldsymbol{\theta}_{s}(t)+\mathbf{A}_{s}(t)\left(\mathbf{u}_{a l v o}-\mathbf{v}_{i}\right) \\
\mathbf{A}^{*}=\mathbf{A}_{s}(t)+\mathbf{A}_{s}(t)\left(\mathbf{u}-\mathbf{w}_{s}-\mathbf{v}_{f}+\mathbf{v}_{i}\right) \times \frac{\left(\mathbf{v}_{f}-\mathbf{v}_{i}\right)^{T}}{\left\|\mathbf{v}_{f}-\mathbf{v}_{i}\right\|^{2}} \\
=\mathbf{A}_{s}+\left(\Delta \boldsymbol{\theta}-\mathbf{A}_{s} \Delta \mathbf{v}\right) \times \frac{\Delta \mathbf{v}^{T}}{\|\Delta \mathbf{v}\|^{2}}
\end{gathered}
$$

$\mathrm{Na}$ Equação (49a), o erro final $\mathbf{u}_{\text {alvo }}-\mathbf{v}_{i}$ no espaço Cartesiano é convertido em um erro no espaço das juntas pela multiplicação por $\mathbf{A}_{s}$. Este erro é adicionado a $\theta_{s}(t)$ para formar a estimativa melhorada $\theta^{*}$. Na Equação (49b), $\Delta \mathbf{v}=\mathbf{v}_{f}-\mathbf{v}_{i}$ é a variação nas coordenadas vistas pelas câmeras e $\Delta \theta=\mathbf{A}_{s}\left(\mathbf{u}_{\text {alvo }}-\mathbf{w}_{s}\right)$ é variação correspondente nos ângulos das juntas durante o movimento fino. A Equação (49b) pode ser reconhecida como uma regra do tipo Widrow-Hoff de correção de erros para as matrizes Jacobianas $\mathbf{A}_{s}$.

Os autores relatam simulações em que depois de 6.000 iterações o sistema já apresenta um comportamento correto, e que depois de 30.000 passos de aprendizagem não existe mais desvios significativos.

Este modelo também foi implementado em um robô PUMA 560 [WALTER \& SCHULTEN, 1993] produzindo erros de posicionamento pequenos. Este modelo também foi capaz de se adaptar a mudanças bruscas em seus parâmetros geométricos como aumento de um dos elos do braço. 


\subsection{Geração de Trajetórias}

GIBET e MARTEAU (1994) propuseram um modelo auto-organizável para planejamento e controle de movimento de um braço robótico com vários graus de liberdade. Realimentação sensorial obtida do espaço de observação é usada para atualizar as variáveis de estado que controlam cada junta do movimento. O modelo automaticamente traduz comandos de alto nível (especificação do ponto inicial e da meta) em uma trajetória completa. Este é um problema inverso já que se tem que encontrar os parâmetros de controle de um sistema multidimensional de modo a alcançar uma determinada posição final desejada. A solução proposta pelos autores não tenta calcular a transformação inversa analiticamente. Tal solução utiliza uma função de energia que serve para caracterizar a evolução dinâmica do sistema em termos de sua minimização. Quando uma posição alvo é especificada, o sistema evolui para um novo estado de equilíbrio estável correspondente a minimização daquela função energia. $\mathrm{O}$ método proposto baseia-se em uma estratégia de otimização (gradiente descendente) de uma função quadrática do erro entre a posição desejada, $\mathbf{a}_{t}$, e a posição atual do braço, q:

$$
E\left(\mathbf{q}, \mathbf{a}_{t}\right)=\frac{1}{2} \cdot\left(M(\mathbf{q})-\mathbf{a}_{t}\right)^{T} \cdot\left(M(\mathbf{q})-\mathbf{a}_{t}\right)
$$

em que $M$ é a transformação que faz ligação entre o vetor de coordenadas de estado (ângulos) e o vetor de coordenadas observadas (posições espaciais), tal que:

$$
\mathbf{a}=M(\mathbf{q}) M
$$

na qual o vetor de estados q caracteriza o estado do sistema motor a qualquer instante. O gradiente descendente provê uma solução ao problema que é numericamente estável e eficiente computacionalmente. Os autores demonstraram que, no caso geral, os pontos de equilíbrio do modelo correspondem efetivamente às posições desejadas e que estas soluções são alcançadas assintóticamente. Portanto, os padrões de movimento não são explicitamente programados mas sim, propriedades emergentes de um sistema dinâmico restringido por leis físicas no espaço e no tempo. 
Dois modelos para movimentos de braços são apresentados. O primeiro descreve o braço com múltiplas juntas como um modelo geométrico: este modelo corresponde a um esquema de controle baseado em posição (position-based control scheme). $\mathrm{O}$ segundo inclui um modelo mecânico do braço articulado na malha de controle, cada junta sendo controlada dinamicamente por forças acionadoras. Este segundo modelo permite que a interação entre variáveis biomecânicas do braço e variáveis do ambiente seja levada em conta, tal que o impacto do braço em um objeto físico pode ser simulado. Em ambos os casos, a plausibilidade do método é demonstrada via simulações usando um braço com quatro graus de liberdade.

A abordagem proposta contrasta com métodos anteriores de controle adaptativo pelo fato de estar mais voltada para a explicação de aspectos fisiológicos de controle motor em humanos do que em robôs industriais. Em particular, o mecanismo de controle não mantém a resposta dinâmica do dispositivo físico em concordância com alguma trajetória desejada pré-especificada. Mais sim, são usadas as coordenadas motoras e sensoriais para modificar de forma adaptativa os parâmetros de controle de um braço mecânico.

A originalidade do modelo está na introdução na malha de realimentação de uma função não-linear que dá margem ao surgimento de comportamentos naturais. Ao usar resultados psicomotores, os autores mostraram que tal modelo é capaz de gerar automaticamente gestos que se assemelham com movimentos humanos.

\subsection{Resumo do Capítulo}

O objetivo principal deste capítulo é apresentar uma revisão bibliográfica de modelos não-supervisionados de redes neurais artificiais para processamento de seqüências temporais e sua aplicação em robótica. Os tipos de estratégias mais comumente encontrados na literatura sobre robótica podem ser classificadas em aprendizagem de seqüências do tipo percepção-ação e de seqüências do tipo trajetórias de robôs. No primeiro caso busca-se encontrar ações adequadas a estímulos sensoriais de entrada. A evolução temporal destes pares percepção-ação formam uma seqüência do tipo percepção-ação. No segundo caso, o sistema (robô) recebe informação sobre a sua situação atual (por exemplo, posição espacial e os correspondentes ângulos das juntas) e determina a próxima situação. No primeiro caso, o robô geralmente é levado 
a percorrer o seu espaço de trabalho em busca de uma representação (modelo) adequada do mundo. No segundo caso, o robô em geral é levado a repetir uma dada trajetória inicialmente pré-determinada (rastreamento).

Os trabalhos relevantes foram apresentados de acordo com a classificação dada às trajetórias no parágrafo anterior. Apesar do interesse primeiro desta dissertação envolver robôs manipuladores, discutiu-se também modelos usados para controle de robôs móveis. A intenção foi colher alguns conceitos que teriam importância para a proposição de um modelo não-supervisionado para aprendizagem de trajetórias de robôs. Os modelos descritos neste capítulo podem ser divididos em:

(i) Redes que aprendem sequiências percepção-ação (Seção 5.2);

(ii) Redes que aprendem trajetórias de robôs (Seção 5.3);

(iii) Redes que aprendem a cinemática inversa (Seção 5.4);

(iv) Redes que geram trajetórias (Seção 5.5).

Além disso, é comum para os modelos (i) e (ii) que a rede funcione fornecendo sempre a próxima ação a ser realizada ou próximo estado da trajetória. Este comportamento é particularmente útil para desfazer ambigüidades e, portanto, será uma propriedade a ser incorporada no modelo a ser proposto no Capítulo 6.

Apesar desta diversidade de métodos, o número de modelos não-supervisionados com aplicação em robótica é pequeno quando comparado a, por exemplo, modelos supervisionados. Mais ainda, algumas questões importantes para o funcionamento de sistemas de robôs não são, ou não foram, abordadas de maneira adequada pelos modelos apresentados neste capítulo. Por exemplo, a incapacidade destes em processar múltiplas trajetórias que possuam pontos em comum. Apesar deste tipo de situação ser comum em ambientes industriais [CHEN et al., 1996], poucos são os modelos de RNAs que abordam o assunto. Portanto, por ser uma propriedade de extrema relevância em aplicações práticas é desejável que o modelo a ser proposto nesta dissertação seja capaz de lidar com trajetórias deste tipo.

Outra limitação de alguns dos modelos mostrados neste capítulo [BUGMANN \& ALTHÖFER, 1995; BUGMANN et al., 1998] está no fato das transições de estados (codificadas nos pesos sinápticos das duas camadas) serem ajustados por procedimentos ad hoc. O que se almeja é que tais transições, assim como a ordem 
temporal das componentes da seqüência, sejam aprendidas através de um processo de auto-organização.

No próximo capítulo serão apresentados algoritmos neurais não-supervisionados para aprendizagem de trajetórias de robôs. No caso, o manipulador PUMA 560 devido a sua grande utilização, tanto em ambiente industrial quanto em ambientes acadêmicos. 


\section{Capítulo 6}

\section{Modelos com Aprendizagem Competitiva e Hebbiana Temporal para Processamento de Seqüências Temporais}

Neste capítulo será proposta uma nova arquitetura de RNAs com aprendizagem não-supervisionada para processamento de padrões temporais. O objetivo final é desenvolver um modelo que tenha a habilidade de aprender, recuperar e gerar de forma precisa e sem ambigüidades sequiências temporais na forma de trajetórias de robôs manipuladores. Além disso, o modelo deve ser capaz de reproduzir as trajetórias aprendidas mesmo quando ocorrem perdas de neurônios e na presença de ruído na leitura sensorial de entrada.

As propriedades e mecanismos desejados serão incorporados ao modelo no decorrer do capítulo visando uma apresentação didática e progressiva do algoritmo. Assim, ao final do capítulo se terá um modelo com todas as características descritas no parágrafo anterior.

O capítulo está organizado como segue. Na Seção 6.1, define-se o problema da modelagem e propriedades desejáveis para o modelo a ser proposto. Na Seção 6.2 é feita uma apresentação mais detalhada do problema a ser modelado, bem como do funcionamento da rede. A Seção 6.3 introduz formalmente o modelo, sua arquitetura e dinâmica. Na Seção 6.4, unidades de contexto são incorporadas ao modelo visando eliminar ambigüidades na codificação de sequiências com estados em comum. A Seção 6.5 apresenta mecanismos que tornam o modelo tolerante à falhas. O capítulo é concluído na Seção 6.6 .

\subsection{O Problema da Modelagem}

Modelagem é um problema no qual se tenta inferir causas a partir das observações dos efeitos que elas produzem. Este procedimento é muitas vezes conhecido como problema inverso, diferente do problema direto que intenciona determinar efeitos a partir de causas [HARPUR, 1997]. 
Problemas diretos são, em geral, mais fáceis de tratar. Normalmente, em um sistema determinístico, existe um mapeamento simples de qualquer conjunto de causas para os seus efeitos. Esta unicidade é uma condição chave para um problema bem colocado (well-posed) [HADAMARD, 1923]. Dificuldades surgem apenas quando se decide como fazer aproximações simplificadoras para o mapeamento e como lidar com conhecimento incompleto das causas.

Problemas inversos, ao contrário, são tipicamente mal colocados (ill-posed) [HADAMARD, 1923]. Isto é, em geral existem muitas possíveis explicações para uma observação particular, ou seja, a solução não é de forma alguma única. Em tais circunstâncias, torna-se necessário saber quais explicações são as mais prováveis, introduzindo desta forma a complexidade extra de um elemento probabilístico que não estava presente no problema direto equivalente.

A robótica é um campo de estudos onde problemas diretos e inversos são comuns. Por exemplo, a cinemática direta é um exemplo de problema bem colocado: usa-se a descrição da configuração das juntas do manipulador para se calcular a posição espacial e a orientação resultante do efetuador do robô. O problema mal colocado correspondente é cinemática inversa, onde se pega a posição e a orientação do efetuador do robô e tenta se determinar o conjunto de ângulos das juntas que resultam naquela posição e orientação. Para este caso, problemas como a existência e unicidade de uma solução surgem freqüentemente.

\subsubsection{Propriedades Desejáveis em um Bom Modelo}

Visto que se deseja avaliar modelos de redes neurais, necessita-se especificar as propriedades que fazem um modelo melhor do que outro. Dentre vários, pode se identificar alguns fatores que venham a ser úteis [HARPUR, 1997]:

Completeza (Completeness): Se o modelo é completo ou sem perdas, então todos os aspectos da entrada são representados, permitindo completa reconstrução do original a partir da representação gerada pelo modelo. Quando isto não é possível, o modelo é dito incompleto ou com perdas. Isto pode ser causado pelo fato do modelo ser insuficiente para representar completamente a entrada, ou por ruído ou imprecisão no sistema de processamento. Este último caso não precisa ser necessariamente um 
problema se a informação perdida não é útil em estágios subsequentes de processamento, por exemplo, quando é devido a ruído no sensor das entradas.

Simplicidade (Simplicity): Podem existir vários modelos completos ou próximos de sê-lo. Em tais circunstâncias, o princípio da lâmina de Occam [WINSTON, 1992] diz para escolher o mais simples. Ao determinar o que se quer dizer com a simplicidade de um modelo, existem dois fatores diferentes e conflitantes a considerar: a complexidade da representação, relacionada à maneira de codificar as variáveis e parâmetros do modelo e a complexidade do modelo em si, relacionada à quantidade de processamento requerida para suas operações. Um equilíbrio entre estes dois fatores vai depender da quantidade relativa de largura de banda de transmissão versus poder de processamento disponível no sistema. Existe também um compromisso entre simplicidade e completeza: algumas vezes deseja-se sacrificar a habilidade em representar eventos completamente para manter a representação simples. Esta é a abordagem adotada pelos algoritmos de compressão tipo incompletos.

Conformidade (Conformity): Bons modelos mantém correspondência com a realidade. Embora pareça difícil especificar exatamente como o modelo deve se adequar à realidade, é possível medir seu sucesso nesta tarefa pela sua capacidade de generalização, i.e., habilidade para responder a estímulos novos oriundos do mesmo ambiente. Um sistema que meramente armazenou todos os dados passados é provável que tenha um mal desempenho a este respeito [SALOMON, 1996].

Adequação ao Propósito (Fitness for Purpose): Um modelo é tipicamente apenas um meio para se chegar a um fim, uma base para descrever o mundo ou decidir o curso de uma ação. Consequentemente, seu valor deve ser determinado em grande parte por sua utilidade em realizar o objetivo principal a que se propõe. Codificar uma imagem em termos de bordas, por exemplo, pode ser suficiente se o sistema como um todo é requisitado a encontrar os limites de objetos, mas não é uma boa escolha se o objetivo global é reconhecer texturas diferentes. Esta idéia se aplica mesmo quando o modelo é completo. 


\subsection{Proposição de Modelos para Processamento Temporal}

Tomando por base as definições apresentadas nos Capítulo 4 e 5, dois ingredientes são exigidos para uma reprodução autônoma de uma sequiência temporal por meio de uma RNA. Primeiro, para o propósito de aprendizagem, um mecanismo deve ser implementado de forma a extrair e armazenar mudanças temporais (transições de estado) e segundo, para o propósito de (re)produção, dinâmicas de ativações e de saídas devem ser definidas de modo a reproduzir seqüências previamente observadas e gerar seqüências não treinadas.

No caso desta dissertação, os mecanismos citados no parágrafo anterior são implementados através de aprendizagem competitiva e aprendizagem hebbiana. Primeiro, os neurônios da rede "competem" pelo direito de representar um dado padrão de entrada. Determinado o vencedor, ele tem seus pesos de alimentação direta ajustados de modo a se parecer com a entrada. Portanto, estes pesos são responsáveis pela codificação da informação espacial contida na sequiência.

As conexões laterais são responsáveis pela modelagem da informação temporal da sequiência, estabelecendo associações entre os padrões de ativação dos neurônios em instantes de tempo consecutivos. Melhor explicando: como somente uma unidade permanecerá ativa por iteração de treinamento, ao se estabelecer correlações entre as ativações do instante atual com as ativações do instante anterior pode-se indicar a ordem de ocorrência dos estados da trajetória. A idéia é que, ao ser ativado, este neurônio "dispare" o neurônio que codificou o próximo estado da rede. Portanto, a rede indica na sua saída o estado atual na entrada (neurônio menos ativo) e o próximo estado na seqüência (neurônio mais ativo).

Assim, com estes conceitos em mente pode-se definir em detalhes o problema a ser modelado pela rede neural.

\subsubsection{Detalhando o Problema a Ser Modelado}

O que se deseja é aprender e reproduzir de forma precisa e sem ambigüidades sequiências temporais na forma de trajetórias de um braço de robô, conhecendo de antemão os estados iniciais e finais das trajetórias. A aprendizagem deve ser resultado 
de um processo de auto-organização, na qual a informação temporal é codificada pela rede sem a ajuda de um "professor".

A precisão refere-se à habilidade do modelo em reproduzir a seqüência aprendida com baixo erro. Isto é particularmente importante em tarefas que exigem precisão no posicionamento do braço. A expressão "sem ambigüidades" diz respeito a certas situações que podem levar o braço mecânico a fazer opções de percurso errôneas durante a reprodução das trajetórias. Estas são as características mínimas exigidas para a proposição do modelo nesta dissertação:

- Processo de aprendizagem simples e rápido: em casos que envolvam aprendizagem em tempo real estas características desempenham papel crucial.

- Baixo custo computacional: esta característica também é de grande importância para implementações em tempo real dos modelos.

- Capacidade de aprender problemas inversos: a realização de trajetórias envolve a resolução da cinemática inversa e da dinâmica inversa que devem ser estabelecidas juntamente com posições espaciais.

- Capacidade de geração de estados na seqüiência: o modelo deve ser capaz de produzir o próximo estado de uma trajetória.

- Aprendizagem de múltiplas trajetórias: o modelo deve ser capaz de aprender várias trajetórias de maneira independente e sem interferência entre elas

- Tolerância à falhas: uma seqüência temporal deve ainda ser reproduzida mesmo na presença de perdas de neurônios, por exemplo, por falha no hardware em uma implantação real do modelo.

- Generalidade: o modelo deve ser potencialmente capaz de funcionar em outras tarefas de processamento temporal, tais como controle de robôs móveis, reconhecimento de sinais de voz e processamento da linguagem natural.

Com estas características em mente, a evolução do modelo proposto é apresentada nas seções que seguem. Tal modelo utilizará as propriedades e características referentes a modelos de RNAs não-supervisionadas discutidas nos Capítulos 3, 4 e 5. 


\subsection{Aprendendo Sequiências Temporais: Categorização e Associação Temporal (CAT)}

O modelo que segue deve manter algumas propriedades comuns de RNA com aprendizagem não-supervisionada como, por exemplo, competição e correlação. Além disso, deve incorporar mecanismos que possibilitem o tratamento de informação temporal. A arquitetura para este modelo está mostrada na Figura 20. Nesta figura podemos perceber os seguintes componentes:

1. Unidades de entrada: são responsáveis pela apresentação dos estímulos de entrada e sua propagação para a camada de saída. $\mathrm{O}$ vetor de entrada será representado por $\mathbf{x}(t)=\left(x_{1}(t), \ldots, x_{n}(t)\right)^{\mathrm{T}}$, em que $n$ é o número de unidades na camada de entrada, $t$ refere-se ao instante de iteração. As principais informações que estão representadas no vetor $\mathbf{x}(t)$ são os ângulos das juntas $\left(\theta_{1}, \theta_{2}, \ldots, \theta_{\mathrm{NGL}}\right)$ e os torques aplicados nas mesmas juntas $\left(\tau_{1}, \tau_{2}, \ldots, \tau_{\mathrm{NGL}}\right)$ para uma dada posição espacial $(x, y, z)$ no instante de amostragem $t$. NGL é o número de graus de liberdade do manipulador sendo utilizado. Em um sistema real estas informações são obtidas a partir de leituras sensoriais. $\mathrm{O}$ vetor $\mathbf{x}$ pode conter também informação de contexto.

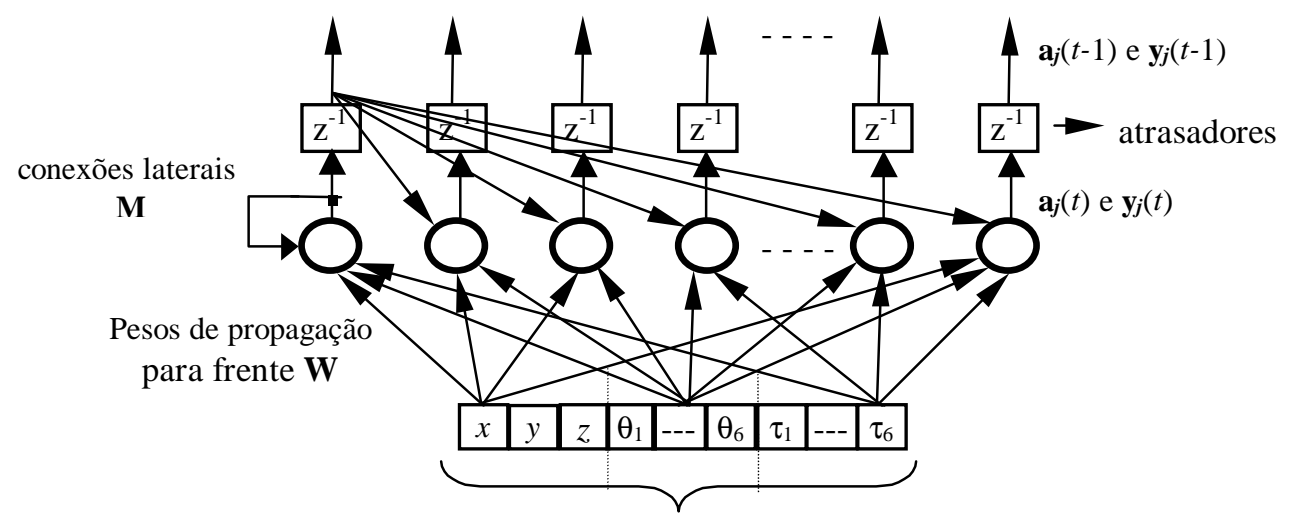

Estímulo sensorial

Figura 20: Arquitetura do modelo neural para processamento de trajetórias de robô. Apenas algumas conexões são mostradas para efeito de simplificação.

2. Unidades de saída: são responsáveis pelo processamento da informação propriamente dita, ou seja, pelo processamento da entrada. Nesta camada, os neurônios inicialmente competem entre si pelo direito de responder ao estímulo de 
entrada e depois propagam esta ativação para determinar o próximo estado da seqüência. Associada a cada neurônio da camada de saída existe uma ativação $a_{j}(t)$, e uma saída $y_{j}(t), j=1,2, \ldots, m$. Apenas uma ativação $a_{j}(t)$ permanece ativa por competição indicando qual neurônio codifica a entrada atual. As saídas $y_{j}(t)$ são calculadas após a determinação da ativação e indicam os neurônios que codificam o padrão de entrada atualmente sendo apresentado à rede, bem como o neurônio que codifica o próximo estado da trajetória.

3. Pesos sinápticos de propagação direta ou intercamadas: estas conexões, representadas por $\mathbf{w}_{j}(t)=\left(w_{j 1}(t), w_{j 2}(t), \ldots, w_{j n}(t)\right)^{\mathrm{T}}$, mapeam o espaço de entrada no espaço de saída. Este mapeamento é obtido por um processo de treinamento competitivo e objetiva classificar os padrões de entrada individualmentes.

4. Atrasadores: com a intenção de manter diferentes padrões de ativação por um certo período de tempo faz-se necessário um modelo de memória de curto prazo. O modelo adotado aqui é de manter atrasadores (time-delays) nas linhas de saída dos neurônios da camada competitiva. Para o presente modelo utiliza-se apenas um atrasador por neurônio de saída.

\section{Pesos sinápticos intracamada (autoconexões e conexões laterais): estas} conexões, representadas por $\mathbf{m}_{j}(t)=\left(m_{j 1}(t), m_{j 2}(t), \ldots, m_{j k}(t)\right)^{\mathrm{T}}$, são responsáveis pela codificação da ordem temporal dos vetores que compõem a seqüência de entrada.

A dinâmica do modelo é descrita sucintamente a seguir. Ao chegar um vetor de entrada, a rede deve operar ativando na saída o neurônio que codifica esta entrada e o neurônio que codifica o próximo ponto da seqüência. Para que se possa diferenciá-los, a saída do neurônio que codificar o estado atual é feita menor do que a saída do neurônio que codificar o próximo estado. O ajuste destas conexões será feito através de uma regra hebbiana temporal. Neste caso, padrões de ativação em instantes de tempo consecutivos são correlacionados, determinando a intensidade das conexões laterais. Uma autoconexão em cada neurônio de saída servirá como elemento atenuador (ou amortecedor) da ativação deste neurônio, garantido que a ativação do neurônio que codifica o próximo estado seja maior.

Um dos aspectos cruciais na reprodução de seqüências na forma de trajetórias de robôs, está na necessidade de manter representações precisas das seqüências consideradas. Exemplificando, se a trajetória contém $N_{p}$ pontos, então sua reprodução 
deve necessariamente envolver os $N_{p}$ pontos originais. Isto é importante porque um dos objetivos do modelo é realizar rastreamento de trajetórias. Mais ainda, se um ponto ocorre mais de uma vez na seqüência, a rede deve ser capaz de reproduzi-lo nas posições corretas. Tal situação pode ocorrer quando o braço é levado a seguir uma trajetória que passa pelo mesmo ponto mais de uma vez. Por último, existe o caso de diferentes trajetórias possuírem um ou mais estados em comum. Este caso é considerado um pouco mais difícil que o anterior porque envolve várias trajetórias, dando margem ao aparecimento de ambigüidades na determinação do próximo ponto a ser alcançado pelo braço.

\subsubsection{Codificando Padrões Temporais: Competição}

Redes competitivas tendem a agrupar padrões semelhantes ou com alto grau de superposição em uma mesma classe representada por um único neurônio. E como será visto no Capítulo 7, as trajetórias consideradas para estudo tem estados bem semelhantes e em alguns casos com superposição. A aplicação de uma rede competitiva a tais trajetórias fica inviável, pois a natureza da tarefa exige que todos os estados sejam reproduzidos durante uma etapa de funcionamento da rede.

Para permitir que os estados das trajetórias sejam codificados por neurônios

diferentes, definiu-se um mecanismo que foi chamado de fator de exclusão que é incorporado ao processo de determinação do neurônio vencedor por distância euclideana mostrada na Equação (7). O fator de exclusão é definido de uma forma geral como segue:

$$
f_{j}(t)=\alpha \cdot a_{j}(t)+1, \quad \text { para todo } j=1,2, \ldots, m
$$

na qual $\alpha$ > 0 é um número grande suficiente para tirar o neurônio $j$ de competições subsequentes e $a_{j}(t)$ é a ativação do neurônio de saída $j$ no instante $t$. Este fator é incluído no processo de escolha do vencedor da seguinte forma:

$$
v(t)=\arg \min _{j}\left\{f_{j}(t) \cdot\left\|\mathbf{x}(t)-\mathbf{w}_{j}(t)\right\|\right\}
$$

que tem o mesmo significado que

$$
f_{v(t)}(t) \cdot\left\|\mathbf{x}(t)-\mathbf{w}_{v(t)}(t)\right\|=\min _{j}\left\{f_{j}(t) \cdot\left\|\mathbf{x}(t)-\mathbf{w}_{j}(t)\right\|\right\}
$$


em que $v(t)$ é o índice do neurônio vencedor no instante $t$. Nota-se que um valor alto para $f_{j}(t)$ exclui o neurônio $v(t)$ das próximas competições por estímulos de entrada, garantindo desta forma que todos os padrões da seqüência sejam codificados por neurônios diferentes. Além disso, este mecanismo resolve os casos em que um padrão ocorre várias vezes na seqüência e aquele em que trajetórias diferentes compartilham pontos em comum. Neste último, toda ocorrência de um padrão é aprendida por um neurônio diferente, ou seja, existirão vários neurônios codificando o mesmo estado se este ocorrer em sequiências distintas.

Uma vez que o neurônio vencedor esteja determinado, sua ativação $a_{v}(t)$ é feita igual a 1, enquanto a dos outros neurônios é feita igual 0 , ou seja:

$$
a_{j}(t)= \begin{cases}1, & \text { se } j=v(t) \\ 0, & \text { se } j \neq v(t)\end{cases}
$$

A Equação (54) diz que apenas um neurônio terá sua ativação não nula: o vencedor da competição. De posse dessa equação, pode-se perceber seu efeito na exclusão do vencedor das competições subsequentes. Ou seja, o valor do fator de exclusão para o vencedor e para os "perdedores" da atual competição será:

$$
\begin{gathered}
f_{v}(t)=\alpha+1 \approx \alpha>>1 \\
f_{j}(t)=1, \quad \text { para } j \neq v(t)
\end{gathered}
$$

Esse valor será usado, na próxima competição, para excluir o vencedor atual da competição e para permitir que os neurônios restantes possam competir em função de suas distâncias em relação ao próximo padrão da sequiência.

O passo seguinte é armazenar o padrão de entrada na rede. Este padrão será incorporado à memória de longa duração (representada pelos pesos sinápticos de alimentação direta) através da seguinte regra de aprendizagem:

$$
\mathbf{w}_{j}(t+1)=\mathbf{w}_{j}(t)+\delta(t) a_{j}(t)\left[\mathbf{x}(t)-\mathbf{w}_{j}(t)\right]
$$

na qual $\delta(\approx 1)$ é o passo de aprendizagem. O estímulo de entrada no instante $t$ é representado por $\mathbf{x}(t)$. Note que apenas o vencedor aprende, já que só ele tem ativação diferente de zero. Portanto, o efeito resultante da aplicação da Equação (57) é a cópia 
do vetor de entrada $\mathbf{x}$ no vetor de pesos $\mathbf{w}_{v}$ associado ao neurônio vencedor. A taxa de aprendizagem $\delta$ é que determinará quão mais parecido o vetor $\mathbf{w}_{v}$ será da entrada $\mathbf{x}$.

Através do uso das Equações (52) - (57), a codificação de todos os padrões pertencentes à seqüência de entrada está garantida. Contudo, resta reproduzi-los na ordem correta. Para tanto, é necessário que a rede aprenda também a ordem temporal de ocorrência dos padrões armazenados pela rede. No presente trabalho, propõe-se que tal ordem seja codificada nas conexões intracamada e pelo valor da saída dos neurônios.

\subsubsection{Modelando a Ordem Temporal por Conexões Sinápticas Intracamada: Associação Temporal}

Uma característica fundamental de modelos de RNAs competitivas é a existência de apenas um neurônio vencedor por competição. Ou igualmente falando, tem-se apenas uma unidade ativa por iteração. Uma forma possível de se estabelecer vínculos entre padrões temporais consecutivos é estabelecendo conexões entre os neurônios vencedores que os codificaram naqueles instantes de tempo. Assim, se no instante $t-1 \mathrm{o}$ neurônio 2 venceu a competição para o padrão de entrada $\mathbf{x}(t-1)$ e no instante $t$, o vencedor para o padrão $\mathbf{x}(t)$ foi o neurônio 5, então uma conexão partindo do neurônio 2 em direção ao 5 é fortalecida.

Como os neurônios pertencem a uma mesma camada, estas ligações são chamadas de conexões intracamada. O neurônio que codifica o padrão de entrada atualmente na entrada terá a sua saída com menor valor do que aquela para o neurônio que codifica o próximo estado. A idéia é fazer com que, durante o funcionamento da

rede, as conexões intracamada permitam a difusão da ativação do neurônio que responde à entrada atual para aquele que codifica o próximo estado da trajetória.

Uma forma de quantificar a idéia proposta no parágrafo anterior é através das regras de aprendizagem descritas a seguir:

$$
\begin{aligned}
& m_{j j}(t+1)=m_{j j}(t)+\beta a_{j}(t) \\
& m_{j r}(t+1)=m_{j r}(t)+\lambda a_{j}(t) a_{r}(t-1)
\end{aligned}
$$


nas quais $\beta, \lambda$ são as taxas de aprendizagem definidas de tal modo que $\beta<\lambda$. Esta restrição garante que a saída do neurônio que codifica o estado atual seja menor que a saída do neurônio que responde pelo próximo estado da trajetória.

Segundo a Equação (58a), um neurônio terá sua autoconexão incrementada de $\beta$ quando ele for considerado vencedor, pois terá sua ativação $a_{j}$ igual a 1 .

A Equação (58b) só altera o valor do peso sináptico $w_{j r}$ quando $a_{j}(t) \neq 0$ e $a_{r}(t-1)$ f0. Como se tem apenas um vencedor por competição, então as conexões laterais são estabelecidas entre os vencedores de competições consecutivas, sempre do vencedor anterior para o vencedor atual. É desta forma que a ordem temporal é incorporada ao modelo. Assim, a Equação (58b) é uma regra do tipo hebbiana, pois se está estabelecendo correlações entre ativações de neurônios. Como estão envolvidas ativações em instantes de tempo diferentes, tem-se uma regra hebbiana para associação temporal, ou simplesmente regra hebbiana temporal.

A saída $y_{j}(t)$ dos neurônios da camada competitiva pode, então, ser determinada pela seguinte equação:

$$
y_{j}(t)=g\left(\sum_{k=1}^{m} m_{j k}(t) a_{k}(t)\right)
$$

na qual para o presente trabalho, adotou-se $g(u)=u$. É importante notar que qualquer função crescente poderia ser utilizada. A razão da escolha de uma função linear reside principalmente na simplificação de uma possível análise matemática do modelo em desenvolvimentos futuros. No caso de implementação em um sistema real, a escolha da função $g($.) deve observar os limites de funcionamento dos atuadores do sistema de controle.

Um outro aspecto importante que deve ser observado está relacionado com as escalas de tempo envolvidas na dinâmica do modelo por iteração de treinamento ou funcionamento da rede. Isto é, uma nova entrada só pode ser amostrada (observada) pela rede após a determinação: (1) do neurônio vencedor, (2) das ativações $a_{j}$ e (3) das saídas $y_{j}$ para a iteração (competição) referente ao instante $t$. Portanto, em uma implementação em um sistema real de controle, a varredura sensorial para formação de padrões de entrada deve ocorrer em uma escala de tempo maior ou igual àquela necessária para a resposta da rede. 


\subsubsection{Resumo do Algoritmo do Modelo CAT}

Os passos do algoritmo de aprendizagem e reprodução da trajetória são listados a seguir para uma melhor compreensão.

(1) Inicialização da rede $(t=0)$ :

$$
\begin{gathered}
w_{j i}(0)=\text { número aleatório entre } 0 \text { e } 1, \text { para } i=1, \ldots, n \text { e } j=1, \ldots, m \\
m_{j k}(0)=0, \text { para } k=1, \ldots, m \text { e } j=1, \ldots, m . \\
a_{j}(0)=y_{j}(0)=0, \text { para } j=1, \ldots, m . \\
f_{j}(0)=1, \text { para } j=1, \ldots, m
\end{gathered}
$$

(2) Leitura dos dados sensoriais de entrada. Faz-se também $t=t+1$.

(3) Determinação do neurônio vencedor de acordo com a Equação (53a).

(4) Determinação das ativações de acordo com a Equação (54).

(5) Atualização do fator de exclusão definido pela Equação (52).

(6) Ajuste dos pesos intercamadas de acordo com a Equação (57).

(7) Ajuste das conexões intracamada segundo as Equações (58a) e (58b).

(8) Determinação das saídas dos neurônios de acordo com a Equação (59).

(9) Repetir passos (2)-(8) até o fim da trajetória.

Os passos (6) e (7) são pulados durante a etapa de funcionamento da rede. Além disso, é importante ressaltar que cada trajetória só é apresentada uma única vez. Esta característica é uma vantagem considerável do presente modelo em relação a outros que utilizam aprendizagem supervisionada [ARAÚJO \& D’ARBO, 1998].

As próximas seções discutem a adição de características ao modelo CAT que permitem ao modelo resolver ambigüidades, ser tolerante à falhas neuronais e generalizar. 


\subsection{Adicionando Contexto ao Modelo}

O modelo proposto ao longo da Seção 6.3 é capaz de armazenar seqüências temporais e reproduzi-las na ordem correta e de forma antecipatória: dada uma entrada, a rede responde indicando o próximo estado ou vetor da sequiência. Mais ainda, este modelo é capaz de aprender várias sequiências desde de que elas não possuam pontos em comum. Entretanto, muitas situações em Robótica envolvem a execução de trajetórias que se cruzam em vários pontos [ARAÚJO \& D’ ARBO, 1998; ARAÚJO \& VIEIRA, 1998], ou passam várias vezes pelo mesmo ponto [ALTHÖFER \& BUGMANN, 1998]. Nestes casos, o modelo discutido anteriormente não é adequado. Portanto, como fazer com que a rede neural reproduza sem ambigüidades a seqüência correta dado que ela possui pontos em comum com outra(s)? A resposta está na inclusão de informação de contexto na arquitetura proposta para o modelo CAT (Figura 21).

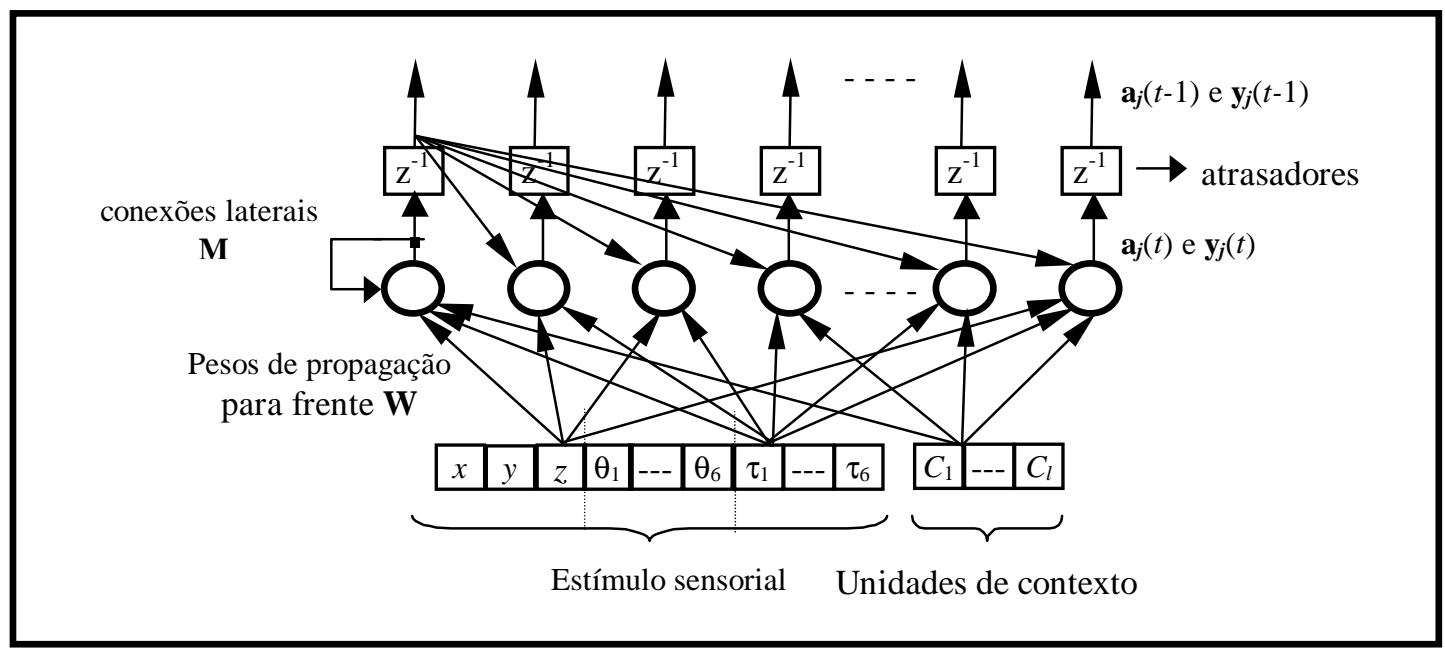

Figura 21: Arquitetura modificada do modelo CAT para inclusão de informação de contexto. Esta é necessária para resolver qualquer ambiguiidade que venha a surgir quando trajetórias se cruzam em um ou mais pontos.

Percebe-se que, em geral, no problema de rastreamento de trajetórias ou posicionamento do braço do robô se tem conhecimento dos estados inicial e final do braço. Assim, pode-se utilizar uma destas informações para diferenciar estados comuns a várias trajetórias. A entrada da rede passa a consistir agora de duas partes: (1) leitura sensorial dos estados da trajetória e (2) informação de contexto. Esta última é fixa e permanece durante as fases de aprendizagem e reprodução das trajetórias, mudando apenas quando outra trajetória passa a ser aprendida. 


\subsection{Tornando o Modelo CAT Tolerante à Falhas}

O algoritmo para o modelo proposto na Seção 6.3 funciona perfeitamente em um ambiente idealizado, onde foram feitas as seguintes suposições: (i) as leituras dos sensores são livres de ruído; e (ii) a perda de um neurônio (por falha do hardware, por exemplo) não está cogitada em hipótese nenhuma. A falha e/ou perda de um neurônio, por exemplo, implica na incapacidade de recuperar uma trajetória inteira. Situação esta extremamente indesejável.

Com o objetivo de torná-lo mais adequado a situações reais de trabalho, algumas modificações adicionais são sugeridas. A idéia é permitir que mais de um neurônio codifique um dado vetor da sequiência. Isto é possível, se o processo de competição for flexibilizado de modo a permitir que mais de um neurônio possa ser usado para codificar cada padrão de entrada. Duas formas de se flexibilizar o processo de competição são descritos a seguir. O primeiro deles é baseado no conceito de vizinhança topológica introduzido por KOHONEN (1990, 1997). Entretanto, a vizinhança não decresce com o passar do tempo permanecendo fixa durante toda a aprendizagem da seqüência. $O$ segundo é baseado no conceito de proximidade do vetor de pesos com o vetor de entrada [MARTINETZ \& SCHULTEN, 1991].

\subsubsection{Incorporando o Conceito de Redundância por Vizinhança}

A arquitetura para este modelo é aquela mostrada na Figura 21. Como o modelo guarda muitas semelhanças com aquele proposto na Seção 6.3.3, apenas os passos do algoritmo que diferem serão mostrados. Onde for preciso, serão tecidos comentários adicionais com o objetivo de elucidar um ou outro aspecto importante do algoritmo.

A única modificação no algoritmo ocorre no passo (4). Neste caso, os neurônios localizados à esquerda e à direita do neurônio vencedor, chamados de neurônios vizinhos, também têm seus pesos ajustados na direção da entrada, porém em uma menor proporção. As ativações passam a ser determinadas pela seguinte fórmula:

$$
a_{j}(t)=\left\{\begin{array}{cl}
\exp \left[\left(-|v(t)-j|^{2} / 2 \rho^{2}\right)\right] & \text { para } j \in \mathbf{V I Z}_{v(t)} \\
0 & \text { para } j \notin \mathbf{V I Z} \mathbf{I Z}_{v(t)}
\end{array}\right.
$$


na qual $v(t)$ é o índice do vencedor, $\mathbf{V I Z} \mathbf{v}_{v(t)}=[v(t)-\mathrm{L}, v(t)+\mathrm{L}]$ representa a vizinhança do neurônio vencedor da competição atual e L é a largura da vizinhança. A largura da exponencial é definida por $\rho$. Outras formas de se calcular a ativação podem ser igualmente utilizadas. A única restrição é que apenas o neurônio vencedor e seus vizinhos sejam ativados. O restante do algoritmo permanece igual.

A idéia continua sendo a mesma, incluindo agora a vizinhança: estabelecer conexões que partem do neurônio vencedor da competição anterior e sua vizinhança em direção ao neurônio vencedor da competição atual e a sua vizinhança.

\subsubsection{Incorporando o Conceito de Redundância por Proximidade}

Neste algoritmo, os neurônios de saída são ordenados com base na sua proximidade em relação ao vetor de entrada. A idéia é semelhante àquela do mecanismo da seção anterior: conexões laterais são estabelecidas entre os $k$ neurônios mais próximos à entrada (ou $k$ primeiros vencedores) na competição anterior e os $k$ neurônios vencedores da competição atual. A motivação é a mesma das modificações anteriores: prover a rede de mecanismos que a tornem menos susceptível a erros, seja pela presença de ruído nas informações sensoriais, ou por falha de neurônios na camada de saída.

Neste algoritmo, o grau de vizinhança é dado pelo grau de semelhança com a entrada medida por distância euclideana. Para cada vetor de entrada, ordena-se a sequiência $\left(\mu_{1}, \mu_{2}, \ldots, \mu_{k}\right), k<m$, de índices dos neurônios de saída por ordem crescente de suas distâncias com relação ao vetor de entrada $\mathbf{x}(t)$ tal que:

$$
\begin{aligned}
f_{\mu_{1}}(t)\left\|\mathbf{x}(t)-\mathbf{w}_{\mu_{1}}(t)\right\|<f_{\mu_{2}}(t)\left\|\mathbf{x}(t)-\mathbf{w}_{\mu_{2}}(t)\right\| & <\cdots \\
\cdots<f_{\mu_{k}}(t)\left\|\mathbf{x}(t)-\mathbf{w}_{\mu_{k}}(t)\right\| & <\cdots<f_{\mu_{m}}(t)\left\|\mathbf{x}(t)-\mathbf{w}_{\mu_{m}}(t)\right\|
\end{aligned}
$$

em que $\mu_{1}(t)$ é o índice do neurônio vencedor (aquele mais semelhante à entrada) da competição atual em $t, \mu_{2}(t)$ é o índice do segundo mais semelhante à entrada da competição atual em $t$, e assim por diante; $k$ é indica o número de neurônios usados para codificar cada padrão de entrada por competição. É esta escolha de mais de um 
neurônio por estado de entrada que evita a perda catastrófica de uma trajetória inteira quando um neurônio falha. As ativações de saída passam ser definidas agora como:

$$
a_{\mu_{i}}(t)=\left\{\begin{aligned}
A \cdot \gamma^{i-1}, & \text { para } i=1, \ldots, k \\
0, & \text { para } i>k
\end{aligned}\right.
$$

em que $A>0$ e $0<\gamma<1$ são valores constantes. As equações (61) e (62) são as únicas modificações impostas ao algoritmo proposto na Seção 6.3.

\subsubsection{Comentários sobre as Modificações Propostas}

Nesta seção são feitos alguns comentários que se aplicam igualmente às modificações propostas nas Seções 6.5.2 e 6.5.1. São elas as seguintes:

(i) Por causa do mecanismo de exclusão, grupos de neurônios que codificam um dado padrão em diferentes competições não se sobrepõem.

(ii) A Equação (58b) conexões laterais são sempre estabelecidas dos neurônios vencedores no instante $t$-1 (representados pelo índice $r$ ) para os neurônios vencedores no instante $t$ (representados pelo índice $j$ ).

(iii) Não existem conexões laterais entre os neurônios do mesmo grupo que respondem para um dado padrão no instante $t$ porque os índices referem-se a instantes de tempo distintos. Existem apenas as autoconexões calculadas pela Equação (58a).

(iv) Definindo $\beta<\lambda$, a saída dos neurônios representando o estado atual é feita menor do que aquela dos neurônios que codificam o próximo estado da trajetória. 
Em suma: para cada instante de tempo, um grupo de neurônios que representam um dado estado da trajetória não estabelece conexões laterais entre si, mas sim com aqueles que codificaram o próximo estado.

\subsection{Resumo do Capítulo}

Neste capítulo foi proposto um modelo para aprendizagem de trajetórias de um braço de robô. Duas são suas características fundamentais: (1) existência de um mecanismo de exclusão e (2) conexões intracamada modelando a ordem temporal da seqüência.

O mecanismo de exclusão é necessário para garantir que todos os estados da trajetória sejam codificados pela rede. O neurônio vencedor da competição é impedido de aprender em competições subsequentes. Desta forma, cada estado da seqüência será representado por um neurônio diferente.

A ordem temporal da seqüência, ou seja, o ordenamento dos estados é obtido pelas conexões intracamada, funcionando da seguinte forma: a rede deve produzir uma padrão de saída que indique o estado atual e o próximo estado da trajetória. Para diferenciar estados, o neurônio que tiver menor valor de saída está indicando o estado atual e àquele que tiver maior valor indica o próximo estado.

O modelo inicialmente apresentado só consegue aprender trajetórias que não possuem pontos em comum. Para resolver esta limitação, introduziu-se informação de contexto na arquitetura deste modelo. O contexto refere-se ao conhecimento da posição espacial inicial ou final de cada trajetória (especificação do problema). Esta informação adicional é incorporada à arquitetura via unidades de contexto que permanecem fixas durante toda a apresentação da trajetória em consideração. Desta forma, os estados são armazenados na rede juntamente com a informação específica da trajetória a qual pertencem. De posse da informação contextual, o modelo é capaz de aprender e reproduzir várias trajetórias com diferentes níveis de dificuldade.

Uma outra questão que surge naturalmente está relacionada à tolerância à falhas do modelo proposto. Da forma como foi apresentado, apenas um neurônio por competição é usado para responder a um dado padrão de entrada. Caso este neurônio venha a se perder por algum motivo, a reprodução da trajetória fica impossibilitada. A forma direta de se resolver tal limitação é permitindo que mais de um neurônio seja 
usado para codificar cada estado da trajetória. Duas possibilidades foram sugeridas: (1) usar o conceito de vizinhança topológica fixa, ou (2) permitir os $k$ neurônios mais semelhantes ( $k$ primeiros vencedores) sejam utilizados. Apesar de utilizar mais de um neurônio por competição, a idéia básica continua: conexões laterais intracamada são estabelecidas dos neurônios vencedores da competição anterior para os vencedores da competição atual, modelando a ordem temporal dos estados da trajetória.

Portanto, os modelos finais tem a arquitetura mostrada na Figura 21 e as seguintes características essenciais:

(1) Aprendizagem competitiva com exclusão

(2) Associação temporal por regra hebbiana

(3) Aprendizagem em uma única passada da seqüência

(4) Redundância na representação dos estados da seqüência

(5) Uso de contexto global (posição espacial inicial ou final)

No próximo capítulo são mostrados vários testes com os modelos discutidos neste capítulo visando confirmar as propriedades apresentadas no parágrafo anterior. Serão avaliados a capacidade de aprender e reproduzir as diferentes trajetórias com precisão e rapidez, na presença ou não de ruídos, e na presença ou não de falhas dos neurônios. 


\section{Capítulo 7}

\section{Simulações e Resultados}

Neste capítulo serão apresentados as simulações realizadas com o modelo descrito no capítulo anterior. Estes experimentos serão divididos em três partes básicas envolvendo a capacidade dos modelos em aprender e reproduzir as diversas trajetórias corretamente independente de sua complexidade, avaliar a tolerância à falhas e a capacidade de generalização da rede.

Antes de dar início às simulações serão feitas algumas apresentações relacionadas à tarefa de rastreamento de trajetórias, ao robô PUMA 560 e às diferentes trajetórias a serem consideradas nos experimentos.

O restante do capítulo está organizado como segue. Na Seção 7.2, os diversos tipos de trajetórias utilizadas nas simulações são apresentadas. Em seguida, na Seção 7.3, as trajetórias da seção anterior são visualizadas através do uso de uma ferramenta gráfica adequada. A Seção 7.4 dá início aos experimentos, explicando as diferentes simulações a serem consideradas.

\subsection{Rastreamento de Trajetórias}

Em muitas operações industriais, requer-se que um robô siga uma determinada trajetória de maneira precisa. Este tipo de tarefa é comumente denominada de rastreamento (tracking). Um exemplo deste tipo de operação é a soldagem a arco [CHEN et al., 1996], na qual o efetuador do robô deve seguir uma trajetória préestabelecida com uma velocidade também pré-estabelecida.

Em muitas outras operações de manufatura, necessita-se de que este robô seja capaz de realizar mais de uma tarefa. Além disso, estas trajetórias podem ter trechos em comum, partilhando diversos estados. Isto implica que seu controlador deve ser capaz de rastrear mais de uma trajetória, distinguindo a trajetória a ser seguida das outras. Entretanto, a maioria dos controladores propostos na literatura [CHEN et al., 1996; BUGMANN et al., 1998] buscam melhorar suas performances somente quando 
aplicados ao rastreamento de uma única trajetória. Obviamente, tais controladores têm aplicação limitada em um ambiente de produção industrial.

O modelo proposto no capítulo anterior será avaliado de acordo com sua capacidade em aprender múltiplas trajetórias e executá-las sem interferência, ou seja, de modo preciso e sem ambigüidades.

\subsubsection{Robô PUMA 560}

O robô manipulador PUMA (Programmable Universal Machine Assembly) é provavelmente o robô mais comum em laboratórios de Universidades e um dos mais comuns em linhas de montagem industriais. O modelo utilizado neste trabalho é o PUMA 560 (Figura 22), que consiste em um robô manipulador com 6 juntas, correspondentes a seis graus de liberdade, arranjadas seqüencialmente. As seis juntas são representadas pela rotação da base (junta 1), rotação do ombro (junta 2) e pela rotação do cotovelo (junta 3), estando as três restantes localizadas no efetuador. Cada membro do braço mecânico é conectado ao outro por uma dessas juntas, similares ao tronco e braço humanos. Os seis graus de liberdade, três para as posições espaciais $x, y$ e $z$ e três para orientação do efetuador tornam o robô capaz de alcançar um ponto qualquer em seu espaço de trabalho por qualquer trajetória. O efetuador, localizado no final do manipulador, interage diretamente com o ambiente externo e pode ser uma garra ou ferramenta (pistola de solda, de pintura, etc.). Os seis graus de liberdade são controlados por seis servomotores DC.

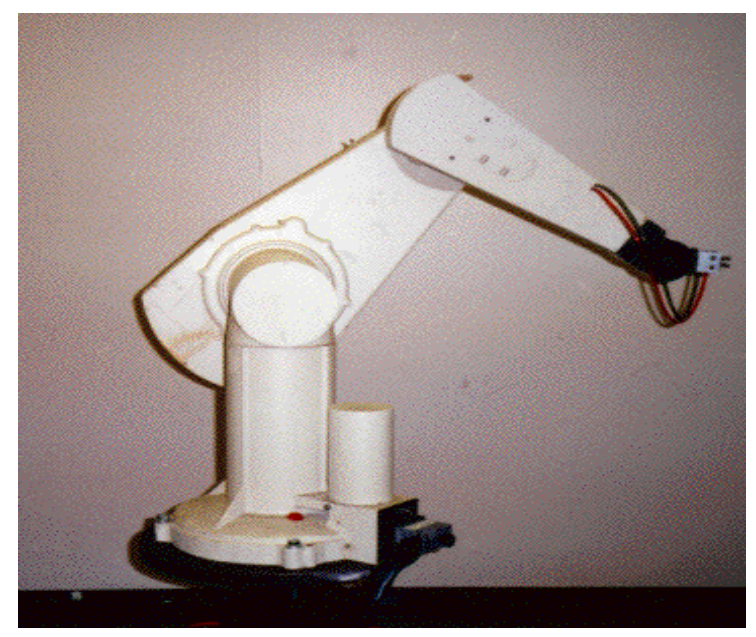

Figura 22: Robô PUMA 560 escolhido para teste dos modelos não-supervisionados para produção de seqüências temporais. 
Detalhes sobre os parâmetros geométricos, cinemáticos e dinâmicos referentes ao robô manipulador PUMA 560 são mostrados no Apêndice V.

\subsubsection{O Sistema Simulado}

O sistema real, apresentado anteriormente, foi simulado graficamente (Figura 23) e as trajetórias para o treinamento da rede neural artificial foram gerados a partir da toolbox ROBOTICS do Matlab® desenvolvida por CORKE (1996) que fornece funções para transformação homogênea, cinemática direta e inversa, geração de trajetórias, dinâmica direta e inversa e animação gráfica. Essa ferramenta é útil tanto para simulações como para analisar resultados de experimentos com robôs reais. A toolbox ROBOTICS utiliza um método geral para calcular a cinemática e dinâmica de manipuladores com elos seriais por descrição de matrizes. Essas matrizes podem ser criadas pelo usuário para qualquer manipulador com elos seriais. A ferramenta já traz essas matrizes para os manipuladores PUMA 560 e Stanford.

Uma simulação gráfica do robô manipulador PUMA 560 [ARAÚJO \& SOUZA, 1997] será usada para visualizar trajetórias que o braço será levado a rastrear.

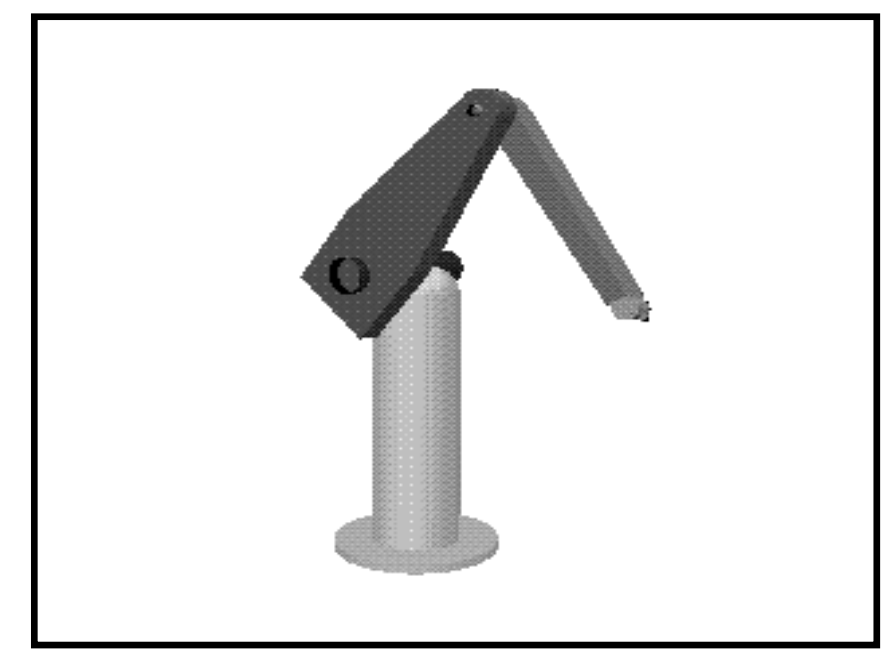

Figura 23: Simulação gráfica do robô PUMA 560 usada para visualização das trajetórias.

Apesar das trajetórias terem sido pré-especificadas usando-se um software específico, em uma implementação real o braço pode ser treinado por um método do tipo teach-by-showing (ou walk-through). Neste caso, um operador guia fisicamente o robô pela sequiência de posições desejadas. Estas posições são aprendidas e reproduzidas pelo robô durante a execução da tarefa. 


\subsection{Trajetórias Consideradas para Estudo}

As diferentes trajetórias consideradas nas simulações deste capítulo estão mostradas na Figura 24. Tais trajetórias foram previamente utilizadas em tarefas semelhantes às discutidas nesta dissertação [BARRETO \& ARAÚJO, 1998; ARAÚJO \& D’ARBO, 1998; ARAÚJO \& VIEIRA, 1998]. Estas foram escolhidas para validação dos modelos por sua diversidade e por apresentarem um grau de complexidade que não é comumente explorado na literatura devido a ambigüidades que surgem naturalmente quando diferentes trajetórias têm pontos em comum.

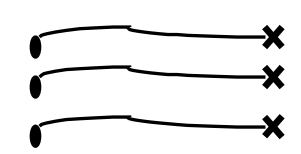

(a)

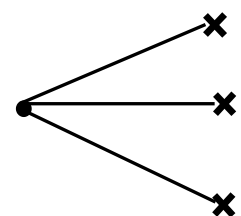

(b)

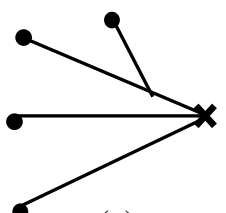

(c)

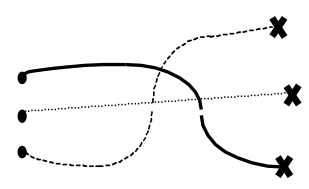

(d)

Figura 24: Trajetórias que tem em comum: (a) Nenhum estado; (b) Apenas o estado inicial; (c) Pelos menos o estado final; (d) Pontos intermediários. $\mathrm{O}$ círculo cheio indica $o$ estado inicial e 0 " $x$ " $o$ estado final da trajetória.

As trajetórias do tipo mostradas na Figura 24a não possuem pontos em comum. Enquanto, as trajetórias nas Figuras 24b-d compartilham pelo menos um estado. Estas últimas impõem maior dificuldade para execução por parte dos modelos, pois introduzem ambigüidades durante a reprodução da trajetória. Este problema é melhor exposto pela seguinte pergunta: Que caminho o braço deve seguir quando estiver em um estado comum a diferentes trajetórias? Conforme foi mostrado no Capítulo 6, estas ambigüidades são resolvidas usando informação de contexto fornecidas à rede como parte da entrada.

Trajetórias que têm em comum o estado final serão representadas pelo símbolo m-1 (muitos-para-1), indicando que partem de estados iniciais diferentes em direção um único estado meta. Lançando mão do mesmo raciocínio, trajetórias com o mesmo estado inicial mas com diferentes estados-meta serão representadas pelo símbolo 1-m. (1-para-muitos).

Trajetórias que não se cruzam serão simbolizadas por $\mathrm{m}-\mathrm{m} / \mathrm{sc}$ que significa : muitos-para-muitos sem cruzamento. Enquanto que trajetórias que se cruzam por m- 
m/cc (muitos-para-muitos com cruzamento). As trajetórias para testes e suas respectivas visualizações são mostradas a seguir.

\subsection{Visualização das Trajetórias}

Em todas as trajetórias a partir deste ponto a letra I indica o estado inicial, enquanto a letra $\mathrm{F}$ indica o estado final. $\mathrm{O}$ primeiro tipo de trajetória a ser mostrada são trajetórias do tipo m-m/sc (Figura 25). Este é o tipo de trajetória mais simples de ser aprendida pois não necessita de informação de contexto.

As trajetórias do tipo 1-m são mostradas na Figura 26. Estas trajetórias se caracterizam por iniciarem em estados diferentes e por terminarem com a mesma configuração para as juntas do manipulador. Os mesmos estados das trajetórias do tipo m-1 serão usados para representar trajetórias do tipo m-1 (Figura 27). A única diferença está na ordem das componentes da trajetória que tem o sentido inverso.

Por fim, as trajetórias do tipo $\mathrm{m}-\mathrm{m} / \mathrm{cc}$ são mostradas na Figura 28. Estas trajetórias se caracterizam também por possuirem mudanças bruscas de direção, impondo um pouco mais de dificuldade na aprendizagem e na reprodução das mesmas.

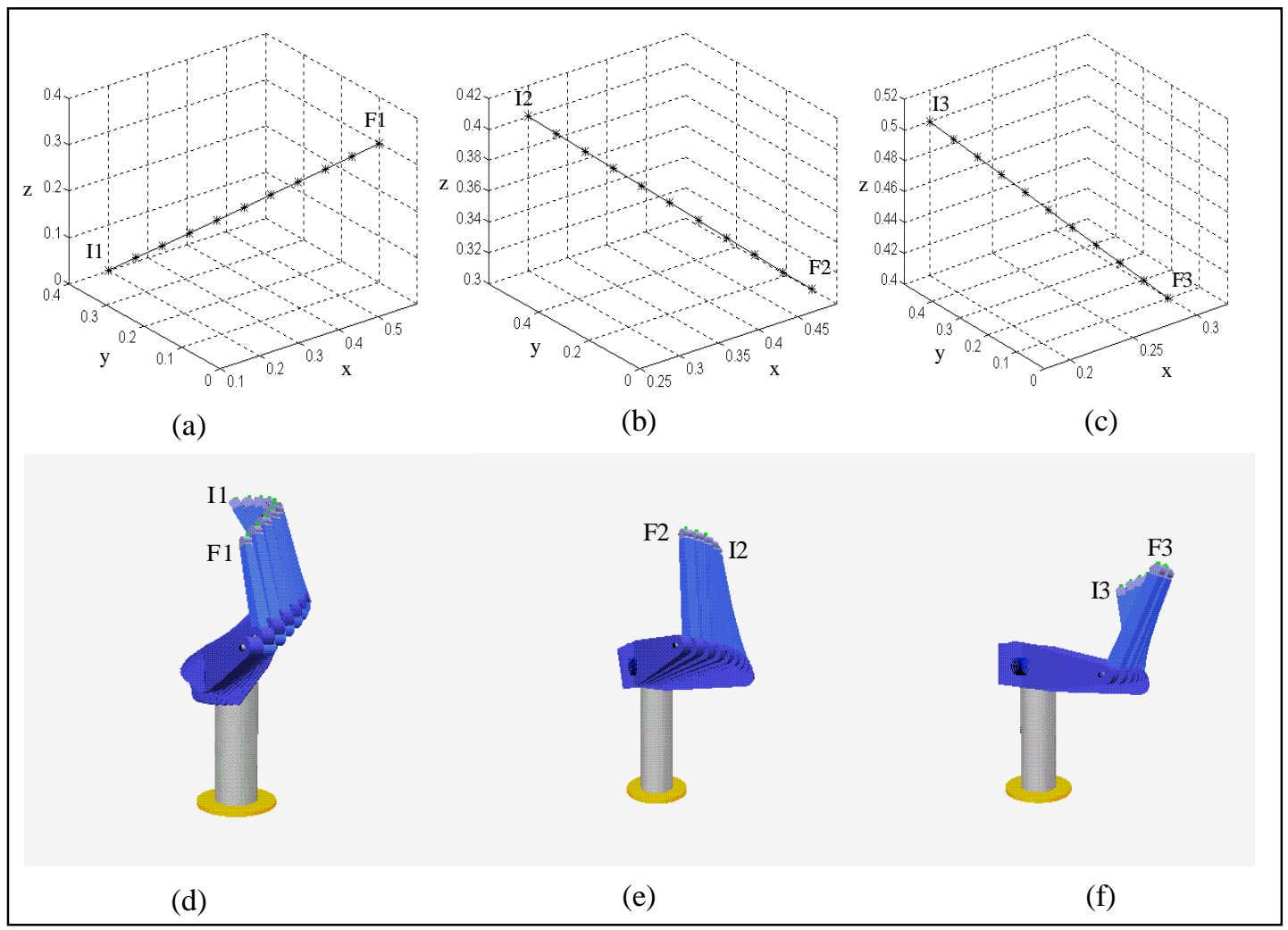

Figura 25: Trajetórias do tipo m-m/sc. (a)-(c) correspondem à posição espacial das trajetórias. Figuras (d)-(f) são a visualização das trajetórias em (a), (b) e (c). 


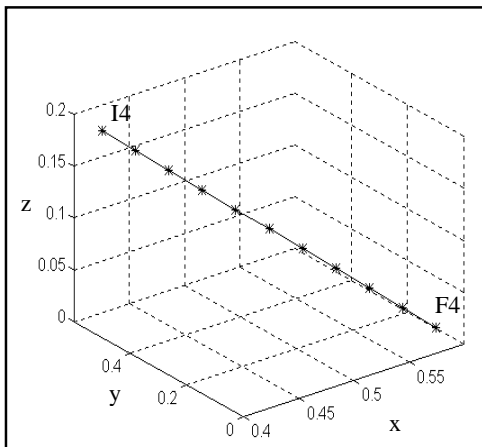

(a)

F4

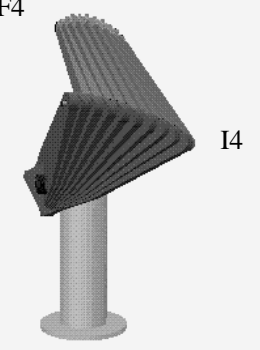

(d)

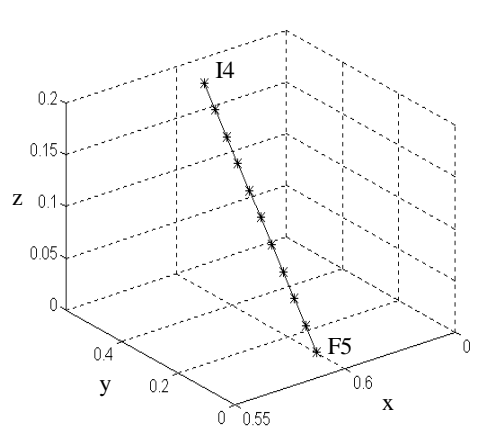

(b)

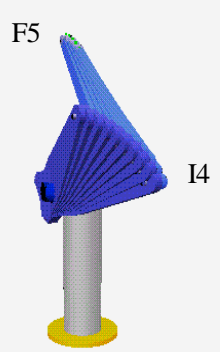

(e)

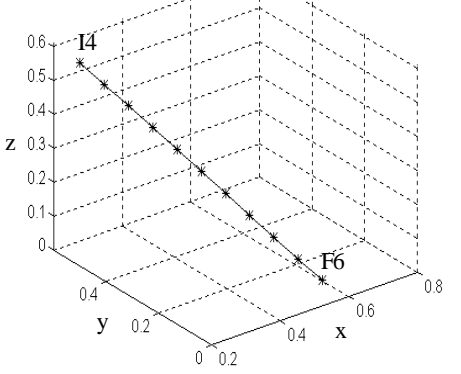

(c)

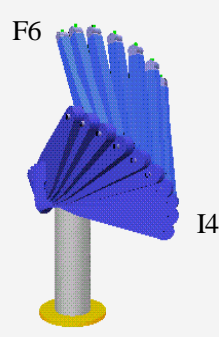

(f)

Figura 26: Trajetórias do tipo 1-m. (a)-(c) correspondem à posição espacial das trajetórias. Figuras (d)-(f) são a visualização das trajetórias em (a), (b) e (c).

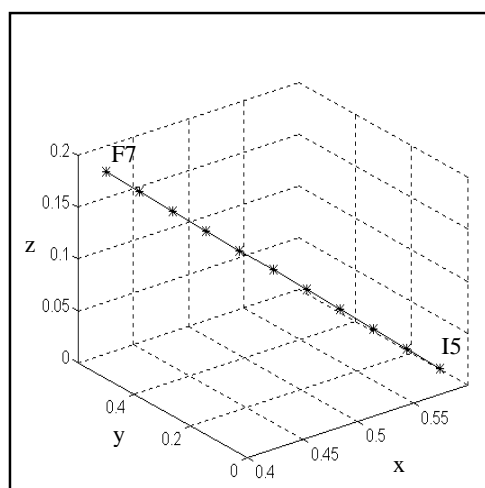

(a)

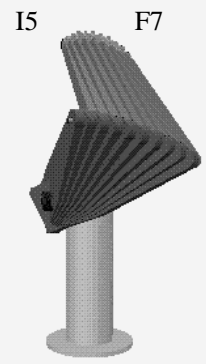

(d)

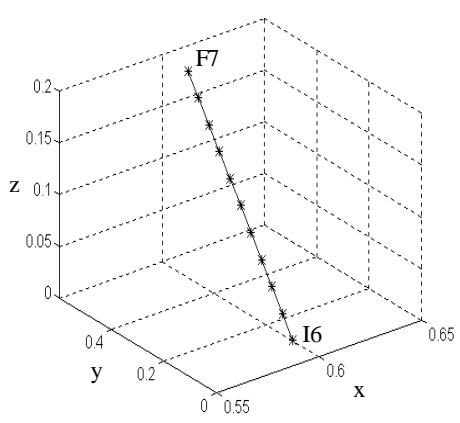

(b)

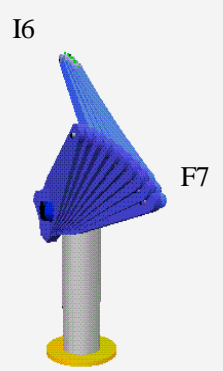

(e)

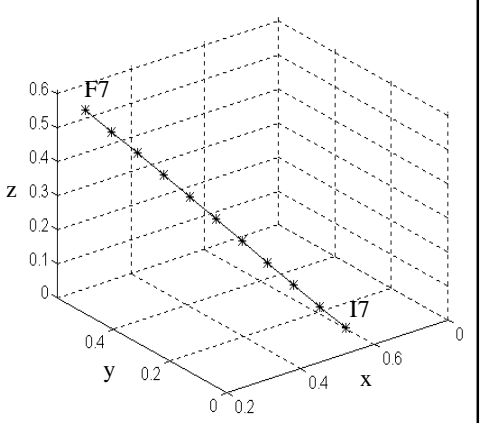

(c)

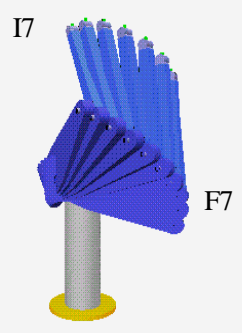

(f)

Figura 27: Trajetórias do tipo m-1. (a)-(c) correspondem à posição espacial das trajetórias. Figuras (d)-(f) são a visualização das trajetórias em (a), (b) e (c). 
As últimas trajetórias consideradas são as do tipo mm-cc, que se cruzam para o presente trabalho só se cruzam em um único ponto (Figura 28).

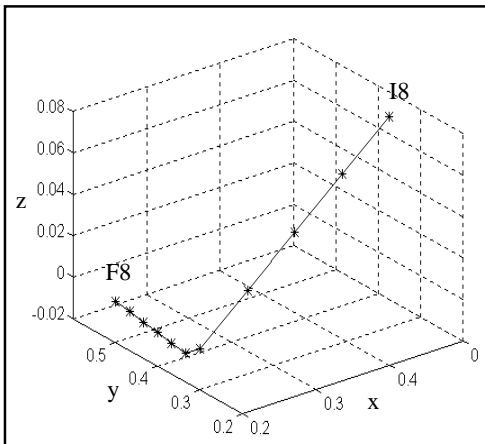

(a)

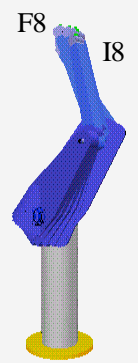

(d)

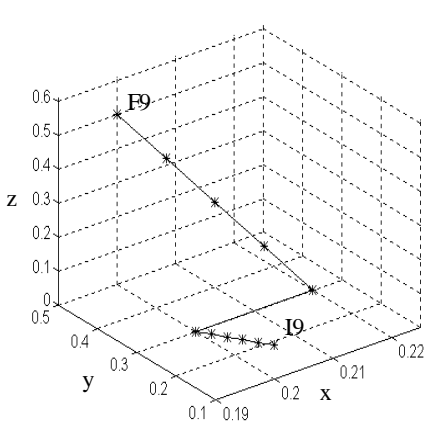

(b)

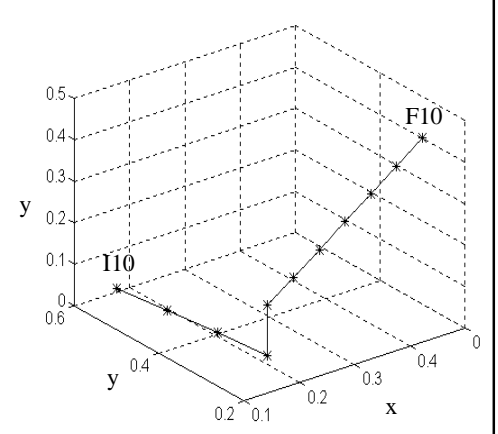

(c)

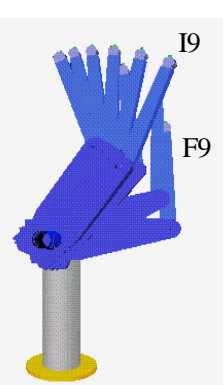

(e)

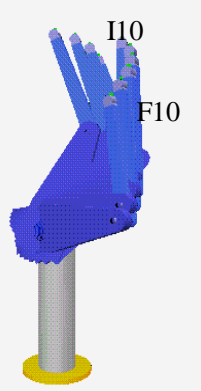

(f)

Figura 28: Trajetórias do tipo m-m/cc. (a)-(c) correspondem à posição espacial das trajetórias. Figuras (d)-(f) são a visualização das trajetórias em (a), (b) e (c).

As trajetórias I8-F8 e I9-F9 se cruzam no ponto $(0,2 ; 0,3 ; 0,0)$, enquanto as trajetórias I9-F9 e I10-F10 se cruzam no ponto $(0,22 ; 0,3 ; 0,0)$. Perceba que estes pontos também tem um grau de superposição considerável.

\subsection{Experimentos}

Nestas seção serão apresentados diversas simulações visando entender e analisar a performance do modelo proposto no Capítulo 6. Os objetivos destas foram tratados no início deste capítulo. Os experimentos a serem realizados são os seguintes:

(1) Funcionamento do modelo básico: nesta etapa, as fases de aprendizagem e reprodução de trajetórias do tipo $\mathrm{m}-\mathrm{m} / \mathrm{sc}$ serão mostradas em detalhe, comparando a trajetória aprendida com a original. A comparação será feita através de ambas, análise qualitativa (visual) e quantitativa (erro de 
rastreamento). Além disso, discutir-se-á como varia o erro de rastreamento em função da taxa de aprendizagem $\alpha$.

(2) Papel do contexto na aprendizagem de trajetórias complexas: nestas simulações será mostrado o papel essencial da informação de contexto na aprendizagem e reprodução de trajetórias com pontos em comum do tipo 1m. Duas situações serão estudadas. A primeira visa mostrar que sem contexto a reprodução sem ambigüidades de trajetórias com pontos em comum não é possível. A segunda estuda como o contexto faz com que incertezas sejam eliminadas.

(3) Tolerância a falhas: nestes experimentos, o modelo com redundância do tipo vizinhança topológica é testado em uma situação de pior caso. Isto é, simula-se a falha de todos os neurônios vencedores que codificam cada componente de trajetórias do tipo m-1. A intenção desta simulação é mostrar que mesmo em situações catastróficas as trajetórias continuam sendo reproduzidas à custa de erros de rastreamento ligeiramente maiores.

(4) Capacidade de generalização: nestas simulações, trajetórias do tipo m-m/cc serão usadas para treinar o modelo com redundância por similaridade. Em seguida, versões ruidosas das mesmas trajetórias serão utilizadas para avaliar a resposta deste modelo de rede. Considera-se aqui que versões ruidosas são, na verdade, padrões não vistos pela rede durante a fase de treinamento. As conclusões obtidas para estes experimentos são igualmente válidas para o modelo com redundância tipo vizinhança topológica.

\subsection{Cálculo do Erro de Rastreamento}

Uma das várias formas de se avaliar a performance de algoritmos, sejam eles neurais ou não, em tarefas de rastreamento de trajetórias é calculando-se o erro de posicionamento do braço para cada ponto da trajetória. Esta grandeza é calculada usando-se a seguinte fórmula:

$$
E_{t}=\frac{1}{N_{p}} \sum_{t=1}^{N_{p}}\left\{\left(x_{r}^{t}-x_{o}^{t}\right)^{2}+\left(y_{r}^{t}-y_{o}^{t}\right)^{2}+\left(z_{r}^{t}-z_{o}^{t}\right)^{2}\right\}
$$


na qual $\left(x_{r}, y_{r}, z_{r}\right)$ e $\left(x_{o}, y_{o}, z_{o}\right)$ são, respectivamente, as coordenadas espaciais reais e as fornecidas pelo modelo; $N_{p}$ é o número de pontos da trajetórias e $t$ é a posição na trajetória. Por exemplo, $t=1$ indica o primeiro vetor da sequiência e assim por diante até a posição meta $\left(t=N_{p}\right)$.

As coordenadas espaciais desejadas e as fornecidas pela rede são obtidas das três primeiras dimensões do vetor de entrada e do vetor de pesos do neurônio vencedor para aquele vetor, respectivamente.

\subsection{Funcionamento - Modelo CAT sem unidades de contexto}

O modelo apresentado na Seção 6.3 é treinado com trajetórias do tipo m-m/sc (Figura 24a). Relembrando: este tipo de trajetória se caracteriza por não possuir pontos em comum. As trajetórias utilizadas foram mostradas na Figura 25. As Figuras 29 e 30 ilustram o funcionamento da fase de treinamento e a produção da trajetória I1F1, respectivamente. O modelo usado é o básico, ou seja, aquele que não possui unidades de contexto nem redundância na representação.

A intenção desta simulação é, principalmente, deixar claro como a ordem temporal da seqüência é codificada e recuperada pelo modelo à medida que as componentes da seqüência vão sendo observadas pela rede. Pode-se perceber claramente como as conexões intracamada são ajustadas a cada competição:

(i) Toda vez que uma unidade de saída é ativada, a autoconexão associada a ela é ajustada de um valor inicial 0 para um final $\beta$ usando-se a Equação (58a);

(ii) Somente as conexões laterais entre neurônios vencedores em competições consecutivas são ajustadas de um valor inicial 0 para um final $\lambda$ usando a regra hebbiana temporal (Equação 58b). Estes ajustes só são executados uma vez durante toda a fase de treinamento da rede. Isto ocorre devido ao fator de exclusão. Portanto, cada conexão lateral modela uma transição de estado. 


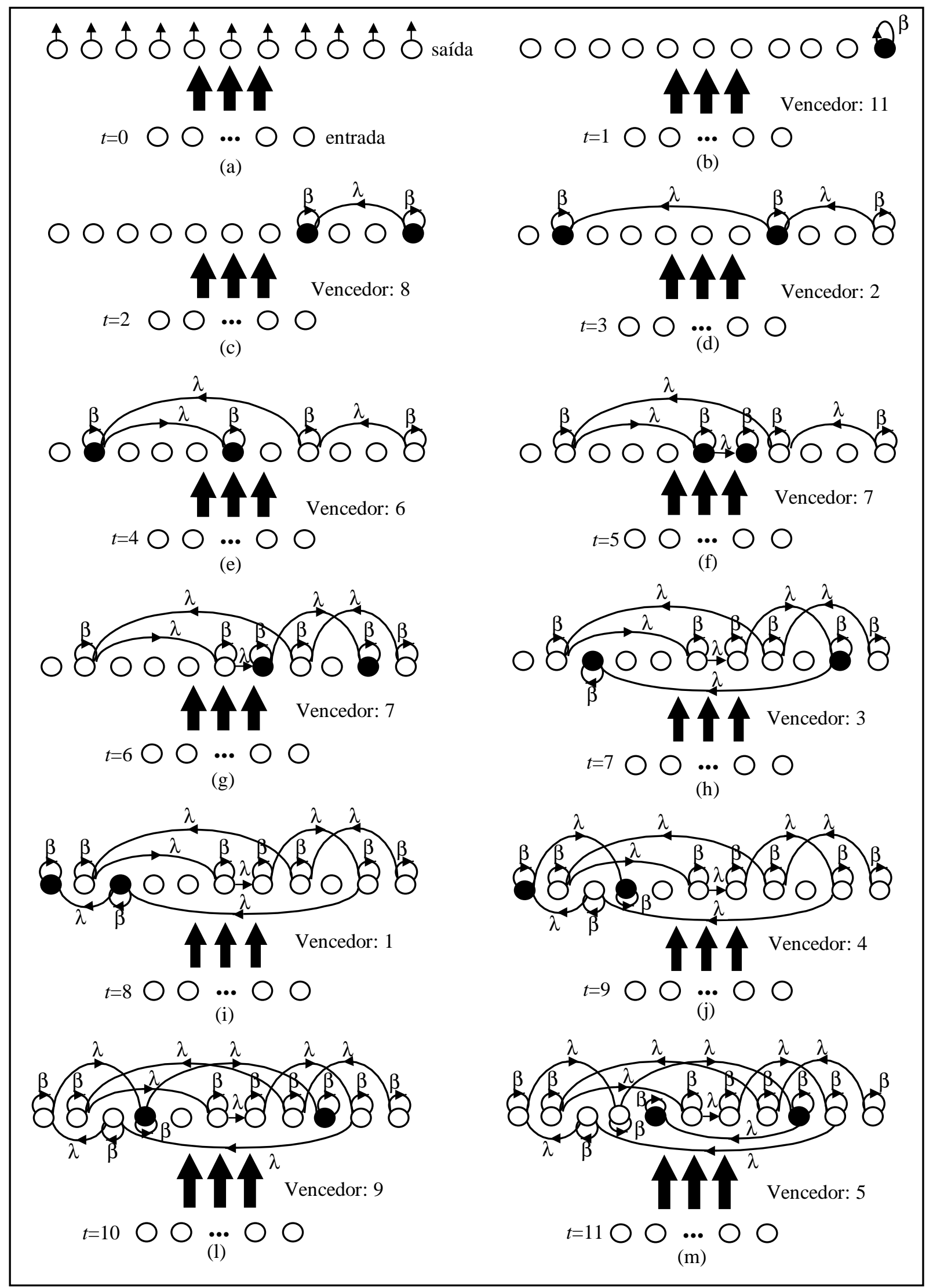

Figura 29: Treinamento do modelo CAT sem contexto para trajetória I1-F1. (a) configuração inicial das conexões intracamada; (b)-(m) estabelecimento das auto-conexões e das conexões laterais. $O$ número de conexões laterais é igual ao número de transições de estado. 


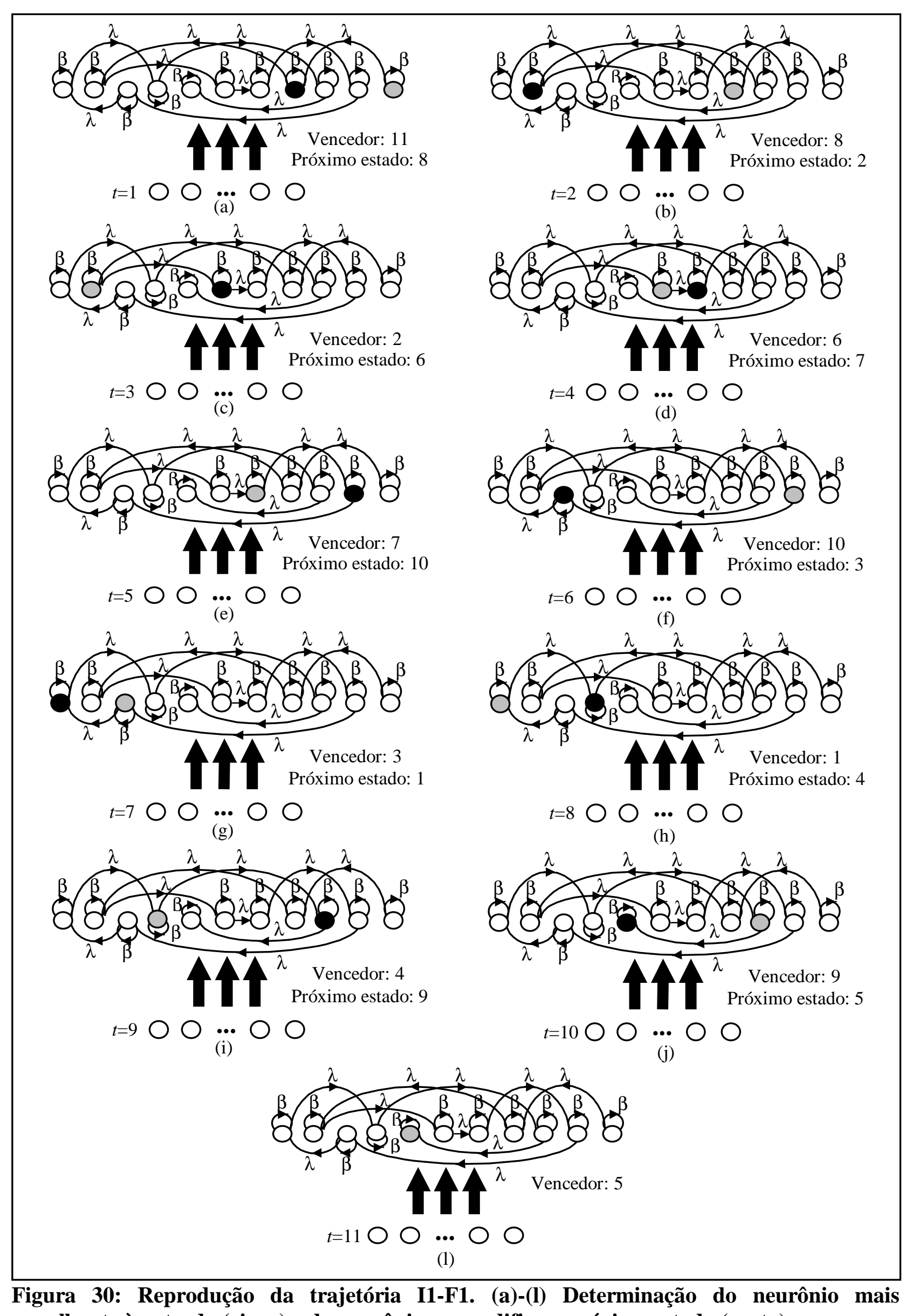
semelhante à entrada (cinza) e do neurônio que codifica o próximo estado (preto). 
De acordo com o algoritmo mostrado na Seção 6.3.3, no início da fase de treinamento (Figura 29a) os pesos intercamadas são inicializados aleatoriamente, sendo representados pelas três setas verticais, enquanto as conexões intracamada (não mostradas) são feitas iguais a zero. As ativações e saídas são inicializadas com zero. Os atrasadores não foram mostrados para simplificar as figuras e a numeração dos neurônios é estabelecida da esquerda para a direita. Os parâmetros da rede tiveram os seguintes valores: $\alpha=10^{6} ; \beta=0,2 ; \lambda=1-\beta=0,8 ; \delta=0,98 ; n=15$ e $m=11$.

Assim que o primeiro padrão (estado inicial da trajetória) é apresentado à rede, esta responde indicando como vencedor o neurônio 11, ou seja $a_{11}(1)=1$. Em seguida este neurônio tem seu fator de exclusão atualizado, $f_{11}=\alpha \cdot a_{11}+1=\left(10^{6}\right) \cdot(1)+1 \approx$ $10^{6}$, garantindo que ele não será utilizado em competições futuras. O próximo passo é atualizar o vetor de pesos intercamadas associado ao neurônio 11 de acordo com a Equação 57. Por último, as conexões intracamada são estabelecidas. Percebe-se que, pelo fato de ser o início do processo de aprendizado, apenas a Equação (58a) de ajuste das autoconexões produz algum efeito (Figura 29b). Isto acontece porque a Equação (58b) utiliza também os valores das ativações de saída no instante anterior, que para o presente caso são todas nulas. Assim, a autoconexão associada ao neurônio 11 sai de um valor inicial nulo para um valor igual a $\beta=0,2$.

O segundo padrão da trajetória é então apresentado. Neste caso, o neurônio escolhido foi o de número 8. É importante ressaltar aqui que caso não existisse o mecanismo de exclusão o nó escolhido seria novamente o neurônio 11. Isto aconteceria porque depois do ajuste de pesos no instante anterior, o vetor de pesos do nó 11 passou a ser mais parecido com o restante dos estados da trajetória do que os outros vetores de pesos que tem valores aleatórios. Após a atualização do fator de exclusão e do ajuste do vetor de pesos associado ao neurônio 8, as conexões intracamada são atualizadas. A autoconexão $m_{8,8}$ tem seu valor estabelecido conforme descrito no parágrafo anterior. Para o presente instante de tempo $(t=2)$, é possível estabelecer associações temporais entre as ativações dos neurônios em competições consecutivas usando a Equação 58b. A única conexão que mudou de valor foi aquela que parte do neurônio 11 para o neurônio 8 , passando a ter o seguinte valor: $m_{8,11}=0+$ $0,8=0,8$. O resultado é mostrado na Figura $29 \mathrm{~b}$, onde percebe-se com clareza o papel das conexões laterais neste modelo: indicar a ordem de ocorrência dos estados da 
trajetória. A saída da rede é calculada usando-se a Equação 59. Os valores obtidos foram $y_{11}(1)=m_{11,11}, a_{11}=(0,2) \cdot(1,0)=0,2$ e $y_{j}(1)=0$ para $j \neq 11$. Pode-se notar que a função da autoconexão é diminuir o valor da ativação do neurônio vencedor. Conforme será visto a seguir, a idéia é que permaneçam com saídas diferentes de zero dois neurônios. O nó que possuir menor valor de saída responde pelo estado atual do braço e o de maior valor pelo próximo estado a ser alcançado. O processo descrito neste e no parágrafo anterior é repetido para todos os estados da trajetória (Figuras 30c-m), até que esta chegue ao seu fim.

Para a fase de reprodução da trajetória, considera-se que a rede está inserida em um sistema de controle de robô, de tal forma que ela fosse utilizada para fornecer sinais de controle aos atuadores das juntas do robô e receber informação sensorial sobre a posição alcançada. A única informação que um operador possivelmente forneceria ao sistema seria o estado inicial e o final da trajetória.

Assim que o primeiro estado da trajetória é apresentado $(t=1)$, o neurônio cujo vetor de pesos está mais próximo do estímulo de entrada é feito vencedor. Para a presente competição o escolhido foi o neurônio 11, o mesmo vencedor na etapa de treinamento. Assim, sua ativação é igual a $a_{11}(1)=1$. Em seguida, calcula-se as saídas dos neurônios de acordo com a Equação 59. O resultado final das saídas (Figura 31a) é o seguinte:

$$
\begin{aligned}
& y_{11}(1)=0+0+0+0+0+0+0+0+0+0+m_{11,11} \cdot a_{11}=(0,2) \cdot(1,0)=0,2 \\
& y_{8}(1)=0+0+0+0+0+0+0+0+0+0+m_{8,11} \bullet a_{11}=(0,8) \cdot(1,0)=0,8 \\
& y_{j}(1)=0 \text { para } j \neq 8 \text { e } j \neq 11 .
\end{aligned}
$$

Estas saídas são interpretadas como segue: o neurônio de menor valor de saída indica o estado atual na entrada da rede, enquanto que a de maior valor indica o próximo estado da trajetória a ser rastreada pelo robô. $\mathrm{O}$ vetor de pesos sinápticos do neurônio 8 fornecerão a informação necessária (posição espacial, ângulos e torques) aos controladores das juntas do robô para alcançar o próximo estado.

Ao alcançar a configuração esperada, a leitura dos sensores para este estado passará a ser a entrada da rede, que indica como saída o próximo estado, e assim por diante. Este processo é repetido até que se chegue ao final da trajetória desejada (Figuras 30b-1). 
$\mathrm{O}$ erro de rastreamento obtido para esta trajetória foi $E_{t}(\mathrm{I} 1-\mathrm{F} 1)=1,29 \times 10^{-4}$. É importante notar que o erro de rastreamento é função da taxa de aprendizagem $\delta$ dos pesos de alimentação direta. A Figura 31 mostra como varia tal dependência. Para cada valor de $\delta$, a rede foi treinada usando sempre os mesmos pesos iniciais.

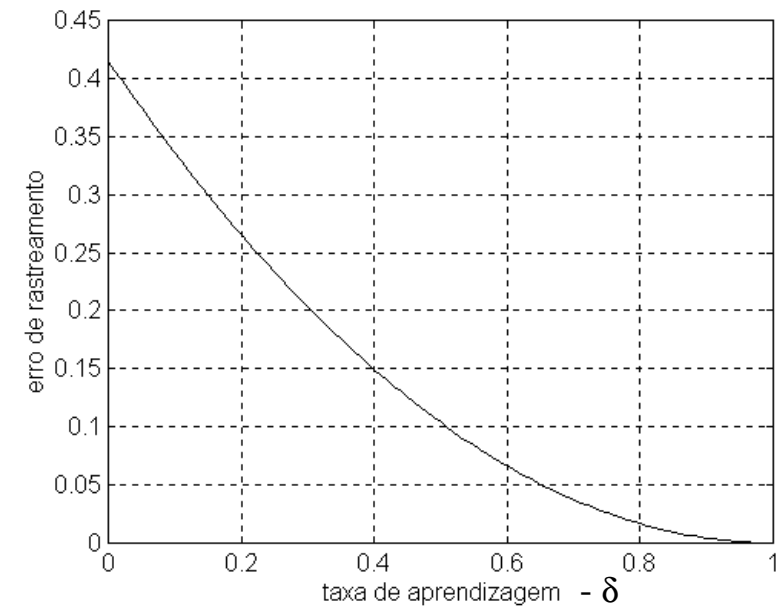

\section{Figura 31: Variação do erro de rastreamento como função da taxa de aprendizagem $\delta$.}

Nota-se que se a taxa de aprendizagem $\delta=1$, então as componentes do vetor de entrada são simplesmente copiadas para os pesos de alimentação direta correspondentes gerando um erro de rastreamento igual a zero. Entretanto, apesar desta ser uma situação desejável, reduz sensivelmente a capacidade de generalização da rede [SALOMON, 1996].

As próximas simulações serão realizadas considerando as três trajetórias já mostradas na Figura 25. Neste caso, deve-se aumentar o número de neurônios na camada competitiva de saída para $m \geq 3 N_{p}$, em que $N_{p}$ é o número de estados da trajetória incluindo os estados inicial e final.

O objetivo destas é mostrar que o modelo básico é capaz de codificar diferentes trajetórias desde que não haja pontos em comum entre elas. Além disso, deseja-se avaliar qualitativamente o resultado desejado e o armazenado pela rede. As figuras mostram os resultados para as posições espaciais (Figura 32), para os ângulos das juntas (Figura 33) e os torques associados (Figura 34).

Para todas as figuras neste capítulo, o símbolo de asterico “*” indica o valor real das componentes da seqüência, enquanto o círculo vazio “o” indica o valor codificado pelos pesos de alimentação direta. 


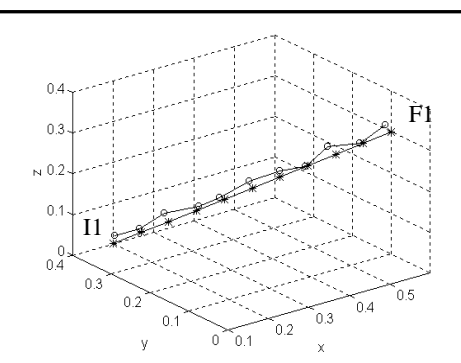

(a)

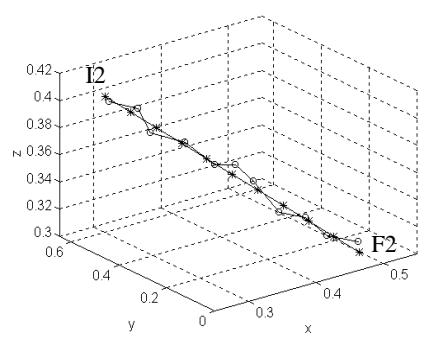

(b)

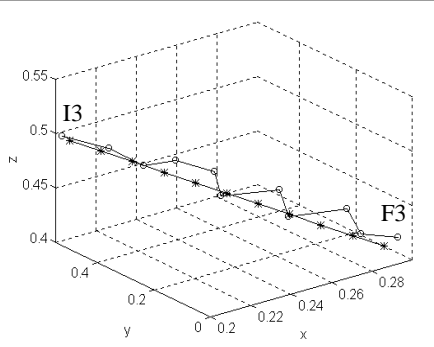

(c)

Figura 32: Trajetórias espaciais fornecidas pela rede e as reais para seqüências m-m/sc usando o modelo CAT sem contexto e sem redundância.

Os erros de rastreamento para as trajetórias da Figura 32 foram: $E_{t}(\mathrm{I} 1-\mathrm{F} 1)=$ $2,1967 \times 10^{-4}, E_{t}(\mathrm{I} 2-\mathrm{F} 2)=1,1824 \times 10^{-4}$ e $E_{t}(\mathrm{I} 3-\mathrm{F} 3)=1,1930 \times 10^{-4}$. Estes valores ilustram a habilidade do modelo em codificar de forma precisa as trajetórias. Os erros poderiam ser ainda menores caso o valor de $\delta$ fosse maior ( 0,99 ou 1 , por exemplo). Os ângulos reais e os obtidos das seis juntas do manipulador são mostrados na Figura 33.

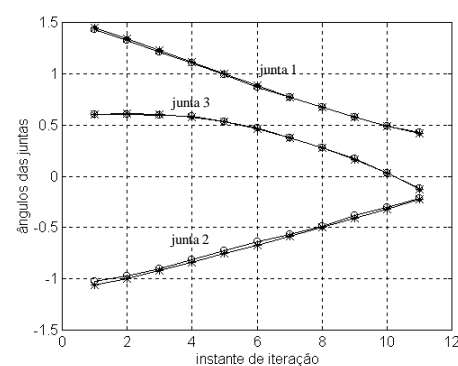

(a)

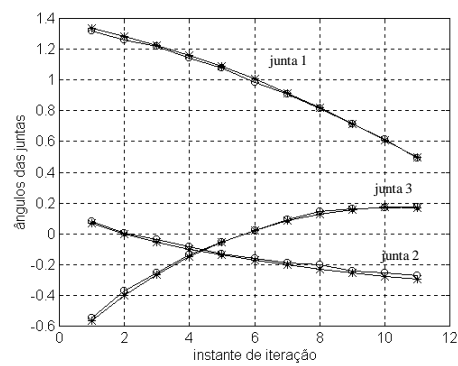

(c)

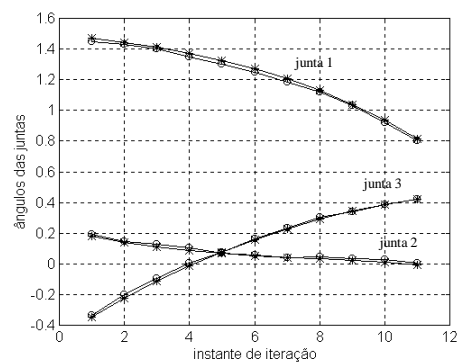

(e)

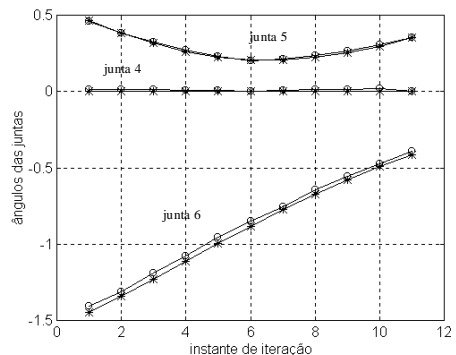

(b)

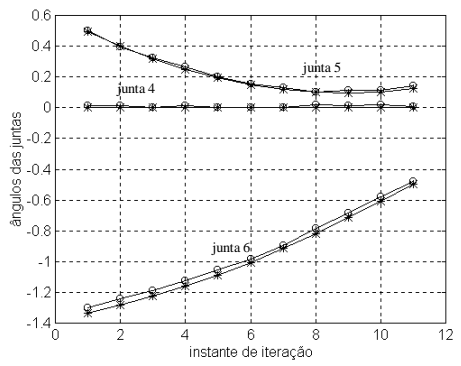

(d)

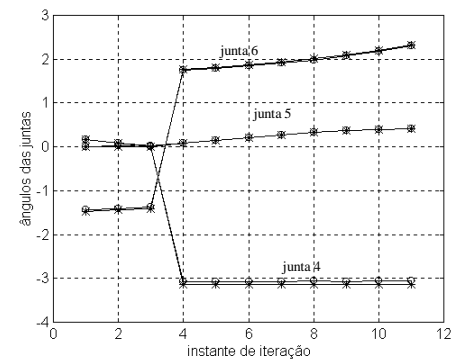

(f)

Figura 33: Ângulos em radianos das juntas (reais e reproduzidos) para sequiências do tipo m-m/sc. Trajetórias: (a)-(b) I1-F1, (c)-(d) I2-F2 e (e)-(f) I3-F3. 
Os resultados obtidos para os torques aplicados em cada junta do manipulador são mostrados na Figura 34.

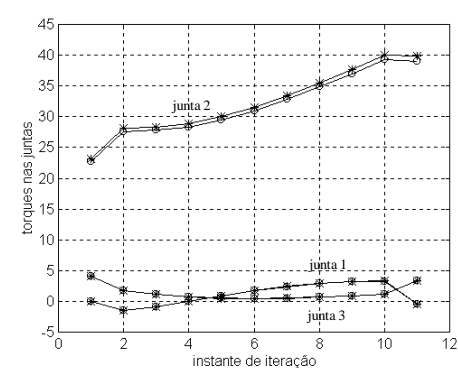

(a)

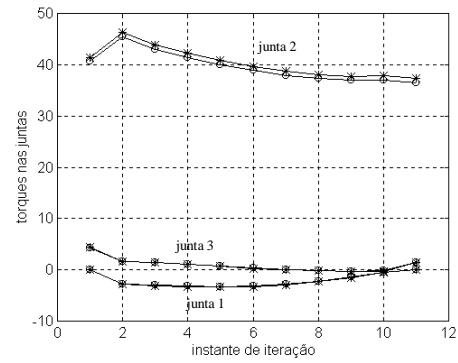

(c)

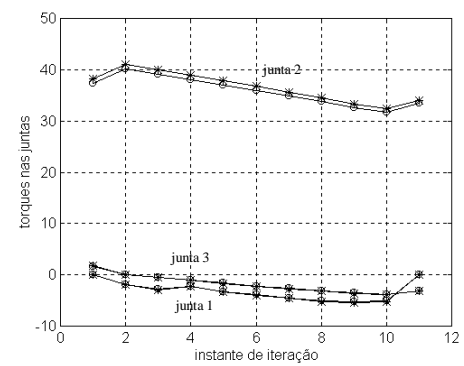

(e)

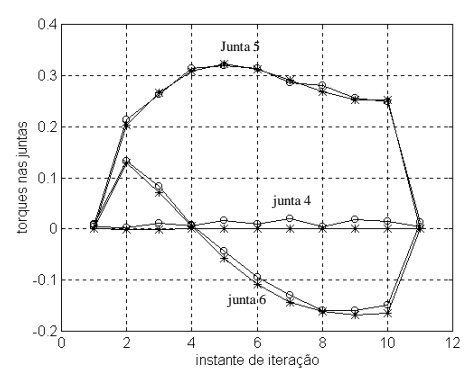

(b)

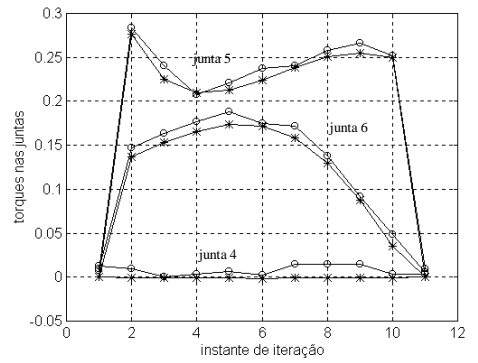

(d)

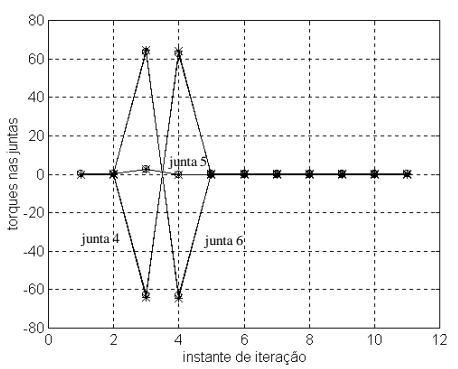

(f)

Figura 34: Torques (em Nm), reais e reproduzidos, nas juntas para trajetórias do tipo m-m/sc. Trajetórias: (a)-(b) I1-F1, (c)(d) I2-F2 e (e)-(f) I3-F3.

Os próximos experimentos levam em consideração trajetórias que possuem pontos em comum. Para ser capaz de aprender estes casos, o modelo básico é acrescido de unidades de contexto.

\subsection{Aprendendo Trajetórias Complexas}

Em certos casos, um robô é levado a percorrer trajetórias que se cruzam em um ou mais pontos. Deste modo, é de fundamental importância que um modelo de rede neural seja capaz de aprendê-las e reproduzi-las sem incertezas ou interferências. O modelo básico não é capaz de reproduzir trajetórias que compartilham pontos entre si. 
A Tabela 1 mostra um caso simples em que a rede não fornece a trajetória de saída adequada, quando treinada com trajetórias que tem o mesmo estado inicial.

Tabela 1: Exemplos de reprodução incorreta de trajetórias 1-m.

\begin{tabular}{|c|c|c|}
\hline $\begin{array}{c}\text { Trajetórias } 1-m \\
\text { sem contexto }\end{array}$ & $\begin{array}{c}\text { Vencedores durante } \\
\text { treinamento }\end{array}$ & $\begin{array}{c}\text { Vencedores durante } \\
\text { reprodução }\end{array}$ \\
\hline I4-F4 & $9 / 5 / 32 / 26 / 24 / 31 / 16 / 21 / 29 / 17 / 20$ & $9 / 5 / 32 / 26 / 24 / 31 / 16 / 21 / 29 / 17 / 20$ \\
\hline I4-F5 & $11 / 2 / 22 / 1 / 27 / 25 / 7 / 12 / 10 / 28 / 18$ & $9 / 5 / 32 / 26 / 24 / 31 / 16 / 21 / 29 / 17 / 20$ \\
\hline I4-F6 & $14 / 30 / 23 / 6 / 8 / 3 / 13 / 15 / 4 / 33 / 19$ & $9 / 5 / 32 / 26 / 24 / 31 / 16 / 21 / 29 / 17 / 20$ \\
\hline
\end{tabular}

Percebe-se que a rede não fornece os vencedores corretos para os estados das trajetórias I4-F5 e I4-F6. A solução para este problema é dotar a rede de um mecanismo que diferencie dois estados idênticos, mas pertencentes a trajetórias diferentes. Isto é implementado através da inclusão de entradas adicionais, fixas durante treinamento e reprodução, que dizem respeito apenas à trajetória sendo treinada atualmente. Essa informação adicional, chamada aqui de contexto, é obtida da especificação do problema que fornece os estados inicial e final das trajetórias.

Para a presente simulação será utilizada como contexto a posição espacial final de cada trajetória. Assim, apesar das 15 primeiras componentes de cada entrada serem idênticas, as três últimas são diferentes (trajetórias 1-m tem estados finais distintos). Desta forma, a rede consegue reproduzir a trajetória correta, pois cada componente é armazenada com esta informação adicional. O resultado é mostrado na Tabela 2.

Tabela 2: Exemplos de reprodução correta de trajetórias 1-m.

\begin{tabular}{|c|c|c|}
\hline $\begin{array}{c}\text { Trajetórias } 1-m \\
\text { com contexto }\end{array}$ & $\begin{array}{c}\text { Vencedores durante } \\
\text { treinamento }\end{array}$ & $\begin{array}{c}\text { Vencedores durante } \\
\text { reprodução }\end{array}$ \\
\hline I4-F4 & $9 / 5 / 32 / 26 / 24 / 31 / 16 / 21 / 29 / 17 / 20$ & $9 / 5 / 32 / 26 / 24 / 31 / 16 / 21 / 29 / 17 / 20$ \\
\hline I4-F5 & $11 / 2 / 22 / 1 / 27 / 25 / 7 / 12 / 10 / 28 / 18$ & $11 / 2 / 22 / 1 / 27 / 25 / 7 / 12 / 10 / 28 / 18$ \\
\hline I4-F6 & $14 / 30 / 23 / 6 / 8 / 3 / 13 / 15 / 4 / 33 / 19$ & $14 / 30 / 23 / 6 / 8 / 3 / 13 / 15 / 4 / 33 / 19$ \\
\hline
\end{tabular}

Uma outra possibilidade seria a inclusão de ruído estocástico durante o treinamento. Este procedimento garante que os estados armazenados sejam diferentes, mas mesmo assim não garante uma reprodução $100 \%$ correta das trajetórias.

A inclusão de contexto permite que outros tipos de trajetórias (por exemplo, m-1 e m-m/cc) sejam também aprendidas e reproduzidas sem ambigüidades. 


\subsection{Tolerância à Falhas nos Neurônios}

No modelo básico, cada estado de entrada é codificado por apenas um neurônio. Caso este neurônio venha a falhar ou se perder a trajetória é totalmente perdida ou reproduzida apenas em parte. Uma forma natural de contornar este problema é usar mais de um neurônio para representar cada estado da trajetória, propriedade esta chamada de redundância. Para esta seção será utilizado o modelo CAT com redundância implementada usando o conceito de vizinhança (Seção 6.5.1).

Os parâmetros do modelo tiveram os seguintes valores: $\alpha=10^{6}, \beta=0,2 ; \lambda=1-\beta$ $=0,8 ; \delta=1 ; \rho=0,14 ; m=150$ e $\mathrm{L}=1$. Por exemplo, se o neurônio 3 for escolhido vencedor então seus vizinhos 2 e 4 também terão seus pesos ajustados e serão excluídos de competições subsequentes.

Os experimentos a seguir simulam uma situação de pior caso, ou seja, todos os neurônios vencedores para cada componente das trajetórias falharam por alguma razão. Assim, a reprodução das trajetórias ficará a cargo dos vizinhos. Os resultados do treinamento para trajetórias do tipo m-1 estão mostrados na Figura 35. As trajetórias reproduzidas pelo vizinho da esquerda do vencedor são indicados por um círculo vazio "o" e as reproduzidas pelo vizinho à direita por um "x".

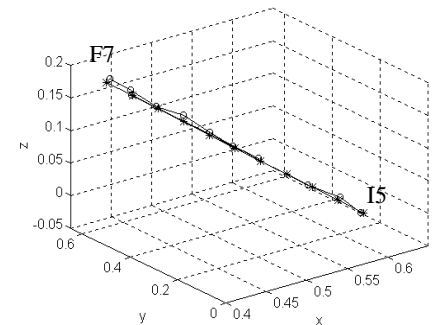

(a)

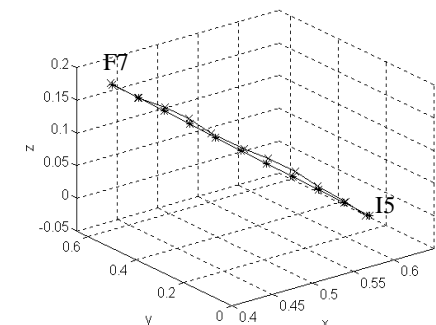

(d)

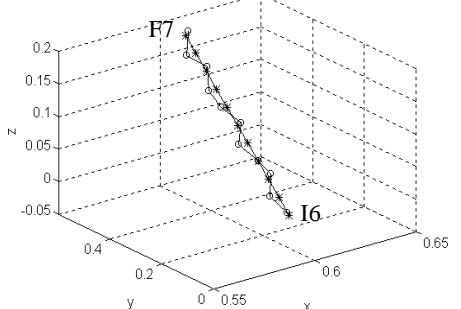

(b)

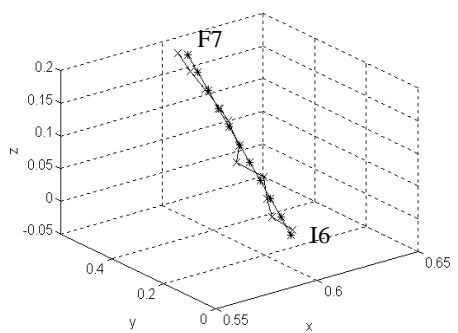

(e)

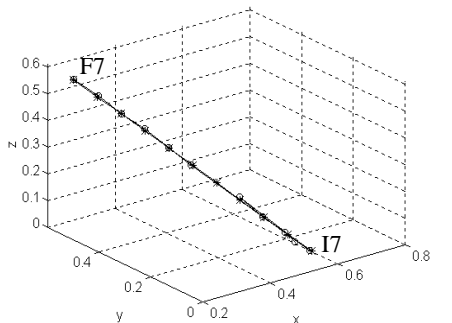

(c)

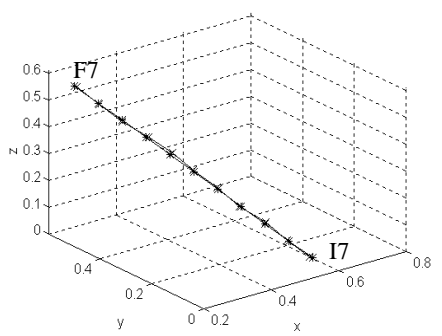

(f)

Figura 35: Trajetórias espaciais fornecidas pela rede e as desejadas para sequiências m-1 usando o modelo CAT com contexto e redundância por vizinhança. (a)-(c) Resultados para vizinhos à esquerda e (d)-(f) para vizinhos à direita. 
Resultados numéricos para trajetória I6-F7 são mostrados na Tabela 3 a seguir. Nesta tabela são mostrados os valores das três primeiras componentes (posição espacial) dos vetores de pesos de alimentação direta do neurônio vencedor e de seus vizinhos.

Tabela 3: Posições espaciais armazenadas pelo vencedor e seus vizinhos.

\begin{tabular}{|c|c|c|c|}
\hline Estado & Vizinho à direita & Vencedor & Vizinho à esquerda \\
\hline 1 & $(0.3991,0.5043,0.2021)$ & $(0.40,0.50,0.20)$ & $(0.4053,0.5016,0.2036)$ \\
\hline 2 & $(0.4185,0.4558,0.1817)$ & $(0.42,0.46,0.18)$ & $(0.4189,0.4617,0.1879)$ \\
\hline 3 & $(0.4404,0.4169,0.1667)$ & $(0.44,0.42,0.16)$ & $(0.4394,0.4231,0.1625)$ \\
\hline 4 & $(0.4595,0.3811,0.1479)$ & $(0.46,0.38,0.14)$ & $(0.4615,0.3847,0.1482)$ \\
\hline 5 & $(0.4758,0.3439,0.1273)$ & $(0.48,0.34,0.12)$ & $(0.4817,0.3439,0.1224)$ \\
\hline 6 & $(0.5034,0.2986,0.1015)$ & $(0.50,0.30,0.10)$ & $(0.4989,0.3049,0.1015)$ \\
\hline 7 & $(0.5219,0.2601,0.0862)$ & $(0.52,0.26,0.08)$ & $(0.5182,0.2635,0.0840)$ \\
\hline 8 & $(0.5432,0.2198,0.0667)$ & $(0.54,0.22,0.06)$ & $(0.4185,0.4558,0.1817)$ \\
\hline 9 & $0.5601,0.1844,0.0446)$ & $(0.56,0.18,0.04)$ & $(0.5559,0.1822,0.04407)$ \\
\hline 10 & $(0.5822,0.1400,0.0211)$ & $(0.58,0.14,0.02)$ & $(0.5837,0.1434,0.0219)$ \\
\hline 11 & $(0.5950,0.0993,0.0023)$ & $(0.60,0.10,0.00)$ & $(0.5973,0.10080 .0008)$ \\
\hline
\end{tabular}

A Tabela 4 mostra os valores dos erros de rastreamento para o modelo CAT com contexto e redundância topológica quando aplicados às trajetórias consideradas nesta dissertação. As trajetórias usadas na Tabela 4 foram: m-m/sc (I1-F1), 1-m (I4F4), m-1 (I5-F7) e m-m/cc (I8-F8). Os valores iniciais dos pesos de alimentação direta foram os mesmos para todos os casos.

Tabela 4: Erros de rastreamento para simulações usando modelo com redundância usando redundância por vizinhança.

\begin{tabular}{|c|c|c|c|}
\hline Trajetória & Vizinho à esquerda & Vencedor & Vizinho à direita \\
\hline $\mathrm{m}-\mathrm{m} / \mathrm{sc}(\mathrm{I} 1-\mathrm{F} 1)$ & $5,2213 \times 10^{-5}$ & 0.00 & $4,1415 \times 10^{-5}$ \\
\hline $1-\mathrm{m}(\mathrm{I} 4-\mathrm{F} 4)$ & $3,5489 \times 10^{-5}$ & 0.00 & $3,7065 \times 10^{-5}$ \\
\hline $\mathrm{m}-1$ (I5-F7) & $3,4346 \times 10^{-5}$ & 0.00 & $2,8334 \times 10^{-5}$ \\
\hline $\mathrm{m}-\mathrm{m} / \mathrm{cc}(\mathrm{I} 8-\mathrm{F} 8)$ & $4,9082 \times 10^{-5}$ & 0.00 & $4,8149 \times 10^{-5}$ \\
\hline
\end{tabular}




\subsection{Capacidade de Generalização (Tolerância ao Ruído)}

Generalização é considerada a capacidade de uma rede neural em fornecer respostas adequadas a um padrão de entrada que não tiver sido visto anteriormente. Portanto, esta é uma propriedade extremamente desejável em redes neurais.

Em robótica, a capacidade de generalização se confunde com o conceito de tolerância ao ruído, já que uma entrada corrompida por ruído pode ser considerada um padrão novo. Assim sendo, testa-se a capacidade de generalização do modelo CAT com contexto e redundância por proximidade euclideana (Seção 6.5.2) na aprendizagem e recuperação de trajetórias do tipo m-m/cc.

Os parâmetros do modelo tiveram os seguintes valores: $\alpha=10^{6}, \beta=0,2 ; \lambda=1-\beta$ $=0,8 ; \delta=1 ; \gamma=0,98 ; k=3 ; n=18$ e $m=100$. As posições espaciais reais e as reproduzidas pelo primeiro vencedor são mostradas na Figura 36. O asterisco “*” indica a trajetória real, enquanto o círculo vazio "o" indica a resposta da rede.

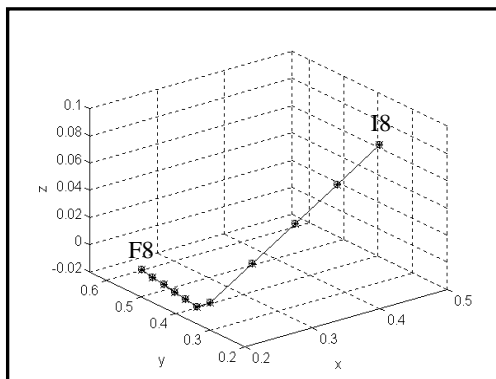

(a)

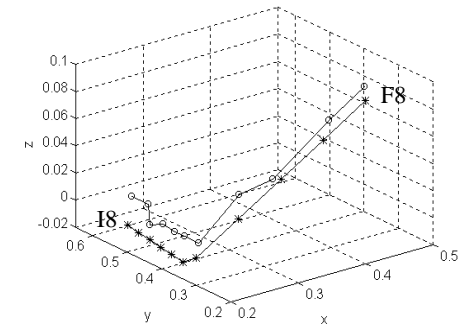

(d)

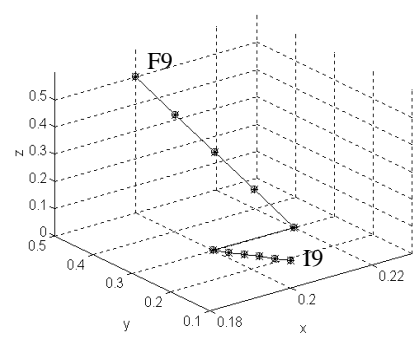

(b)

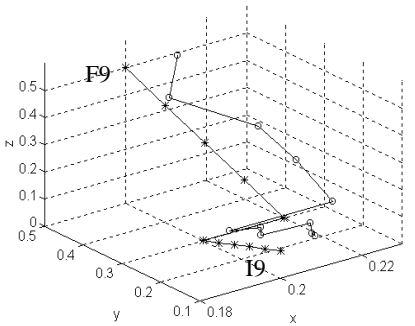

(e)

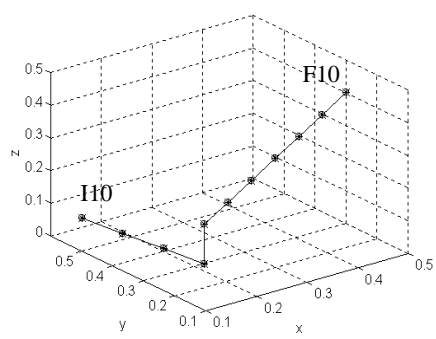

(c)

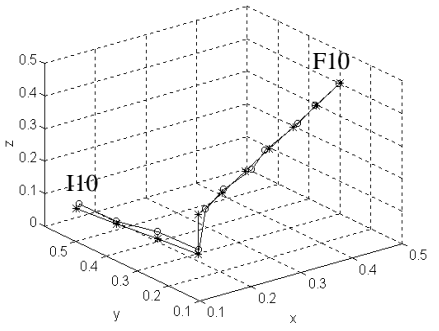

(f)

Figura 36: Trajetórias espaciais reais e geradas pela rede para sequiências do tipo m-m/cc usando o modelo com contexto e redundância por proximidade euclideana. (a)-(c) Entradas treinadas e (d)-(f) entradas não treinadas (com ruído). Todos os resultados são referentes ao primeiro vencedor.

Os erros de rastreamento para as trajetórias na Figura 36d-f são: $E_{t}(\mathrm{I} 8-\mathrm{F} 8)=$ 0,$000315 ; E_{t}(\mathrm{I} 9-\mathrm{F} 9)=0,000257$ e $E_{t}(\mathrm{I} 10-\mathrm{F} 10)=0,000172$. 
Tomando o resultado para a trajetória I8-F8 como exemplo, a Tabela 5 mostra os 3 primeiros $(k=3)$ neurônios vencedores para cada um dos 11 estados da trajetória durante o treinamento e teste. O treinamento é feito usando entradas "limpas", sem ruído. Enquanto que o teste inclui ruído estocástico gaussiano (média $=0$ e variância $=$ 0,09), simulando erros de medida. A segunda coluna, mostra os vencedores durante treinamento e a terceira mostra os vencedores durante a fase de teste. Pode-se perceber que a trajetória I8-F8 com ruído foi recuperada corretamente, com pequeno erro de rastreamento, porque o primeiro vencedor para cada estado pertencia ao grupo que codificou este mesmo estado durante a fase de treinamento. Portanto, conclui-se que o mecanismo de redundância funciona "aumentando" a bacia de atração para cada um dos estados da trajetória, além de tornar a rede tolerante a falhas.

Tabela 5: Vencedores durante treinamento e teste para entradas sem ruído ( $2^{\mathrm{a}}$ coluna) e com ruído estocástico ( $3^{\mathrm{a}}$ coluna).

\begin{tabular}{|c|c|c|}
\hline Estado & $\begin{array}{c}\text { Vencedores treino } \\
\text { (sem ruído) }\end{array}$ & $\begin{array}{c}\text { Vencedores teste } \\
\text { (com ruído) }\end{array}$ \\
\hline 1 & $37-16-83$ & $16-83-37$ \\
\hline 2 & $17-64-30$ & $64-30-17$ \\
\hline 3 & $69-7-25$ & $7-25-69$ \\
\hline 4 & $35-23-68$ & $23-68-35$ \\
\hline 5 & $43-74-86$ & $74-86-43$ \\
\hline 6 & $78-44-10$ & $44-10-78$ \\
\hline 7 & $12-36-45$ & $36-45-12$ \\
\hline 8 & $15-67-32$ & $67-32-15$ \\
\hline 9 & $63-95-47$ & $95-47-63$ \\
\hline 10 & $24-46-54$ & $46-54-24$ \\
\hline 11 & $97-14-82$ & $14-82-97$ \\
\hline
\end{tabular}

\subsection{Resumo do Capítulo}

Neste capítulo foram mostrados diversos experimentos que tinham como objetivo maior avaliar a performance do modelo proposto no Capítulo 6. Tais experimentos consistiram na simulação da aprendizagem e reprodução de sequiências 
temporais na forma de trajetórias do braço do robô PUMA 560. As trajetórias utilizadas levavam em consideração principalmente a existência de pontos em comum. Os testes realizados estudaram o funcionamento (aprendizagem e reprodução), o papel das unidades de contexto, a tolerância à falhas e a capacidade de generalização dos três modelos.

Os testes de funcionamento foram realizados utilizando-se o modelo básico para facilitar o entendimento do mecanismo de aprendizagem da ordem temporal da seqüência via conexões laterais. Esta aprendizagem é implementada através de uma regra hebbiana temporal que correlaciona padrões de ativação da rede em instantes de tempo consecutivos. É importante ressaltar que o número de pontos em uma trajetória, ou seja, o tamanho da seqüência não afeta o desempenho do modelo.

O funcionamento do modelo CAT básico está limitado à codificação de trajetórias sem pontos em comum. Para que seja possível aprender trajetórias que compartilham estados faz-se necessária a presença de unidades de contexto. Estas permitem diferenciar estados idênticos mas pertencentes à seqüências diferentes.

Permitindo que mais de um neurônio codifique cada estado de uma trajetória particular evita-se a perda total ou parcial da trajetória, tornando o modelo tolerante à falhas. A redundância na representação pode ser implementada utilizando-se o conceito de vizinhança topológica ou o de similaridade com a entrada. Esta redundância na representação também é útil em situações em que a rede necessite generalizar conforme foi verificado.

Dos resultados pode-se concluir que os modelos CAT com contexto e redundância satisfazem todos os requisitos necessários para uma reprodução de seqüências temporais de maneira precisa e sem ambigüidades. Isto é possível devido aos seguintes fatores: (a) existência de um mecanismo de exclusão, (b) presença de informação de contexto, e (c) redundância na representação dos estados das trajetórias.

Nas simulações mostradas neste capítulo todas as trajetórias (Figuras 25-28) foram utilizadas com o algoritmo proposto e suas variações, calculando-se o erro de rastreamento e a ordem de reprodução de suas componentes. O resultado obtido em relação à precisão foi muito semelhante para todas. Optou-se por mostrar apenas as mais relevantes para não sobrecarregar à apresentação dos resultados. 


\section{Capítulo 8}

\section{Conclusões}

Esta dissertação teve como objetivo maior a proposição de um modelo de rede neural não-supervisionada para processamento de sequiências temporais em robótica. Três foram as áreas envolvidas nesta pesquisa: (1) redes neurais artificias e paradigmas de aprendizagem não-supervisionadas, (2) redes neurais não-supervisionadas para processamento temporal, e (3) redes neurais não-supervisionadas em Robótica. Tomando por base esta divisão, os capítulos foram distribuídos visando facilitar o entendimento dos principais conceitos relacionados com cada uma das três áreas citadas. Em todos os capítulos procurou-se focalizar em pontos que fossem úteis para o modelo proposto.

O Capítulo 1 fez uma breve explicação da natureza do problema e da organização do restante da dissertação. Já Capítulo 2 tratou da apresentação do problema e de conceitos ligados ao processamento de seqüências temporais propriamente dito. Entre estes, destacam-se definições de seqüências temporais, de contexto, grau e tipos de seqüências. O processamento de padrões temporais foi dividido em quatro classes básicas de problemas, a saber: (1) reconhecimento de seqüências, (2) reprodução de seqüências, (3) associação de seqüências, e (4) produção de seqüências temporais. O problema abordado nesta dissertação envolveu a produção de sequiências temporais na forma de trajetórias do robô PUMA 560.

No Capítulo 3 foram apresentadas arquiteturas de RNAs não-supervisionadas e seus dois principais paradigmas de aprendizagem para processamento de padrões estáticos: competição e correlação. A intenção é usar estes paradigmas em conjunto no modelo proposto. Neste capítulo, a atenção foi voltada principalmente para a forma como a informação é codificada pelos pesos sinápticos e como estes são ajustados. Procurou-se também entender porque informação temporal não é codificada de forma adequada por estes modelos.

No Capítulo 4 foram mostrados diversos modelos não-supervisionados dotados de mecanismos capazes de processar informação temporal. Para que se possa estabelecer associações entre padrões ocorrendo em instantes de tempo diferentes, a 
rede neural deve possuir uma capacidade de memória de curta duração. As principais implementações de MCD foram também discutidas neste capítulo.

Em geral, os modelos descritos no Capítulo 4 são versões temporais de algoritmos amplamente usados em processamento de padrões estáticos como, por exemplo, o mapa auto-organizável de Kohonen. Estas versões "dinâmicas" incorporam informação temporal de duas maneiras: considera informação temporal nos padrões de entrada mantendo o algoritmo neural original ou introduz um modelo de MCD à dinâmica de ativação e aprendizagem do modelo original de modo a manter diferentes representações da entrada por um certo período.

As propriedades principais extraídas deste capítulo e que foram utilizadas no modelo proposto dizem respeito à $\mathrm{MCD}$ com linhas de atraso para estabelecer associações entre padrões consecutivos e à importância do contexto na reprodução sem ambigüidades das seqüências.

O Capítulo 5 apresentou modelos de redes neurais não-supervisionadas para planejamento e controle de robôs (manipuladores ou móveis). Neste capítulo dividiu-se os tipos de sequiências normalmente encontradas em robótica em dois tipos básicos: seqüências do tipo percepção-ação e sequiências do tipo trajetórias de robôs. Foram apresentados ainda modelos que resolviam o problema da cinemática inversa em robôs manipuladores. É importante ressaltar que nenhum destes modelos nãosupervisionados para robótica abordou o problema do aprendizado de trajetórias múltiplas com estados em comum. Uma característica interessante que foi utilizada no modelo proposto consiste na reprodução dos estados da trajetória de modo antecipatório, ou seja, quando um determinado estado da trajetória é apresentado à rede, esta responde fornecendo o próximo estado da trajetória.

Os capítulos anteriores mostraram o estado da arte em processamento de seqüências temporais usando modelos não-supervisionados. De posse de alguns conceitos e definições extraídas destes capítulos, foi proposto no Capítulo 6 um modelo que de rede para processamento de sequiências temporais sob a forma de trajetórias do robô PUMA 560. Trajetórias para teste foram geradas a partir da toolbox Robotics do Matlab® e podem conter estados em comum. Tais estados consistem na informação de posição espacial, nos ângulos das juntas do manipulador e do torque aplicado à cada uma destas juntas. Estas trajetórias são aprendidas pela rede de forma a serem reproduzidos na ordem correta, de modo preciso e sem incertezas. 
Estas são decorrentes da codificação de múltiplas trajetórias com estados em comum. As características originais do modelo proposto são enumeradas a seguir:

(i) Aprendizagem competitiva com exclusão dos neurônios vencedores;

(ii) Redundância na representação de cada estado da trajetória;

(iii) Aprendizagem hebbiana para modelar a ordem temporal dos padrões da sequiência de entrada;

(iv) Aprendizagem de múltiplas trajetórias através do uso de informação de contexto global (no presente caso, dada apenas pela posição espacial final desejada para o braço).

Juntas, as quatro características acima permitem que a rede aprenda e reproduza padrões temporais com precisão e sem ambigüidades. Além disso, conforme foi mostrado nas simulações do Capítulo 7 , o modelo é tolerante à faltas nos neurônios e à presença de ruído na entrada. Portanto, pode-se afirmar que o modelo reúne uma quantidade de propriedades que são de grande importância para o projeto de sistemas robóticos inteligentes, a saber:

(i) Processo de aprendizagem simples e rápido, com baixo custo computacional quando comparado com técnicas de aprendizagem supervisionada;

(ii) Reprodução acurada dos padrões armazenados pelos pesos sinápticos intercamadas;

(iii) Capacidade de reproduzir seqüências sem ambigüidades quando estas compartilham estados;

(iv) Tolerância à falhas, visto que uma seqüência pode ainda ser reproduzida mesmo quando ocorrem perdas de neurônios;

(v) Aprendizagem da cinemática e da dinâmica inversa.

Além disso, o modelo pode facilmente ser adaptado para funcionar em outras tarefas de processamento de seqüências como, por exemplo, controle de robôs móveis e processamento de linguagem natural. 
Outras contribuições do presente trabalho de pesquisa foram a reunião, em um único documento, de diferentes conceitos e definições relacionados com o processamento temporal usando redes não-supervisionadas e a proposição de uma nova interpretação para a função de conexões laterais em modelos de RNAs nãosupervisionadas: modelagem da ordem de ocorrência de eventos temporais.

Em desenvolvimentos futuros, a performance do modelo proposto nesta dissertação será explorada em situações de produção de trajetórias entre dois estados quaisquer. Ou seja, dado apenas os estados inicial e o final a rede deve se autoorganizar de forma a interpolar entre estes dois pontos, gerando ângulos e torques adequados à realização da tarefa. A presença de obstáculos é outro ponto a se considerar neste problema de produção de trajetórias. Uma possível extensão do modelo proposto também deve levar em consideração à capacidade de se adaptar à mudanças nos parâmetros geométricos, mecânicos e dos sensores.

A maioria das abordagens para processamento temporal que usam redes neurais assumem uma taxa fixa de amostragem do sinal de entrada, tal que a rede e a entrada estejam sempre sincronizadas. De acordo com este cenário, a ordem dos eventos é a única propriedade do tempo sendo modelada. O problema com esta suposição é que, em muitas outras aplicações do mundo real, as entradas não vem na forma de seqüências com taxa de amostragem fixa, mas sim como sinais dinâmicos com escalas de tempo que variam. Desta forma, a modelagem dinâmica desses sinais requer não apenas a aprendizagem da ordem temporal de tais seqüências, mas também a habilidade de lidar com variação temporal no sinal. Assim, uma outra possível extensão para o presente trabalho seria a proposição de modelos com propriedades de lidar com aprendizagem de seqüências e variabilidade temporal.

Em trabalhos futuros, envolvendo o modelo descrito neste documento, pretendese desenvolver uma análise matemática detalhada que servirá para fundamentar e/ou tirar conclusões a respeito de determinadas características, como por exemplo: se o mecanismo de redundância do modelo favorece ou não o surgimento de crosstalk, influenciando na recuperação dos estados da trajetória. 


\section{Referências}

Ahalt, S. C.; Krishnamurthy, A. K.; Chen, P.; Melton, D. E. (1990). Competitive learning algorithms for vector quantization. Neural Networks, v.3, p.277-290.

Althöfer, K.; Bugmann, G. (1995). Planning and learning goal-directed sequences of robot arm movements. In: Fogelman-Soulié F. and Gallinari P.(eds.), Proceedings of the International Conference On Artificial Neural Networks (ICANN'95), Paris, France, v.1, p.449-454.

Araújo, A. F. R.; D’Arbo, H. (1998). Partially recurrent neural network to perform trajectory planning, inverse kinematics, inverse dynamics. Artigo aceito para apresentação, IEEE International Conference on System, Man, and Cybernetics, San Diego, USA.

Araújo, A. F. R.; Souza, F. (1997). Estudo de interface gráficas para aplicação em sistemas dinâmicos. V SICUSP - Simpósio de Iniciação Científica da Universidade de São Paulo, projeto 2, v.2, p.120.

Araújo, A. F. R.; Vieira, M. (1998). Associative memory used for trajectory generation and inverse kinematics problem. Proceedings of the IEEE World Congress on Computacional Intelligence (IJCNN), Anchorage, USA, p.2057-2052.

Barreto, G. de A.; Araújo, A. F. R.; Rosa, M. de O. (1997). Algoritmo de busca heurística usando redes neurais competitivas para planejamento ótimo de trajetória de um robô móvel. Anais do III Congresso Brasileiro de Redes Neurais, Florianópolis, SC, Brasil, p.408-413.

Barreto, G. de A.; Araújo, A. F. R. (1998a). Improving the performance of differential competitive learning in clustering tasks. Proceedings of the IASTED Conference on Artificial Intelligence and Soft Computing, Cancún, México, 27-30 May, p.431-434.

Barreto, G. de A.; Araújo, A. F. R. (1998b). The role of excitatory and inhibitoy learning in EXIN networks. Proceedings of the IEEE World Congress on Computacional Intelligence (IJCNN), Anchorage, USA, p.1032-1037.

Barreto, G. de A.; Araújo, A. F. R. (1998c). Competitive and Temporal Hebbian Learning for Production of Robot Trajectories. Artigo aceito para apresentação do V Simpósio Brasileiro de Redes Neurais (SBRN'98), Belo Horizonte, MG.

Bradski, G.; Carpenter, G.A.; Grossberg, S. (1994). STORE: working memory networks for storage and recall of arbitrary temporal sequences. Biological Cybernetics, n.71, p.469-480.

Bugmann, G.; Koay, K. L.; Barlow, N.; Phillips, M.; Rodney, D. (1998) Stable encoding of robot trajectories using normalized radial basis functions: 
Application to an Autonomous Wheelchair. Proceedings of the 29th International Symposium On Robotics, Advanced Robotics: Beyond 2000, Birmingham, UK, 27-30 April, 1998.

Chappell, C. J.; Taylor, J. G. (1993). The temporal Kohonen map. Neural Networks, v.6, p.441-445.

Chen, P.C.Y; Mills, J.K.; Smith, K.C. (1996). Performance improvement of robot continuous-path operation through iterative learning using neural networks. Machine Learning, n.23, p.75-105.

Corke, P.I. (1996). A Robotics toolbox for MATLAB. IEEE Robotics; Automation Magazine, v.3, n.1, p.24-32.

Craig, J.J. (1989). Introduction to Robotics: Mechanics and Control, $2^{\mathrm{a}}$ edição, Addison-Wesley.

Dayan, P.; Zemel, R.S. (1995). Competition and multiple cause models. Neural Computation, v.7, n.3, p.565-579.

Denavit, J.; Hartenberg, R. S. (1955) A kinematic notation for lower-pair mechanisms based on matrices. Journal of Applied Mechanics, p. 215-221.

Denham, M. J.; McCabe, S. L. (1995). Robot control using temporal sequence learning. Proceedings of the World Congress on Neural Networks, v.II, p.346348.

Denham, M. J.; McCabe, S. L. (1996). Biological temporal sequence processing and its application in robot control. Proceedings of the UKACC International Conference on CONTROL'96, p.1266-1271.

de Vries, B.; Principe, J.C. (1992). The gamma model - A new neural model for temporal processing, Neural Networks, v.5, p.1205-1209.

DeSieno, D. (1988). Adding a conscience to competitive learning. Proceedings of the IEEE International Conference on Neural Networks, San Diego, USA, v.1, p.117-124.

Diamantaras, K. I.; Kung, S. Y.; Diamantaras, K. (1996). Principal component neural networks: Theory and applications. John Wiley \& Sons.

Euliano, N. R.; Principe, J. C. (1996). Spatio-temporal self-organizing feature maps. Proceedings of the International Conference on Neural Networks (ICNN'96), Washington, DC., USA, v.4, p.1900-1905.

Földiák, P. (1989). Adaptive network for optimal linear feature extraction, Proceeedings of the IEEE/INNS Joint Conference on Neural Networks, San Diego, USA, v.1, p.401-405. 
Földiák, P. (1990). Forming sparse representations by local anti-Hebbian learning. Biological Cybernetics, n.64, p.165-170.

Gibet, S.; Marteau, P.F. (1994). A self-organized model for the control, planning; learning of nonlinear multi-dimensional systems using a sensory feedback. Journal of Applied intelligence, n.4, p.337-349.

Girolami, M.; Fyfe, C. (1996). A temporal model of linear anti-Hebbian learning. Neural Processing Letters, n.4, p.139-148.

Granger, R.; Whitson, J.; Larson, J.; Lynch G. (1994). Non-Hebbian properties of long term potentiation enable high-capacity encoding of temporal sequences, in: Proceedings of the National Academy of Science USA, v.91, p.10104-10108.

Gray, R.M. (1984). Vector quantization. IEEE ASSP Magazine, p.4-29, April.

Grossberg, S. (1969). Some networks that can learn, remember, and reproduce any number of complicated space-time patterns, Journal of Mathematics and Mechanics, v.19, p.53-91.

Grossberg, S. (1974). Classical and instrumental learning by neural networks. Progress in Theoretical Biology. New York: Academic Press, v.3, p.51-141.

Grossberg, S. (1976). Adaptive patttern classification; universal recoding I: Parallel development; coding of neural feature detectors, Biological Cybernetics, v.23, p.121-134.

Grossberg, S. (1997). Birth of a leaning law. Boston University Technical Report, CAS/CNS-TR-97-017. Disponível em http://cns-web.bu.edu/Profiles/Grossberg/ Learning.html.

Hadamard. J. (1923). Lectures on the Cauchy problem in linear partial differential equations. New Haven, CT: Yale University Press.

Halperin, D.; Kavraki, L.; Latombe, J.-C. (1998). Robot algorithms. CRC Handbook of Algorithms and Theory of Computation, M. Atallah (ed.), Boca Raton, FL:CRC Press, capítulo 21.

Harpur, G. F. (1997). Low entropy coding with unsupervised neural networks. Cambridge, 150p., Phd Thesis, Department of Engineering, University of Cambridge.

Haykin, S. (1994). Neural networks: a comprehensive foundation. Macmillan College Publishing Company, Inc., Englewood Cliffs, NJ, USA.

Hebb, D.O. (1949). The organization of behavior. New York: Wiley. 
Heikkonen, J.; Surakka, M.; Riekki, J. (1995). Self-organizing controller for a mobile robot. Proceedings of International Conference on Engineering Applications of Neural Networks, Otaniemi, Espoo, Finland, p.53-56.

Heikkonen, J.; Koikkalainen, P. (1997). Self-organization and autonomous robots. In: $O$. Omidvar and P. van der Smagt, Neural Systems for Robotics, Academic Press, p.297-337.

Hertz, J., Krogh, A.; Palmer, R.G. (1991) Introduction to the theory of neural computation. Addison-Wesley Publishing Company, Redwood City, CA.

James, D.L.; Miikkulainen, R. (1995). SARDNET: A Self-Organizing Feature Map for Sequences. In: G. Tesauro; D. S. Touretzky; T. K. Leen (eds.), Advances in Neural Processing Systems 7, Cambridge, MA: MIT Press, p.577-584.

Kangas, J. (1990). Time-Delayed Self-Organizing Maps. Proceedings of the International Joint Conference on Neural Networks, San Diego, CA, USA, v.II, p.331-336.

Kohonen, T. (1990). The self-organizing map. Proceedings of IEEE, v.78, p.14641480 .

Kohonen, T. (1997). Self-organizing maps. 2ed., Springer-Verlag.

Kong, S.-G.; Kosko, B. (1991). Differential competitive learning for centroid estimation and phoneme recognition. IEEE Transactions on Neural Networks, v.2, n.1, p.118-124.

Kopecz, K. (1995). Unsupervised learning of sequences on maps with lateral connectivity. Proceedings of the International Conference on Artificial Neural Networks (ICANN'95), v.2, p.431-436.

Kosko, B. (1992). Neural networks and fuzzy systems: a dynamical systems approach to machine intelligence. Prentice Hall, Englewood Cliffs, NJ, USA.

Koutroumbas, K; Kaloupsidis, N. (1994). Qualitative analysis of the parallel and asynchronous modes of the Hamming network. IEEE Transactions on Neural Networks, v.5, n.1., p.380-391.

Kuperstein, M. (1988). Neural model for adaptive Hand-eye coordination for single postures. Science, v.239, p.1308-1311.

Kuperstein, M.; Rubinstein, J. (1989). Implementation of an adaptive neural controller for sensory-motor coordination. IEEE Control Systems Magazine, v.9, n.3, p.25-30.

Lippmann, R.P. (1987). An introduction to computing with neural nets. IEEE ASSP Magazine, p.4-22, April. 
Marshall, J.A. (1990a). Representation of uncertainty in self-organizing neural networks. Proceedings of the International Neural Network Conference, Paris, France, p.809-812.

Marshall, J.A. (1990b). A self-organizing scale-sensitive neural network. Proceedings of the International Joint Conference on Neural Network, San Diego, USA, p.649-654.

Marshall, J.A. (1995). Adaptive perceptual pattern recognition by self-organizing neural networks: context, uncertainty, multiplicity, and scale. Neural Networks, v.8, n.3, p.335-362.

Martinetz, T.M.; Ritter, H.J.; Schulten, K.J. (1990). Three-dimensional neural net for learning visuomotor coordination of a robot arm. IEEE Transactions on Neural Networks, v.1, n.1, p.131-136.

Martinetz, T.M.; Schulten, K. J. (1991). A "neural gas" network learns topologies. In: Kohonen et al., (eds.), Proceedings of the International Conference on Neural Networks, Espoo Finland, June 24-28, v.1, p.397-407.

Mozer, M.C. (1993). Neural net architectures for temporal sequence processing, in: Predicting the Future and Understanding the Past (A. Weigend $\mathrm{e} N$. Gershenfeld, eds.), Redwood City, CA: Addison-Wesley, p.243-264.

Musílek, P. (1995). Neural networks in navigation of mobile robots: A survey. Neural Network World, n.6, p.929-943.

Oliveira, J.M.; Amaral, J.R. (1997). Princípios de neurociência. TECNOPRESS Editora e Publicidade Ltda.

Oja, E. (1982). A simplified neuron model as a principal component analyser. Journal of Mathematical Biology, n.15, p.267-273.

Rao, R.P.N.; Fuentes, O. (1996). Learning navigational behaviors using a predictive sparse distributed memory. Proceedings of From Animals to Animats; The 4th International. Conference on Simulation of Adaptive Behavior, MIT Press, p.382-390.

Ray, S.R.; Kargupta, H. (1996). A temporal sequence processor based on the biological reaction-diffusion process. Complex Systems, v.9, n.4.

Ritter, H.J.; Martinez, T.M.; Schulten, K. J. (1992). Neural computation and selforganizing maps: An Introduction.Reading: Addison-Wesley.

Rumelhart, D.E.; Zipser, D. (1985). Feature discovery by competitive learning. Cognitive Science, n.9, p.75-112. 
Salomon, R. (1996). Neural network in the context of autonomous agents: some concepts revisited. Proceedings of the Artificial Neural Network in Engineering Conference (ANNIE`96), p.109-116, New York: ASME Press.

Sum, J.P.F.; Tam, P.K.S. (1996). Note on the Maxnet dynamics. Neural Computation, n.8, p.491-499.

Tank, D.W.; Hopfield, J.J. (1987). Neural computation by concentrating information in time, Proceedings of the National Academy of Science USA, v.84, p.1896-1900.

Varsta, M; Heikkonen, J.; Millán, J. del R. (1997). Context Learning with the SelfOrganizing Map. Workshop on Self-Organizing Map (WSOM'97), Helsinki University of Technology, Finland, June 4-6.

von der Malsburg, Ch. (1973). Self-organization of orientation sensitive cells in the striate cortex. Kybernetik, v. 14, p.85-100.

Yen, J.-C.; Chang, F.-J.; Chang, S. (1994). A new winners-take-all architecture in neural networks. IEEE Transactions on Neural Networks, v.5, n.5, p.838-843.

Waibel, A.; Hanazawa, T.; Hinton, G.E.; Shikano, K.; Lang, K.J. (1989). Phoneme recognition using time-delay neural networks, IEEE Transactions on ASSP, n.37, p.328-339.

Walter, J.A.; Schulten, K.J. (1993). Implementation of self-organizing neural networks for visuo-motor control of an Industrial Robot. IEEE Transactions on Neural Networks, v.4, n.1, p.86-95.

Wang, D. L. (1995). Temporal pattern processing. In: The Handbook of Brain Theory and Neural Networks, M. A. Arbib (ed.), MIT Press, 967-971, 1995.

Wang, D. L.; Arbib, M. A. (1990). Complex temporal sequence learning based on short-term memory. Proceedings of IEEE, v.78, p.1536-1543.

Wang, D. L.; Arbib, M. A. (1993). Timing and chunking in processing temporal order. IEEE Transactions on Systems, Man, Cybernetics, v.23, p.993-1009.

Wang, D. L.; Yuwono, B. (1995). Anticipation-based temporal pattern generation. IEEE Transactions on Systems, Man, Cybernetics, v.25, p.615-628.

Wang, D. L.; Yuwono, B. (1996). Incremental learning of complex temporal patterns. IEEE Transactions on Neural Networks, v.7, n.6, p.1465-1481.

Winston, P.H. (1992). Artificial Intelligence. 3ed., Addison-Wesley, 1992. 


\section{APÊNDICE I}

\section{Redes Neurais Artificiais - Conceitos Básicos}




\section{Redes Neurais Artificiais - Conceitos Básicos}

$\mathrm{Na}$ busca por máquinas inteligentes, um modelo cujo funcionamento se deseja replicar ou reproduzir é o cérebro humano. O cérebro humano possui características úteis para uso em qualquer sistema "inteligente" artificial, como por exemplo: robustez e tolerância a falhas; flexibilidade, adaptabilidade e capacidade de aprendizado; capacidade de processar informação nebulosa, probabilística, ruidosa ou inconsistente; processamento paralelo; tamanho reduzido, grande capacidade de processamento e baixo consumo de energia. Logo, é natural que surjam modelos computacionais que visam reproduzir algumas das "virtudes" listadas acima, e que tais modelos possam ser utilizados em máquinas, onde se espera que melhoria de seu desempenho durante a execução de uma tarefa específica.

Em geral, tais modelos artificiais exploram uma característica específica do funcionamento do cérebro (memória, visão, etc.), de modo que uma gama enorme de algoritmos tem sido propostos. Contudo, estes modelos guardam um grande número de semelhanças entre si, como por exemplo serem constituídos de modelos simplificados de células nervosas, também chamadas de neurônios.

O neurônio é o elemento construtivo básico do sistema nervoso. O cérebro humano é composto por aproximadamente $10^{11}$ a $10^{12}$ células nervosas, com cerca de $10^{15}$ interconexões em caminhos de transmissão. Os neurônios se ligam entre si formando uma imensa e complexa rede, na qual recebem impulsos eletroquímicos, processam estes impulsos e os retransmitem a outras células nervosas. São os neurônios e suas conexões sinápticas que servem de inspiração às redes neurais artificiais. ROSEMBLATT (1962) aponta cinco componentes importantes em um neurônio (ver Figura 37).

- DENDRITOS: em forma de galhos secos, são captadores e condutores de estímulos nervosos, excitatórios ou inibitórios, de outros neurônios, transportandoos ao corpo celular.

- CORPO CELULAR: neste encontra-se o Núcleo, que é o responsável pelo processamento dos estímulos nervosos aferentes. Envia um novo impulso ao axônio, dependendo da comparação entre o resultado do processamento e a diferença de potencial entre as paredes interna e externa do neurônio. 
- AXÔNIO: expansão linear do corpo celular, conduzindo informações a grandes distâncias, por propagação de um sinal elétrico transitório, chamado potencial de ação.

- SINAPSES: região situada entre as terminações do axônio de um neurônio (denominadas pré-sinápticas) e as superfícies receptoras dos dentritos ou do corpo celular de outro neurônio (denominadas pós-sinápticas). As sinapses funcionam como válvulas capazes de controlar a transmissão de impulsos nervosos ou potenciais de ação e regular a sua intensidade. Durante a vida de um sistema nervoso, as sinapses estão em constante formação e modificação.

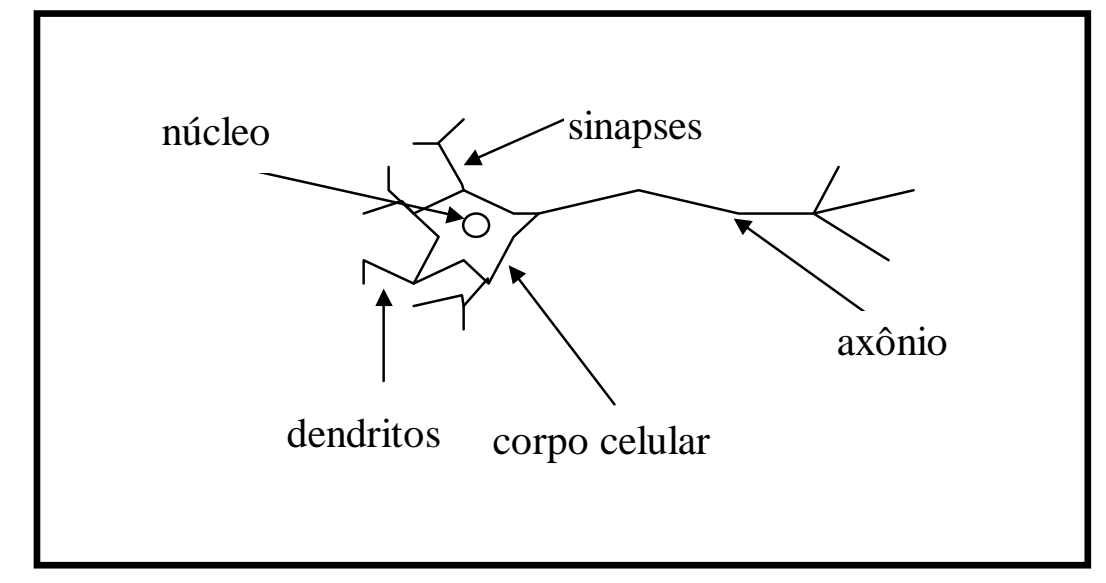

Figura 37: Esquema simplificado de um neurônio.

Assim, uma rede neural artificial (RNA) pode ser vista como um conjunto de elementos processadores simples, baseados em neurônios, que são ligados uns aos outros através de conexões análogas às sinapses. Estas conexões armazenam o "conhecimento" da rede e os diversos padrões de atividade expressam os vários objetos codificados pela rede.

Em outras palavras, as conexões fazem o papel de memória de longo prazo, enquanto que o estado de ativação das unidades de uma rede realizam o papel de memória de curto prazo. O conhecimento da rede é adquirido por meio de um processo de treinamento no qual, em suas versões mais básicas, apenas as conexões entre as unidades são variadas através da mudanças de pesos. O entendimento do neurônio é, portanto, o ponto de partida para criação de uma rede neural.

O modelo mais explorado e que serve como base para a maioria dos estudos, é o PERCEPTRON que foi proposto originalmente por ROSENBLATT (1962). O 
Perceptron (Figura 38) equivale a um único neurônio, tem sua forma e características inspiradas no neurônio biológico. É através desta abstração que se constróem diferentes modelos de redes neurais com características próprias, mas que possuem o Perceptron como unidade básica. As entradas equivalem a sinais que chegam aos dendritos, os pesos representam as sinapses, as regras de propagação e ativação são a função do núcleo e a saída representa o sinal que o axônio propaga.

As entradas $x_{i}, i=1,2,3, \ldots, n$ são binárias; os pesos $w_{j i}$ podem ser positivos (excitatórios) ou negativos (inibitórios); a regra de agregação é dada por: $N E T_{j}=\sum_{i=1}^{n} w_{j i} x_{i}$, a regra de ativação determina se o somatório é maior ou não que um certo limiar (threshold); a saída será 1 se a somatória for maior ou igual ao limiar, e será 0 se a somatória for menor que o limiar. O conhecimento do sistema é armazenado pelas conexões. O treinamento do sistema consiste em alterar os valores destas conexões, empregando algoritmos de treinamento, até obtermos uma saída desejada.

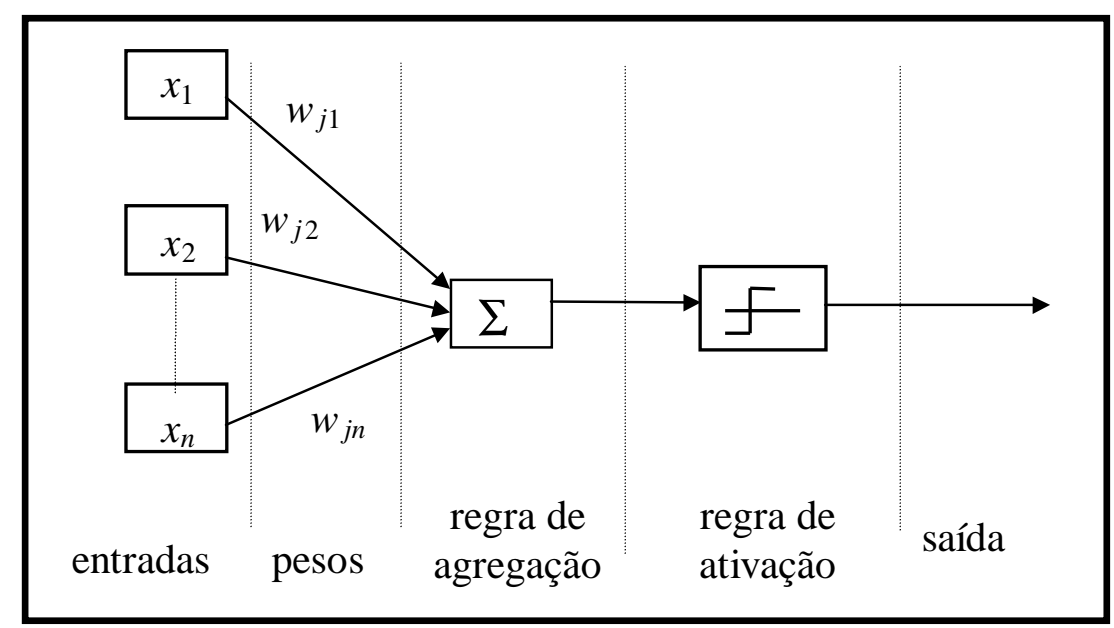

Figura 38: Modelo chamado Perceptron.

Algoritmos de treinamento de redes neurais podem ser supervisionados ou nãosupervisionados. No primeiro caso, utiliza-se um "professor”. Durante o treinamento, são fornecidos pares formados pela entrada e pela saída-desejada e apenas as conexões entre as unidades são variadas através das mudanças dos pesos ajustados como função do erro entre a saída desejada e a saída obtida pela rede em treinamento. No caso dos algoritmos não-supervisionados, a própria rede se encarrega de fazer o mapeamento entre um espaço de entrada para um espaço de saída, auto-organizando suas conexões sinápticas para isto. Os algoritmos supervisionados são normalmente mais usados em 
aplicações de Engenharia, por encontrarem uma resposta desejada. Contudo, os modelos não-supervisionados são mais plausíveis sob os pontos de vista biológico e psicológico.

\section{Framework para Análise e Projeto de RNAs}

RUMELHART \& McCLELLAND (1988) propuseram oito características, comuns à maior parte dos modelos de redes neurais artificiais, as quais formam um framework básico discutido a seguir:

1) Um conjunto de unidades de processamento: é o primeiro estágio da elaboração de um modelo de RNAs. Possui dois aspectos importantes: o primeiro é quanto cada unidade de processamento vai se parecer com uma célula neural; o segundo é o significado de cada unidade, ou seja, o que ela representa individualmente e em conjunto.

2) Um padrão de conectividade entre as diferentes unidades: $O$ padrão de conectividade define o conhecimento do sistema, determinando como uma rede responde a uma dada entrada. Tal padrão é codificado por pesos $w_{j i}$, representando conexões sinápticas excitatórias ou inibitórias entre as unidades $i$ e $j$ (Figura 39).

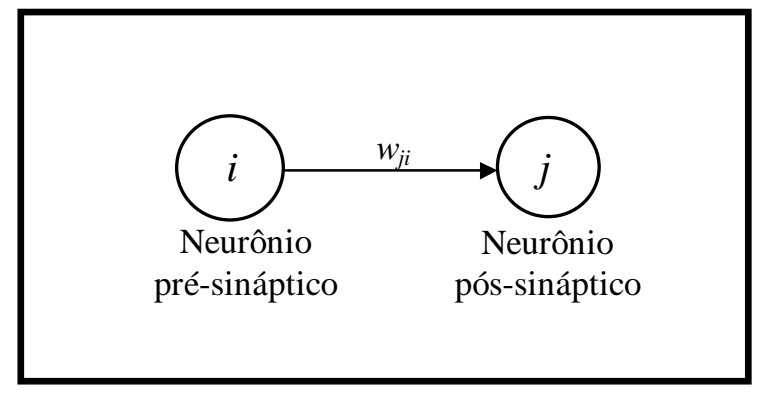

Figura 39: Representação de uma conexão sináptica entre dois neurônios.

3) Definição de diferentes estados de ativação: cada estado de ativação de uma unidade em uma rede neural tem um significado associado. Existem inúmeras possibilidades de estados de ativação das unidades e suas escolhas levam em conta a 
representação escolhida. O estado de ativação pode ser: contínuo ou discreto; limitado ou ilimitado; ter valores reais, binários, bipolares, ou série de valores.

4) Uma Regra de Propagacão: A função desta regra é combinar os valores de entrada de uma unidade com os valores da matriz de conexões para produzir o efeito total "sentido" pela unidade. A regra de propagação equivale à modificação da situação eletroquímica do neurônio.

5) Uma regra de ativacão: Esta regra atualiza o estado de ativação de cada unidade, considerando-se a entrada ponderada desta unidade e seu estado de ativação presente. A regra determina se a unidade está ativa ou não.

6) Uma função de saída para cada unidade: Os sinais que fazem com que as unidades interajam são transmitidos por uma função de saída $y_{j}=f\left(a_{j}(t), w_{j i}(t), t\right)$. A função de saída transforma o estado de ativação de uma unidade $a_{j}(t)$ para um sinal de saída $y_{j}(t)$.

7) Uma regra de aprendizagem: Mudanças nos pesos (conexões) sinápticos são coordenadas por um processo de aprendizagem que pode ser envolver três situações: aparecimento de novas conexões; perda de conexões existentes e modificação de conexões já existentes.

8) Um ambiente no qual o sistema opera: A definição do ambiente deve considerar: sinais de entrada, que são fornecidos à rede como características do meio; um contexto, representando na rede informações importantes para o processamento das entradas, e uma saída que leva informação processada ao meio.

Definidas as características de um modelo de rede neural tais como: o número de unidades de processamento nas camadas diversas camadas, as regras de ativação e propagação, a regra de aprendizagem, os tipos de conexões entre unidades da mesma camada e entre diferentes camadas e também o meio em que vai atuar, este modelo está apto a ser testado em diferentes áreas. 


\section{APÊNDICE II}

Simulação com Modelos de Rede Neural Competitiva 


\section{Simulação com um Modelo de Rede Neural Competitiva}

Neste apêndice é mostrada uma simulação envolvendo o modelo competitivo WTA descrito pelas Equações (7) e (9), e o modelo diferencial (Seção 3.4.2). As redes usadas tem duas entradas e quatro saídas. O conjunto de treinamento é formado por 2000 vetores $(x, y)$ gerados a partir de uma distribuição gaussiana com desvio padrão igual a 0,09 , e com centróides ou modos em $(1 / 3,1 / 3),(1 / 3,2 / 3),(2 / 3,1 / 3)$ e $(2 / 3$, 2/3). A Figura 40 mostra a evolução do treinamento dos vetores de pesos sinápticos $\left(w_{j 1}, w_{j 2}\right)$ onde $\eta=0,01$. Os valores dos peso iniciais foram $\{(0.48,0.48),(0.52,0.48)$, $(0.52,0.52),(0.48,0.52)\}$. Os pesos finais depois das 5000 repetições foram $(0.323$, $0.330),(0.660,0.337),(0.324,0.660),(0.672,0.666)\}$. Pode-se perceber que os vetores de pesos convergiram para os centróides das distribuições.

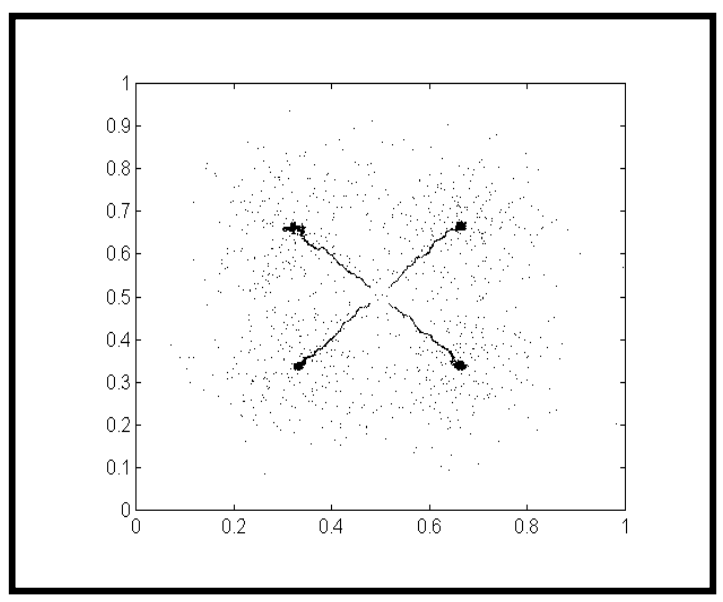

Figura 40: Convergência dos vetores de peso sinápticos para os centróides da distribuição considerada.

A Figura 41 mostra as trajetórias das componentes individuais de um dos vetores de pesos dos dois modelos, convergindo para o centróide em $(2 / 3,1 / 3)$.
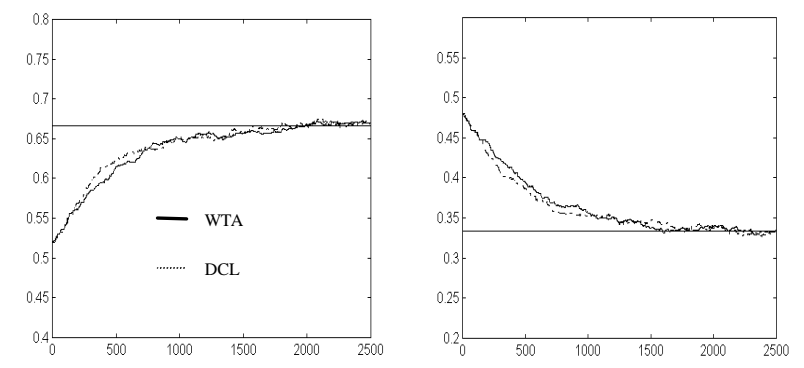

Figura 41: Trajetórias de um dos vetores de pesos do modelo, convergindo para o centróide em $(2 / 3,1 / 3)$ 


\section{APÊNDICE III}

Regras de Aprendizagem Instar e Outstar 


\section{Regras de Aprendizagem Instar e Outstar}

Regras de aprendizagem de neurônios do tipo instar e outstar foram propostas por GROSSBERG $(1974,1997)$ e tem sido usadas em muitos paradigmas de rede neurais artificiais.

Um instar (Figura 42a) consiste de um neurônio alimentado por um conjunto de entradas através de pesos sinápticos. Um outstar (Figura 42b) é um neurônio acionando um conjunto de pesos. Instar e outstar podem ser interconectados de modo a formar redes arbitrariamente complexas, e Grossberg os propôs como modelos de certas funções biológicas. A aparência em forma de estrela sugere os nomes; entretanto, eles não são usualmente desenhados desta forma em diagramas de RNAs.

\section{III.1 Treinamento de um Neurônio do tipo INSTAR}

Um instar executa reconhecimento de padrões; isto é, ele é treinado para responder a um vetor de entrada $\mathbf{X}$ específico e para nenhum outro. Este treinamento é executado ajustando seus pesos para serem parecidos com o vetor de entrada. A saída de um instar é calculada como a soma ponderada de suas entradas, conforme descrito a seguir. Visto de uma outra maneira, este cálculo representa o produto interno do vetor de entrada com o vetor de pesos, que é uma medida de similaridade para vetores normalizados. Conseqüentemente, o neurônio vem a responder mais fortemente para o padrão de entrada para o qual ele foi treinado.

A operação de treinamento é expressa pela fórmula que segue:

$$
w_{j i}(t+1)=w_{j i}(t)+\alpha y_{j}(t)\left[x_{i}(t)-w_{j i}(t)\right]
$$

na qual:

$w_{j i}(t)=$ peso sináptico da entrada $x_{i}(t)$ para o neurônio $j$

$x_{i}(t)=$ componente $i$ da entrada

$\alpha=$ taxa de aprendizagem 


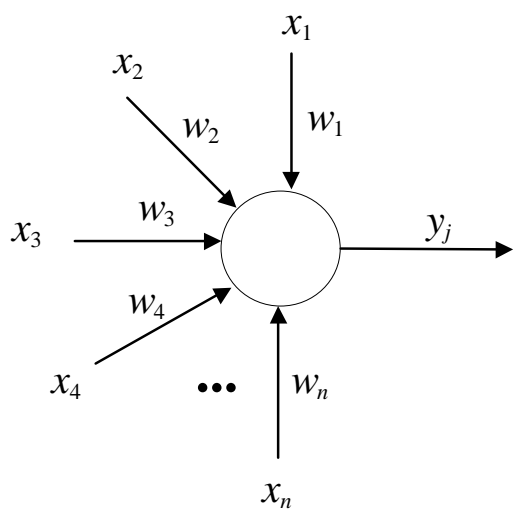

(a)

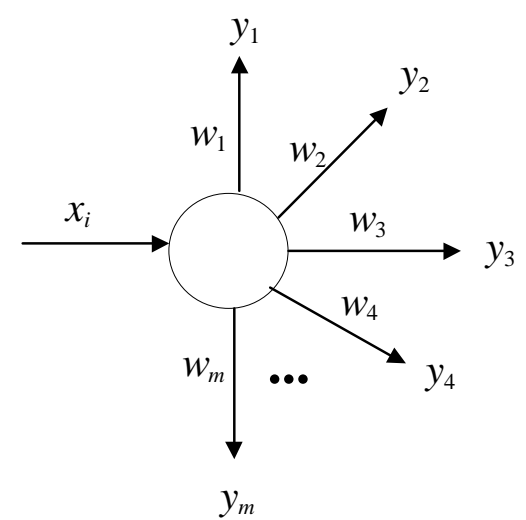

(b)

Figura 42: Tipos de representações para neurônios segundo GROSSBERG (1974). (a) neurônio instar e (b) neurônio outstar.

A Equação (64) diz que se um pesos sináptico é governados por uma regra do tipo instar, então este peso é ajustado apenas quando sua saída (neurônio póssináptico) está ativa. Quando totalmente treinado, a aplicação do vetor de entrada $\mathbf{X}_{i}$ ativará o neurônio instar. Pode ser observado que isto pode ser realizado em um único ciclo de treinamento, se $\alpha=1$. Entretanto, elimina a habilidade do neurônio em generalizar. Propriamente treinado, o instar não responderá apenas para um único vetor específico, mas também para variações pequenas daquele vetor. Isto é conseguido ajustando gradualmente os pesos dos neurônios à medida que ele for treinado sobre uma gama de vetores representando variações normais do vetor desejado. Desta forma, os pesos convergem para valores médios (centróides) dos vetores de treinamento, desenvolvendo a habilidade em responder a qualquer membro daquela classe (Apêndice II).

\section{III.2 Treinamento de um Neurônio do tipo OUTSTAR}

Enquanto que o neurônio instar dispara sempre que um padrão de entrada específico é aplicado, um outstar tem uma função complementar. Ele produz um padrão de excitação desejado para outros neurônios sempre que dispara.

Para treinar um outstar, seus pesos são ajustados para parecer um vetor de saídas desejadas. O algoritmo de treinamento pode ser expresso matematicamente como: 


$$
w_{j i}(t+1)=w_{j i}(t)+\beta x_{i}(t)\left\lfloor y_{j}(t)-w_{j i}(t)\right\rfloor
$$

onde $\beta$ é a taxa de aprendizagem. Nesta equação, o peso sináptico $w_{j i}$ só é ajustado quando o sinal pré-sináptico (vértice) $x_{i}(t)$ está ativo. Assim como o instar, os pesos outstar são gradualmente treinadas sobre uma sequiência de vetores representando variações normais do ideal. Desta forma, o padrão de excitação de saída de um neurônio representa uma medida estatística do padrão de treinamento, e pode realmente convergir para o vetor desejado se tudo o que ele viu foram versões distorcidas. 


\section{APÊNDICE IV}

Simulações com o Modelo EXIN 


\section{Simulações com o Modelo EXIN}

Neste apêndice são mostradas simulações envolvendo o modelo EXIN descrito pelas Equações (21)-(25). Este modelo foi desenvolvido com o objetivo de lidar com problemas de contexto, incertezas, multiplicidade e escala. Os padrões de treinamento da rede EXIN consistem de 6 vetores binários (0 ou 1) apresentados repetidamente em ordem aleatória ou seqüencial: $A, A B, A B C, C D, D E$ e $D E F$. Por exemplo, o padrão $A B$ é representado pelo vetor $(1,1,0,0,0,0)^{T}$. Estes padrões apresentam um grau de superposição representado pelos bits que tem em comum. A rede usada nas simulações tem 6 entradas e 6 unidades de saída. As unidades de saída são rotuladas de acordo com o padrão que ela codificou após o treinamento. A Figura 43 mostra a configuração final dos pesos excitatórios e inibitórios da rede EXIN depois de 3000 ciclos de treinamento ( $\cong 500$ apresentações para cada padrão).

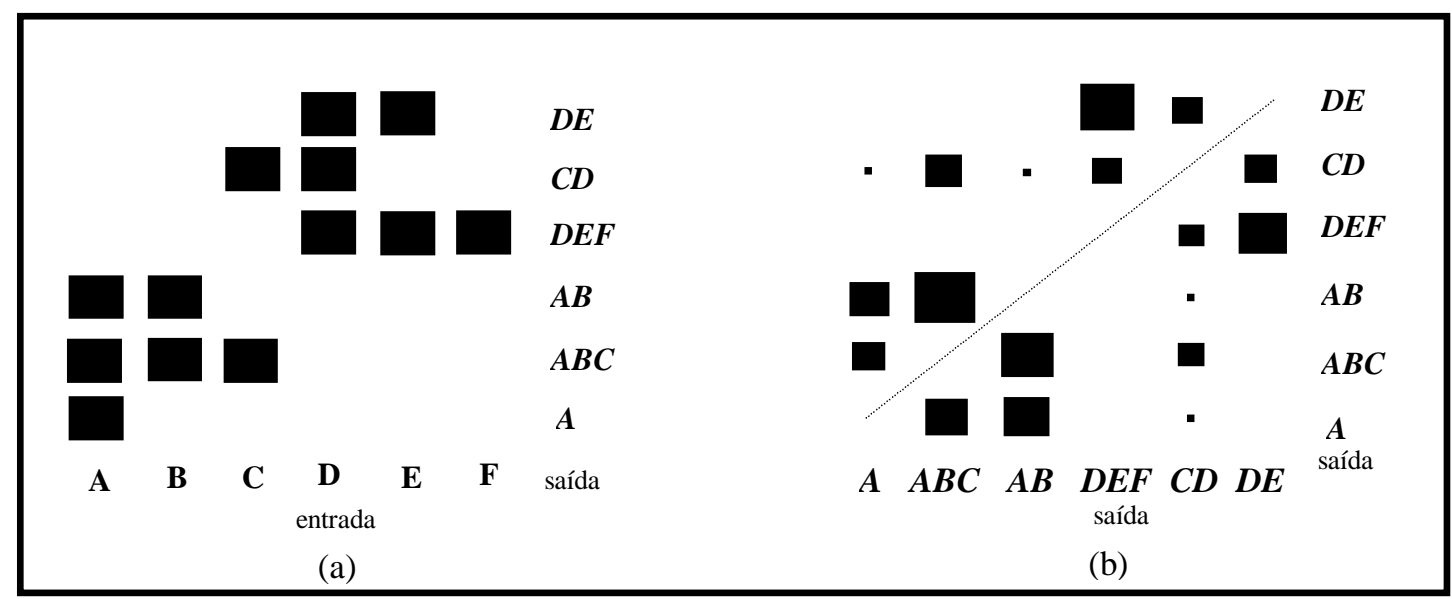

Figura 43: Pesos finais após treinamento. (a) pesos excitatórios; (b) pesos inibitórios. Os valores dos pesos são proporcionais ao lado dos quadrados.

Pela Figura 43b nota-se que as conexões laterais inibitórias são mais intensas entre unidades que codificam padrões superpostos. Inibições laterais entre padrões que não se superpõem são fracas ou inexistentes. A resposta da rede aos padrões treinados é mostrado na Figura 44a. Cada padrão ativa apenas a unidade que o codificou.

Padrões múltiplos são formados através da operação de Ou-lógico aplicada aos bits dos padrões usados no treinamento da rede na seção anterior. Por exemplo, o OUlógico entre os padrões $A B+C D=(1,1,0,0,0,0)+(0,0,1,1,0,0)=(1+0,1+0$, $0+1,0+1,0+0,0+0)=(1,1,1,1,0,0)=A B C D$. Este padrão, apesar de ser formado por dois padrões conhecidos pela rede, é considerado desconhecido. A resposta da rede para tais padrões é mostrada na Figura 44b. É interessante perceber que a rede 
ativa as unidades de saída que formam o padrão de entrada, ou seja, EXIN permite que padrões múltiplos sejam representados pela ativação simultânea de várias unidades. Este tipo de representação é denominada esparsa, para diferenciar da representação local usada pelas redes WTA. A Equação (25) produz uma estrutura de autoorganização que permite que vários neurônios vençam uma competição, ao invés de forçar um único vencedor. Desta forma, quando padrões de entrada múltiplos são apresentados, todos eles podem ser representados por unidades distintas.

Padrões ambíguos são de grande importância em aplicações práticas de redes neurais artificiais. Quando padrões não-vistos são mostrados à rede, ela expressa sua incerteza.

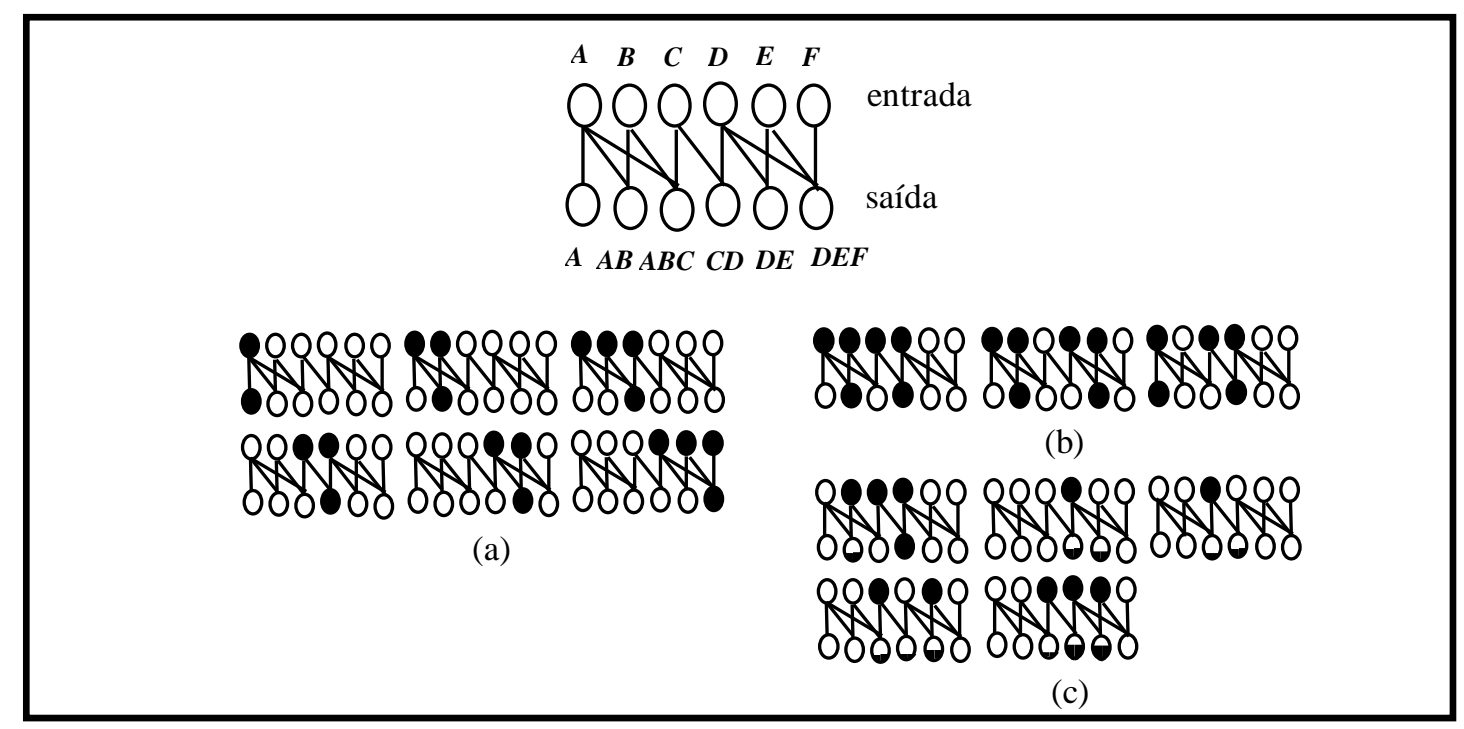

Figura 44: Resposta da rede para os diferentes tipos de padrões de treinamento e de teste. (a) padrões de treinamento; (b) Padrões múltiplos e (c) padrões ambíguos (representação de incerteza). Conexões inibitórias não são mostradas por motivos de clareza.

A Figura 44c mostra a resposta da rede a padrões ambíguos. Quando apenas a entrada $C$ é mostrada, a rede responde ativando parcialmente os neurônios que codificam padrões que contenham a entrada $C$. Neste caso, as unidades $C D$ e $A B C$ são ativadas parcialmente. $\mathrm{O}$ neurônio $C D$ é ativado mais fortemente pois, apesar de receber aproximadamente a mesma excitação, recebe menos inibição que o neurônio $A B C$. É interessante notar que a rede leva em consideração o tamanho do padrão (escala), ativando mais fortemente aquele em que a entrada tiver maior influência.

Outras simulações envolvendo este o modelo EXIN e variações dele podem ser encontradas em BARRETO \& ARAÚJO (1998b). 


\section{APÊNDICE V}

Parâmetros geométricos, cinemáticos e dinâmicos referentes ao manipulador robô PUMA 560 utilizado nesta dissertação. 


\section{Robô PUMA 560 - Parâmetros}

Robôs típicos são manipuladores constituídos de elos conectados serialmente por juntas. Cada elo é movido por um atuador. O movimento dos elos é uma rotação angular ou uma translação retilínea. Cada junta tem um grau de liberdade podendo ser de quatro tipos: linear ou prismática (Figura 45a), rotacional (Figura 45b), de torção (Figura 45c) e revolvente (Figura 45d). Para manipuladores com $n$ juntas numeradas de 1 a $n$, há $n+1$ elos numerados de 0 a $n$. O elo 0 é a base do manipulador, geralmente fixo, e o elo $n$ carrega o efetuador. A junta $i$ conecta o elo $i$ ao elo $i-1$.

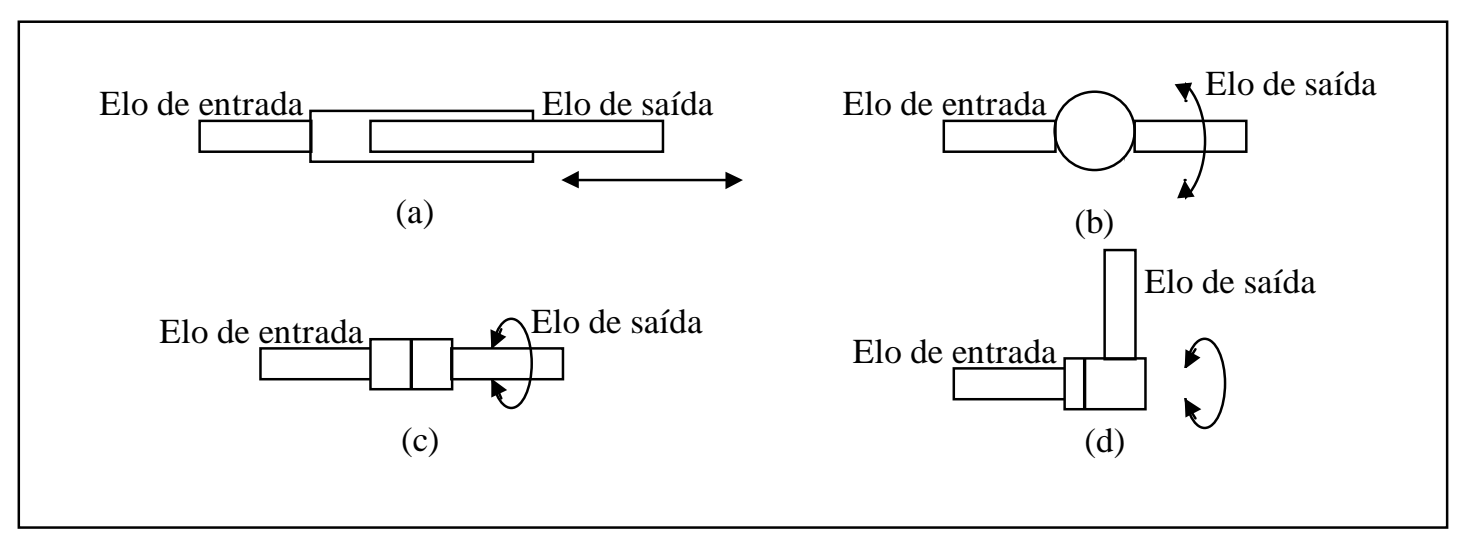

Figura 45: Tipos de juntas: (a) linear ou prismática, (b) rotacional, (c) de torção e (d) revolvente.

Para a análise de um sistema manipulador, é uma prática comum definir um sistema de coordenadas globais que é geralmente fixo à base do manipulador e é tomado como referência e um sistema de coordenadas locais fixas em cada elo. Este último se move com o elo. DENAVIT \& HARTENBERG (1955) propuseram um método sistemático e generalizado utilizando matriz algébrica para descrever a geometria espacial dos elos de um manipulador com relação ao sistema de coordenadas globais; a representação D-H. Esta, define um sistema de coordenadas locais para cada elo.

A representação D-H de um elo rígido depende de quatro parâmetros geométricos associados com cada elo. Estes quatro parâmetros descrevem completamente qualquer junta de revolução ou prismática. Os parâmetros para os elos e juntas (Figura 46) podem ser resumidos como segue: 
- $\theta_{i}$ : é o ângulo entre os eixos $\mathrm{x}_{\mathrm{i}-1}$ e $\mathrm{x}_{\mathrm{i}}$ sobre o eixo $\mathrm{z}_{\mathrm{i}-1}$. É positivo no sentido horário.

- $d_{i}$ : é a distância da origem do (i-1)-ésimo sistema de coordenada para a interseção do eixo $\mathrm{z}_{\mathrm{i}-1}$ com o eixo $\mathrm{x}_{\mathrm{i}}$ ao longo do eixo $\mathrm{z}_{\mathrm{i}-1}$. Se o eixo $\mathrm{z}_{\mathrm{i}-1}$ e o eixo $x_{i}$ não se cruzarem, então é a distância perpendicular entre os eixos $x_{i}$ e $x_{i-1}$.

- $a_{i}$ : é a distância da origem do i-ésimo sistema de coordenada para a interseção dos eixos $\mathrm{z}_{\mathrm{i}-1}$ e $\mathrm{x}_{\mathrm{i}}$ ao longo do eixo $\mathrm{x}_{\mathrm{i}}$.

- $\alpha_{\mathrm{i}}$ : é o ângulo de rotação medido do eixo $\mathrm{z}_{\mathrm{i}-1}$ positivo, ou sua projeção paralela, para o eixo $z_{i}$ positivo sobre o eixo $x_{i}$ positivo, onde a direção positiva é o sentido horário.

Para uma junta de revolução, $\theta_{i}$ é a variável da junta e $d_{i}$ é constante; para uma junta prismática, $d_{i}$ é a variável e $\theta_{i}$ é constante.

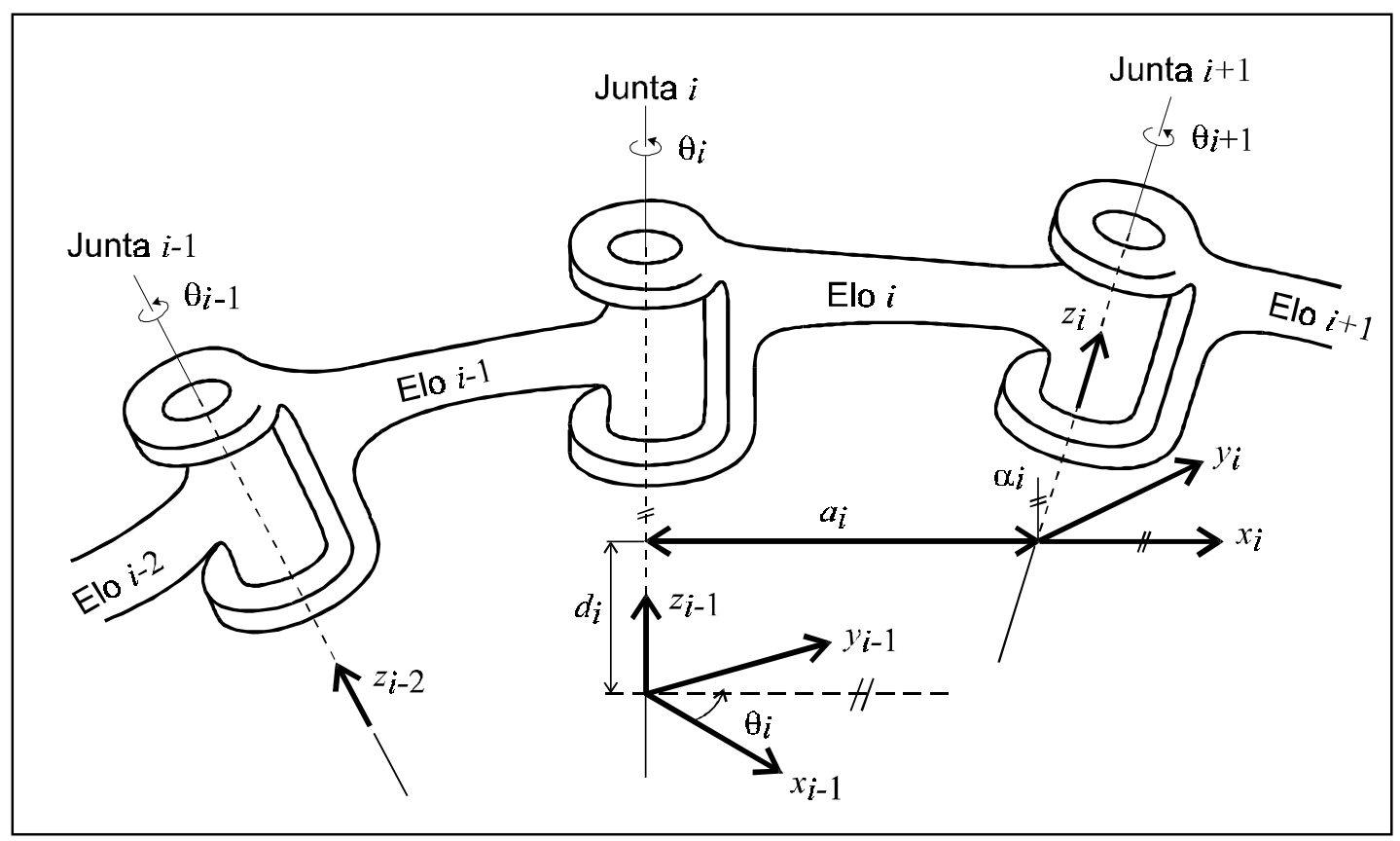

Figura 46: Parâmetros para os elos e juntas.

As constantes cinemáticas, valores de massa e centro de gravidade, os momentos de inércia sobre os centros de gravidade, e a inércia induzida, para cada um dos seis elos, são mostradas nas tabelas que seguem. Estes valores são necessários para efeito de geração das trajetórias usando a toolbox ROBOTICS. 
Tabela 6: Constantes cinemáticas, $\alpha$ em graus, a e $d$ estão em m.

\begin{tabular}{|c|c|c|c|}
\hline$I$ & $\alpha_{i}$ & $a_{i}$ & $d_{i}$ \\
\hline 1 & 90 & 0 & 0 \\
\hline 2 & 0 & 0.4318 & 0 \\
\hline 3 & -90 & 0.0203 & 0.15005 \\
\hline 4 & 90 & 0 & 0.4318 \\
\hline 5 & -90 & 0 & 0 \\
\hline 6 & 0 & 0 & 0 \\
\hline
\end{tabular}

Tabela 7: Valores da massa $(\mathrm{kg})$ e centro de gravidade $(\mathrm{m})$ dos elos.

\begin{tabular}{|c|c|c|c|c|}
\hline$i$ & $m_{i}$ & $r x_{i}$ & $r y_{i}$ & $r z_{i}$ \\
\hline 1 & 0 & 0 & 0 & 0 \\
\hline 2 & 17.4 & -0.3638 & 0.006 & 0.2275 \\
\hline 3 & 4.8 & -0.0203 & -0.0141 & 0.070 \\
\hline 4 & 0.82 & 0 & 0.019 & 0 \\
\hline 5 & 0.34 & 0 & 0 & 0 \\
\hline 6 & 0.09 & 0 & 0 & 0.032 \\
\hline
\end{tabular}

Tabela 8: Momentos de inércia sobre centro de gravidade $\left(\mathrm{kg}-\mathrm{m}^{2}\right)$.

\begin{tabular}{|c|c|c|c|c|c|c|}
\hline$I$ & $I x x_{i}$ & $I y y_{i}$ & $I z z_{i}$ & $I x y_{i}$ & $I y z_{i}$ & $I x z_{i}$ \\
\hline 1 & 0 & 0.35 & 0 & 0 & 0 & 0 \\
\hline 2 & 0.13 & 0.524 & 0.539 & 0 & 0 & 0 \\
\hline 3 & 0.066 & 0.086 & 0.0125 & 0 & 0 & 0 \\
\hline 4 & $1.8 \mathrm{e}-3$ & $1.3 \mathrm{e}-3$ & $1.8 \mathrm{e}-3$ & 0 & 0 & 0 \\
\hline 5 & $0.3 \mathrm{e}-3$ & $0.4 \mathrm{e}-3$ & $0.3 \mathrm{e}-3$ & 0 & 0 & 0 \\
\hline 6 & $0.15 \mathrm{e}-3$ & $0.15 \mathrm{e}-3$ & $0.04 \mathrm{e}-3$ & 0 & 0 & 0 \\
\hline
\end{tabular}

Tabela 9: Inércia induzida (ARMATURE) e prazer suficiente

\begin{tabular}{|c|c|c|}
\hline$i$ & $J m_{i}$ & $G_{i}$ \\
\hline 1 & $200 \mathrm{e}-6$ & -62.6111 \\
\hline 2 & $200 \mathrm{e}-6$ & 107.815 \\
\hline 3 & $200 \mathrm{e}-6$ & -53.7063 \\
\hline 4 & $33 \mathrm{e}-6$ & 76.0364 \\
\hline 5 & $33 \mathrm{e}-6$ & 71.923 \\
\hline 6 & $33 \mathrm{e}-6$ & 76.686 \\
\hline
\end{tabular}

